\title{
Detecção de Violações de SLA em Coreografias de Serviços Web
}

\author{
Victoriano Alfonso Phocco Diaz \\ DISSERTAÇÃO APRESENTADA \\ $\mathrm{AO}$ \\ INSTITUTO DE MATEMÁTICA E ESTATÍSTICA \\ DA \\ UNIVERSIDADE DE SÃO PAULO \\ PARA \\ OBTENÇÃA DO TÍTULO \\ $\mathrm{DE}$ \\ MESTRE EM CIÊNCIAS \\ Programa: Ciência da Computação \\ Orientador: Prof. Dr. Daniel Macêdo Batista
}

Durante o desenvolvimento deste trabalho o autor recebeu auxílio financeiro do CNPq, da HP Brasil por meio do projeto Baile e do programa FP7/2007-2012 da Comissão Europeia pelo projeto $\mathrm{n}^{\circ} 257178$ (CHOReOS - Large Scale Choreographies for the Future Internet) 


\title{
Detecção de Violações de SLA em Coreografias de Serviços Web
}

\author{
Esta versão definitiva da tese/dissertação \\ contém as correções e alterações sugeridas \\ pel Comissão Julgadora durante a defesa \\ realizada em 22/03/2013. Uma cópia da \\ versão original está disponível no Instituto \\ de Matemática e Estatística \\ da Universidade de São Paulo.
}

Comissão Julgadora:

- Prof. Dr. Daniel Macêdo Batista (orientador) - IME-USP

- Prof. Dr. Nelson Luis Saldanha da Fonseca - IC-Unicamp

- Prof. Dr. Marco Aurélio Gerosa - IME-USP 


\section{Agradecimentos}

Primeiramente eu quero agradecer à minha família. À minha mãe Saturnina, pelo grande e constante apoio apesar da distância. Ao meu pai Florentino, pela confiança que sempre deposita em mim. Ao meu irmão Fernando, porque ele também é um bom amigo. Aos meus tios, avós, primos, obrigado a todos vocês pelo carinho e afeto que sempre me dão.

Gostaria de expressar meus sinceros agradecimentos ao meu orientador Daniel Macêdo Batista. Ele é uma ótima pessoa, excelente orientador e bom amigo. Eu agradeço ao Daniel por todas as dicas, palavras e principalmente por acreditar em mim.

Durante todo este período de mestrado, não somente aprendi e obtive conhecimento da área. Neste anos eu conheci ótimas pessoas, as quais são de diversas cidades, países, culturas e costumes que ampliaram minha visão do mundo. Estou agradecido e fico muito contente de tê-las como boas amizades. A Valentina, a Florence, o Rafael, o Everton, a Deysi, o Enrique, o Marcelo, o Rogerio, o Lucas, o Marcos, o Fabio, o Jacques, Yanik, entre outros muitos que eu considero bons amigos.

Quero agradecer também aos meus bons amigos que vieram de Arequipa para iniciar o mestrado aqui, o Carlos e a Rosario. Ao pessoal e funcionários do IME pela amizade oferecida. Ao pessoal de Computação como o Lucas, o Fabio, o Wesley, o Strauss, o William, o Felps, o Glaucus, o Victor, entre outros. Ao pessoal do laboratório do LIAMF, ao pessoal de Visão Computacional, ao pessoal de Matemáticas e Estatísticas. Aos meus compatriotas e bons amigos no IME como o Alvaro, o Carlos, a Rosario, o Frank, o Leandro, o Edu, a Ericka, o Juan, o Jesús Mena, a Karina, o Daniel, a Edith, o Miguel, o Jesus Mesias, o Caratos, o Mija, o Harry, o Pablito, o Geiser, a Evelyn, o Jorge, a Leissi, entre outros. Também eu gostaria de agradecer aos meus compatriotas e bons amigos da Poli-USP e da Física.

Outro grupo de excelentes amigos que gostaria de agradecer são da turma de graduação como o Fabian, o Ysaacx, o Yayo, o Carlos, o DJ, o Robert, o Ernest. Além do mais, agradeço a boa amizade de amigos que também estão estudando, ou ensinam em outros países e que compartilham suas boas experiências, tais como o Jorge, o Omar, a Claudia, o Yayo, o Jesus Bellido, a Lisney, o Paiche, a Rosa, entre outros.

Paragrafo à parte merecem o pessoal do CHOReOS e Baile. Aos professores Daniel, o Fábio, o Alfredo e o Marco, pelos conselhos e incentivos e porque sua experiência serviu no meu aprendizado. Aos membros alunos desses projetos, tais como o Felps, o Cadú, o Felipe, o Gustavo, o Eduardo, o Leonardo, o Nelson, o Daniel Cukier, e todos os demais membros dessa excelente galera.

Em especial agradeço ao CNPQ e aos projetos Baile e CHOReos pelo financiamento e incentivo a minha pesquisa. Por fim, quero terminar com uma frase que sempre levo em consideração:

"Nunca conheci um homem tão ignorante que fosse impossível aprender algo dele". Galileo Galilei 


\section{Resumo}

Coreografias de serviços Web representam uma forma mais escalável e flexível de compor serviços do que uma abordagem centralizada como a orquestração, e seu papel na integração e comunicação de sistemas de larga escala é vital para os objetivos da SOC (Computação Orientada a Serviços) e da Internet do Futuro. Atualmente coreografias de serviços Web possuem vários desafios de pesquisa, dos quais a qualidade de serviço (QoS) e o monitoramento de coreografias de serviços Web são linhas importantes. O objetivo deste trabalho é propor e implementar um mecanismo de monitoramento não intrusivo de coreografias de serviços Web baseado em SLAs (Acordos de Nível de Serviço) que especificam as restrições de atributos de QoS de maneira probabilística. Esta dissertação propõe um mecanismo para coreografias de serviços Web que: (1) define requisitos de QoS; (2) especifica contratos probabilísticos sobre parâmetros de QoS usando SLA; e (3) realiza um monitoramento não intrusivo de coreografias de serviços Web para detectar violações de SLA.

Palavras-chave: Qualidade de Serviço (QoS), Monitoramento de Serviços Web, Coreografias de Serviços Web, Computação Orientada a Serviços, Acordo de Nível de Serviço (SLA), Internet do Futuro. 


\section{Abstract}

Web services choreographies are a more scalable and flexible way to compose services than a centralized approach like orchestrations, and its role in the integration and communication of large-scale systems is vital for the goals of SoC (Service Oriented Computing) and Future Internet. Currently, Web services choreographies have several research challenges. From all challenges, quality of service (QoS) and monitoring of Web services choreography are important research lines. The goal of this work is to propose and implement a mechanism for non-intrusive monitoring of Web services choreography based on SLAs (Service Level Agreements) that define constraints of QoS attributes in a probabilistic way. This thesis proposes a mechanism for Web services choreographies that:(1) defines QoS requirements; (2) specifies probabilistic contracts on QoS parameters using SLAs; and (3) monitors, non-intrusively, the enactment of Web services choreographies to detect SLA violations.

Keywords: Quality of Service (QoS), Web Service Monitoring, Web Service Choreographies, ServiceOriented Computing (SoC), Service Level Agreement (SLA), Future Internet. 


\section{Sumário}

Lista de Abreviaturas $\quad$ vii

Lista de Figuras $\quad$ viii

Lista de Tabelas $\quad$ x

1 Introdução $\quad 1$

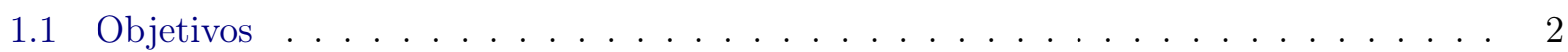

1.2 Considerações Preliminares . . . . . . . . . . . . . . . . . . . 2

1.3 Organização da Proposta . . . . . . . . . . . . . . . . . . . . . . 3

2 Conceitos Básicos $\quad 5$

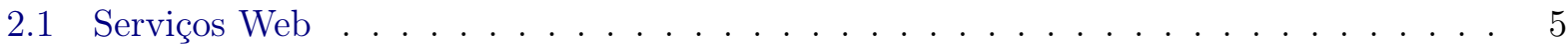

2.2 Computação Orientada a Serviços . . . . . . . . . . . . . . . . 8

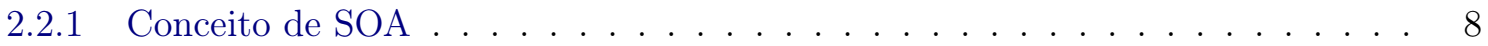

2.3 Composição de Serviços . . . . . . . . . . . . . . . . . . . . . . . . . . . . . 9

2.4 Internet do Futuro: A Internet das Coisas . . . . . . . . . . . . . . . . . . 12

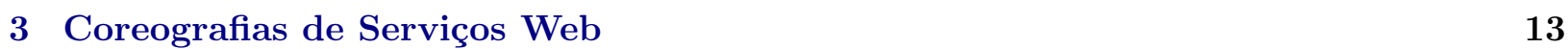

3.1 Padrões e Linguagens . . . . . . . . . . . . . . . . . . . . 13

3.2 Orquestração e Coreografia de serviços . . . . . . . . . . . . . . . . . . . . . 14

3.3 Processos de Negócio . . . . . . . . . . . . . . . . . . . . . . . . . 15

3.4 Elementos de um Modelo de Coreografia . . . . . . . . . . . . . . . . . . . . . 16

3.4.1 Modelos baseados em Autômatos . . . . . . . . . . . . . . . . . 17

3.4 .2 Modelos baseados em Redes de Petri . . . . . . . . . . . . . . . . . . . 18

3.4 .3 Modelos baseados em Álgebra de Processos . . . . . . . . . . . . . . . . . . 18

3.5 Linguagens de Coreografias de Serviços . . . . . . . . . . . . . . . . . . . 18

3.6 Ferramentas e Arcabouços . . . . . . . . . . . . . . . . . . . . . . . . 19

3.7 Coreografias em BPMN . . . . . . . . . . . . . . . . . . . 20

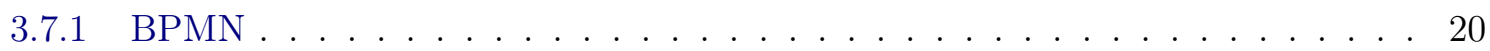

3.7.2 Coreografia de Processos . . . . . . . . . . . . . . . . . . . . . . 21

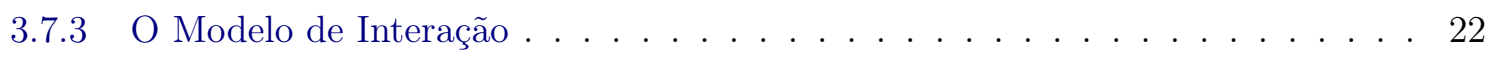

3.8 Considerações . . . . . . . . . . . . . . . . . . . . . . . . . . . 23 
4 QoS e Monitoramento em Coreografias de Serviços Web 26

4.1 QoS em Sistemas Orientados a Serviços . . . . . . . . . . . . . . . . . . . . . 29

4.2 SLAs Probabilísticos . . . . . . . . . . . . . . . . . . 34

4.3 Trabalhos Relacionados: QoS em Coreografias de Serviços Web . . . . . . . . . . . 35

4.4 Monitoramento em Coreografias de Serviços Web . . . . . . . . . . . . . . . 35

4.5 Trabalhos Relacionados: Monitoramento em Coreografias de Serviços Web . . . . . . 36

4.5.1 Monitoramento de Coreografias de Serviços Web Baseado em QoS . . . . . 36

4.5.2 Monitoramento de Serviços Web usando SLAs Probabilísticos . . . . . . . . . 38

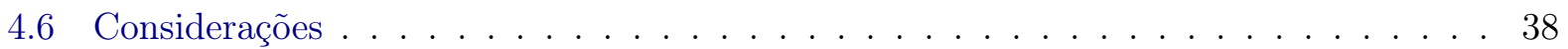

5 Visão geral $\quad 39$

5.1 Visão Geral . . . . . . . . . . . . . . . . . . . . . . . . . . . . . 39

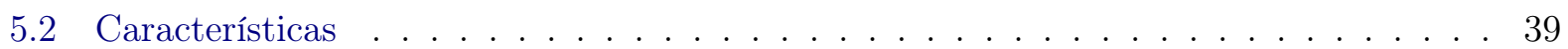

5.3 Modelo de QoS . . . . . . . . . . . . . . . . . . . . . . 41

5.3 .1 Modelo de Falhas . . . . . . . . . . . . . . . . . . . . . . . . . . . . . . 43

5.4 Simulador de Coreografias de Serviços . . . . . . . . . . . . . . . . . . 43

5.4 Trabalhos Relacionados . . . . . . . . . . . . . . . . . . . 43

5.4 .2 Arquitetura . . . . . . . . . . . . . . . . . . . . 44

5.5 Considerações . . . . . . . . . . . . . . . . . . . . . . . . 45

6 Mecanismo para Deteç̧ão de Violações de SLAs em Coreografias de Serviços Web $\quad 46$

6.0.1 Etapa 1: Definição de Requisitos de QoS - Analiticamente . . . . . . . . . . 46

6.0.2 Etapa 1: Definição de Requisitos de QoS - Simulações . . . . . . . . . . . . 47

6.0.3 Etapa 2: Estabelecimento de Contratos de QoS (SLAs) . . . . . . . . . . . . 49

6.0 .4 Etapa 3: Monitoramento de SLAs . . . . . . . . . . . . . . . . . 50

6.0 .5 Detecção de violações de SLA . . . . . . . . . . . . . . . . . . . 51

6.1 Considerações . . . . . . . . . . . . . . . . . . . . . . . . . 52

7 Experimentos $\quad 53$

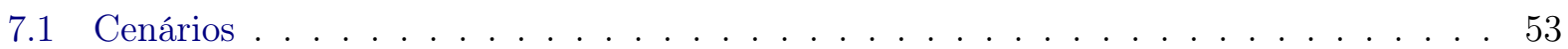

7.2 Primeiro conjunto de experimentos - Definição de Requisitos de QoS Analiticamente 54

7.2 .1 Mapeamento . . . . . . . . . . . . . . . . 54

7.2 .2 Definição de pesos . . . . . . . . . . . . . . . . . . 55

7.2 .3 Simulações . . . . . . . . . . . . . . . . . . . 56

7.2 .4 Análise de Resultados . . . . . . . . . . . . . . . . . . . . . 56

7.3 Segundo conjunto de experimentos - Definição de Requisitos de QoS em Coreografias 57

7.3.1 Análise de Resultados . . . . . . . . . . . . . . . . . . . . . 58

7.4 Terceiro conjunto de experimentos - Estabelecimento de contratos de QoS . . . . . . 59

7.5 Quarto conjunto de experimentos - Monitoramento de QoS em Coreografias . . . . . 60

7.6 Considerações Finais . . . . . . . . . . . . . . . . . . . . . . . . . . . 64 
8 Conclusões $\quad 66$

8.1 Considerações Finais . . . . . . . . . . . . . . . . . . . . . . . 66

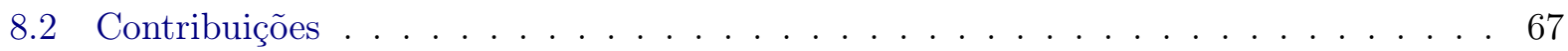

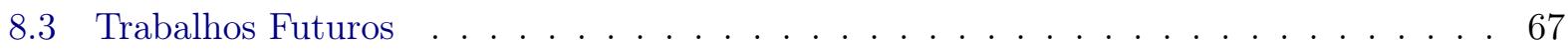

A Especificação da coreografia para o monitoramento no ChorSim $\quad 69$

$\begin{array}{ll}\text { B Configuração da plataforma para o monitoramento no ChorSim } & 71\end{array}$

C Configuração da implantação para o monitoramento no ChorSim 73

$\begin{array}{ll}\text { Referências Bibliográficas } & 75\end{array}$ 


\section{Lista de Abreviaturas}

$\begin{array}{ll}\text { B2B } & \text { Negócio a Negócio (Business to Business) } \\ \text { BPEL } & \text { Business Process Execution Language } \\ \text { BPEL4Chor } & \text { Business Process Modeling Notation for Choreography } \\ \text { BPMI } & \text { Business Process Management Initiative } \\ \text { BPMN } & \text { Business Process Modeling Notation } \\ \text { CPP } & \text { Collaboration Protocol Profile } \\ \text { ebXML } & \text { Electronic Business XML } \\ \text { ESB } & \text { Enterprise Service Bus } \\ \text { GSPN } & \text { Generalized Stochastic Petri Net } \\ \text { OWL-S } & \text { Semantic Web Ontology Language } \\ \text { DAML-S } & \text { DARPA Agent Markup Language } \\ \text { OMG } & \text { Object Management Group } \\ \text { P2P } & \text { Ponto a Ponto (peer-to-peer) } \\ \text { PDF } & \text { Função Densidade de Probabilidade (Probability Density Function) } \\ \text { QoS } & \text { Qualidade de Serviço (Quality of Service) } \\ \text { REST } & \text { Representational State Transfer } \\ \text { RTT } & \text { Round Trip Time } \\ \text { SOA } & \text { Arquitetura Orientada a Serviços (Service Oriented Architecture) } \\ \text { SOC } & \text { Computação Orientada a Serviços (Service Oriented Computing) } \\ \text { SLA } & \text { Acordo de Nível de Serviço (Service Level Agreement) } \\ \text { SOAP } & \text { Simple Object Access Protocol } \\ \text { TI } & \text { Tecnologia de Informação } \\ \text { UDDI } & \text { Universal Description, Discovery and Integration } \\ \text { UML } & \text { Unified Modeling Language } \\ \text { W3C } & \text { World Wide Web Consortium } \\ \text { WS } & \text { Serviço Web (Web Service) } \\ \text { WSCI } & \text { Web Service Choreography Interface } \\ \text { WSDL } & \text { Web Service Description Language } \\ \text { WS-CDL } & \text { Web Service Choreography Description Language } \\ \text { WSI } & \text { Web Services Interoperability } \\ \text { WSLA } & \text { Web Service Level Agreement } \\ \text { XML } & \text { Extensle Markup Language } \\ & \end{array}$




\section{Lista de Figuras}

1.1 Visão geral da arquitetura e componentes do arcabouço CHOReOS. . . . . . . . . 4

2.1 Modelo da arquitetura de serviços Web . . . . . . . . . . . . . . . . . 6

2.2 Evolução das arquiteturas de sistemas de software ( traduzida de [Pel05]) . . . . . . 8

2.3 Roteiro para o desenvolvimento de SOA [PTDL07] . . . . . . . . . . . . . . . . 9

2.4 Arquitetura genérica para um sistema de composição de serviços Web [EA06] . . . . 10

3.1 A coreografia define colaborações entre participantes que interagem entre si [ADHR05] 14

3.2 Orquestração Vs. Coreografia $[$ Pel03] . . . . . . . . . . . . . . . . . . 15

3.3 Coreografia como solução para modelagem de processos de negócio inter-organizacionais 16

3.4 Categorização de linguagens de coreografias de serviços Web (baseada em [Eng09]) . 18

3.5 Conjunto dos principais elementos do BPMN [DDO07] . . . . . . . . . . . . . . 21

3.6 Exemplo de modelo de interconexão de coreografias: oferta de investimento [KLW10]. 22

3.7 Representação de uma tarefa de coreografia $[\mathrm{NF} 10] \ldots \ldots$. . . . . . . . . . . . 23

3.8 Uma tarefa de coreografia de um sentido e seu diagrama de colaboração [NF10] . . . 24

3.9 Uma tarefa de coreografia de dois sentidos e seu diagrama de colaboração [NF10] . . 24

3.10 Exemplo de modelo de interação de coreografias: oferta de investimento [KLW10]. 25

4.1 Classificação de atributos de QoS (traduzida de [ADHR05]) . . . . . . . . . . . . . 27

4.2 Tempos na invocação de serviços (traduzida de [MRLD09]) . . . . . . . . . . . . . 27

4.3 Modelo multi-camada de QoS para coreografias de serviços Web (baseada em [Ros09]) 30

4.4 QoS do modelo de serviços Web de acordo com WSDL [Pan10] . . . . . . . . . . . . 31

4.5 Exemplo de SLA [KL03] . . . . . . . . . . . . . . . . . . . . . . . 33

4.6 Definição de SLAs na camada de coreografias de serviços . . . . . . . . . . . . . . . 33

4.7 Registro de medidas do tempo de resposta para um serviço Web (traduzida de

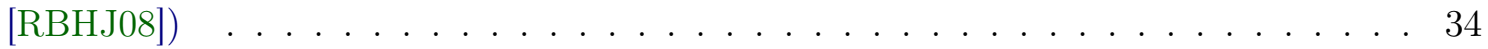

5.1 Arquitetura do monitoramento de coreografias baseado em SLAs probabilísticos . . . 40

5.2 Elementos BPMN para modelagem de coreografias que são levados em consideração. $\quad 40$

5.3 Etapas para realização do monitoramento. . . . . . . . . . . . . . . . . . . 41

5.4 Interação de serviços a partir de interações atômicas do BPMN2 . . . . . . . . . . . . 42

5.5 Atributos de QoS em uma interação com um serviço Web. . . . . . . . . . . . . . . . 42

5.6 Atributos de QoS calculados. (1) Recebendo requisições de um cliente ou serviço. (2) enviando requisições para um outro serviço. (3) recebendo resposta de um outro serviço. (4) enviando resposta para um cliente ou serviço solicitante. . . . . . . . . . 44

5.7 Arquitetura do simulador de coreografias. . . . . . . . . . . . . . . . . . . 45 
6.1 Mapeamento de eventos e gateways para módulos de redes de Petri . . . . . . . . . . 48

6.2 Mapeamento de dois tipos de tarefas de coreografia para módulos de redes de Petri com suporte a $\mathrm{QoS} \ldots \ldots \ldots \ldots$. . . . . . . . . . . . . . . . . . . . 48

7.1 Exemplo de modelo de interação de coreografias: oferta de investimento [KLW10]. . 53

7.2 Coreografia de serviços da aplicação de $\mathrm{CDN}\left[\mathrm{BDF}^{+} 08\right] \ldots \ldots \ldots \ldots$. . . . . . . 54

7.3 GSPN obtido da coreografia do cenário de exemplo . . . . . . . . . . . . . . . 55

7.4 Modelo de falhas que mostra a largura de banda efetiva devido à degradação da largura de banda em um período de 100 segundos. . . . . . . . . . . . . . . . 57

7.5 Tempo médio de resposta total da coreografia em função do tamanho de resposta do serviço WS1 com larguras de banda de 1Mbps até 16Mbps (intervalos de confiança não são visíveis por terem ficado muito pequenos) . . . . . . . . . . . . . . . . 59

7.6 Tempo médio de resposta total da coreografia em função do tamanho de resposta do serviço WS1 segundo o modelo de falha. A largura de banda varia de 1Mbps até

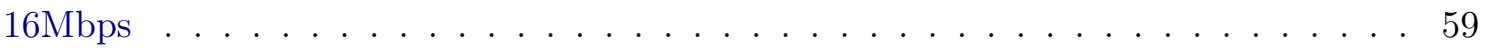

7.7 Distribuição de probabilidade empírica (ECDF) do contrato do serviço $W S_{1}$ com

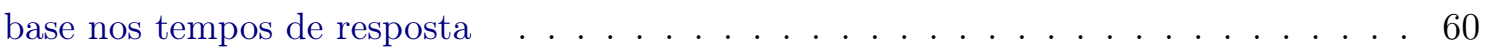

7.8 Monitoramento e deteç̧ão de violações de SLA para o cenário 1. . . . . . . . . . . . 62

7.9 Monitoramento e deteç̧ão de violações de SLA para o cenário 2 . . . . . . . . . . 62

7.10 Monitoramento e deteç̧ão de violações de SLA para o cenário 3 . . . . . . . . . 63

7.11 Monitoramento e detecção de violações de SLA para o cenário 4 . . . . . . . . . . 63 


\section{Lista de Tabelas}

4.1 QoS no modelo WSDL estendido . . . . . . . . . . . . . . . . . 30

4.2 Quantis de tempos de resposta (obtida de [RBHJ08]) . . . . . . . . . . . . . 35

5.1 Modelo de QoS e de falhas . . . . . . . . . . . . . . . . . . 44

7.1 Descrição das posições da GSPN resultante . . . . . . . . . . . . . . . . . . 55

7.2 Descrição de transições da GSPN resultante . . . . . . . . . . . . . . . . . . . . . . . . . . . . . . . . . . . . . . 55

7.3 Configuração de pesos nos Cenários 1 e $2 \ldots \ldots \ldots \ldots$. . . . . . . . . . 56

7.4 Resultados $(\mathrm{em} \%) \ldots \ldots \ldots \ldots \ldots \ldots$

7.5 Configuração dos cenários de simulação . . . . . . . . . . . . . . . . . . 58

7.6 Configuração de valores dos atributos de QoS nas requisições . . . . . . . . . . . . . 58

7.7 Configuração de valores dos atributos de QoS nas respostas . . . . . . . . . . . . 58

7.8 Quantis do contrato probabilístico dos tempos de resposta de $W S_{1}$. . . . . . . . 60

7.9 Definição de valores na configuração para o monitoramento. . . . . . . . . . . . . . 61

7.10 Estabelecimento das taxas de degradação de tempo de processamento dos serviços

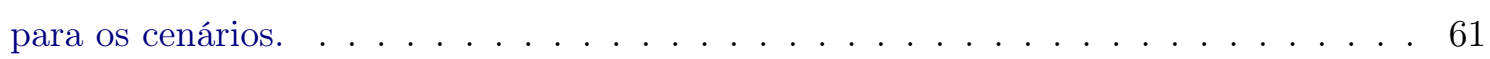




\section{Capítulo 1}

\section{Introdução}

O modo de desenvolver aplicações e sistemas complexos tem evoluído com o passar do tempo até convergir, atualmente, para arquiteturas de software e modelos de computação orientados a serviços, o que é chamado de SOC. SOC é um paradigma que utiliza serviços como base para construir e dar suporte a um desenvolvimento rápido, de baixo custo, de baixo acoplamento e de fácil composição de aplicações heterogêneas distribuídas [PTDL08]. Essas composições podem ser realizadas principalmente de duas formas: orquestração e coreografia, das quais a coreografia de serviços é mais colaborativa e especifica a composição desde uma perspectiva global.

A orquestração de serviços é uma composição centralizada, já que uma entidade denominada orquestrador é responsável por coordenar a comunicação dos serviços participantes. Por outro lado, a coreografia de serviços é uma composição descentralizada já que é uma descrição de interações ponto a ponto entre os serviços participantes, ou seja, nesse modelo, não há a figura de um controlador central [BWR09].

Dada a natureza distribuída e colaborativa de uma coreografia de serviços, ela é indicada como a melhor alternativa de integração de sistemas complexos e heterogêneos em larga escala [VGF10].Além disso, devido ao número crescente de dispositivos móveis que se conectam à Internet, uma abordagem orientada a serviços centralizada como a orquestração pode não ser escalável em termos de largura de banda para lidar com o número cada vez mais crescente de dispositivos e serviços. Nesse cenário, uma abordagem descentralizada, como a coreografia, pode se tornar a mais adequada para as características da Internet do Futuro [Stu12].

Por outro lado, um fator chave para a realização de comportamento adaptativo para sistemas orientados a serviços, e especificamente em composição de serviços, é a disponibilidade e suporte de informação de QoS [Ros09]. A característica distribuída das coreografias de serviços Web torna necessário que haja adaptação, a fim de que os requisitos de QoS das aplicações sejam atendidos. Como consequência, o monitoramento de QoS torna-se importante, porque observa, coleta e reporta informações de QoS em tempo de execução e durante a evolução do sistema baseado em serviços [JDM10]. A partir do monitoramento é possível alavancar a seleção, composição, adaptação, auto-cura (self-healing) e otimização de serviços Web baseadas em QoS [Ros09].

A forma mais trivial de representar os requisitos de QoS é através de contratos rígidos, em que as métricas devem ser respeitadas à risca em $100 \%$ dos casos, por exemplo, atraso $<10 \mathrm{~ms}$. Entretanto, esses contratos não representam o comportamento dinâmico dos atributos de QoS dos serviços Web. Portanto, uma melhor forma de representar os requisitos de QoS é através de contratos não rígidos e baseados em probabilidade. Neste caso os requisitos estipulam distribuições de probabilidade relacionadas com os valores dos requisitos de QoS, por exemplo, atraso $<10 \mathrm{~ms}$ em $95 \%$ das vezes em que a métrica for monitorada. Além disso, assim como ocorre em outros sistemas em redes [BCdFZ10], é importante que o monitoramento das métricas de QoS seja feito de forma não intrusiva e que retorne valores bem próximos dos valores reais.

Atualmente, implementar e executar uma coreografia de serviços real é uma tarefa complexa já que a tecnologia para dar suporte a esse paradigma de composição de serviços está imatura, especialmente pela falta de motores de execução cientes de coreografia [KELL10]. Assim, os mecanismos 
para medir parâmetros de QoS, e estabelecer requisitos de QoS não estão bem desenvolvidos para coreografias.

Esta pesquisa propõe um monitoramento de coreografias de serviços Web baseado em restrições de atributos de QoS de maneira probabilística com o objetivo de detectar violações de SLAs entre os participantes da coreografia. O monitoramento será realizado de maneira não intrusiva, e é desenvolvido acima de um simulador para realizar enactment de coreografias de serviços. Tal simulador possui suporte de QoS, principalmente atributos relacionados com tempo de processamento, tempo de resposta e atributos de rede. O monitor é responsável pela coleta e medição dos atributos de QoS dos serviços individuais, e por agregar as medidas de acordo com a composição e, finalmente, por verificar a existência de violação de alguma restrição de QoS segundo contratos pré-estabelecidos.

\subsection{Objetivos}

O objetivo principal deste trabalho é :

- Propor mecanismos de modo a detectar violações de SLAs baseadas em restrições probabilísticas de QoS em coreografias de serviços Web.

Os objetivos secundários deste trabalho são:

- Propor mecanismos para definir requisitos de QoS em coreografias de serviços Web.

- Propor uma técnica de monitoramento de coreografias de serviços Web com restrições de QoS definidas probabilisticamente.

- Desenvolver um simulador de coreografias de serviços Web com suporte à definição de atributos de QoS.

- Realizar avaliações do mecanismo de monitoramento de coreografias.

\subsection{Considerações Preliminares}

Para o cumprimento dos objetivos deste trabalho, consideram-se várias etapas:

1. Desenvolvimento de um simulador de coreografias de serviços Web com suporte à definição de atributos de QoS.

2. Definição de requisitos de QoS e estabelecimento de contratos entre os serviços participantes que interagem em uma coreografia.

3. Realização do monitoramento da coreografia, estimando as distribuições de probabilidade dos parâmetros de QoS.

Na etapa (1) construiu-se um simulador de coreografias por conta da falta de implementações para rodar coreografias com suporte a QoS. Na etapa (2) se definem requisitos de QoS baseados em avaliações de desempenho de coreografias usando modelos de falhas probabilísticos de atributos de QoS. Com base nesses requisitos de QoS se estabelecem os contratos probabilísticos. Foram utilizadas duas abordagens para definir requisitos de QoS:

- Analítica: Usando GSPN como representação intermediária da especificação de uma coreografia e adicionando características de QoS.

- Simulações: Por meio de avaliações de desempenho usando o simulador de coreografias. 
Na etapa (3), o monitoramento utiliza os quantis das distribuições de probabilidade empíricas, de acordo com os valores medidos dos parâmetros de QoS, e os compara com os quantis definidos nos SLAs para verificar alguma violação do contrato. Os parâmetros de QoS que serão utilizados são o tempo de resposta, o tempo de processamento, o atraso de rede e a largura de banda efetiva das interações entre os serviços. A reação (punição, adaptação, reconfiguração, entre outros) ante a deteç̧ão de alguma violação de um SLA não está no escopo desta pesquisa.

Esta pesquisa foi desenvolvida no contexto e apoio de dois projetos:

- O projeto CHOReOS ${ }^{1}$ - Coreografias de larga escala para o Internet do futuro.

- O projeto Baile ${ }^{2}$ - Habilitando coreografias escaláveis de serviços na nuvem.

Esta dissertação está principalmente envolvida no projeto $C H O R e O S$. O projeto $C H O R e O S$ visa implementar um arcabouço para desenvolvimento de coreografias escalavéis. A sua meta é permitir que especialistas de um domínio possam desenvolver soluções descentralizadas de ultra larga escala (ULS) compostas de serviços heterogêneos que são adaptavéis e cientes da QoS (Qualidade de Serviço). A Figura 1.1 mostra de maneira geral a arquitetura e os diversos componentes que compõen o arcabouço CHOReOS.

As contribuições desta dissertação estão relacionadas especificamente com alguns arcabouços componentes do CHOReOS. Assim, estão relacionadas dentro do arcabouço de Especificação de Coreografias, já que inclui aspectos de restrições de QoS na especificação da coreografia. Estão relacionadas com os componentes de monitoramento e contratos de SLA do arcabouço de Validação, Verficação e Governança. Além do mais, a presente pesquisa também está relacionada com a implantação e enactment da coreografia por causa do simulador de coreografias que foi desenvolvido.

\subsection{Organização da Proposta}

O restante deste texto está organizado da seguinte forma. No Capítulo 2 são apresentados os aspectos e conceitos básicos, tais como serviços Web, SOA, composição de serviços e Internet do futuro. No Capítulo 3 são descritos os conceitos de coreografia de serviços Web. No Capítulo 4 são descritos os fundamentos de QoS, SLA e monitoramento em coreografias de serviços, além de serem resumidos os trabalhos relacionados a esta pesquisa. No Capítulo 5 se apresenta a visão geral do monitoramento de coreografias, o modelo de QoS e a construção do simulador de coreografias. No Capítulo 6 são descritas as técnicas e algoritmos para atingir os objetivos desta pesquisa. O Capítulo 7 descreve os experimentos realizados e analisam-se os resultados encontrados. Por fim, o Capítulo 8 apresenta as conclusões, considerações finais e os trabalhos futuros.

\footnotetext{
${ }^{1}$ Projeto CHOReOS: http://www.choreos.eu

${ }^{2}$ Projeto Baile: http://ccsl.ime.usp.br/baile/
} 


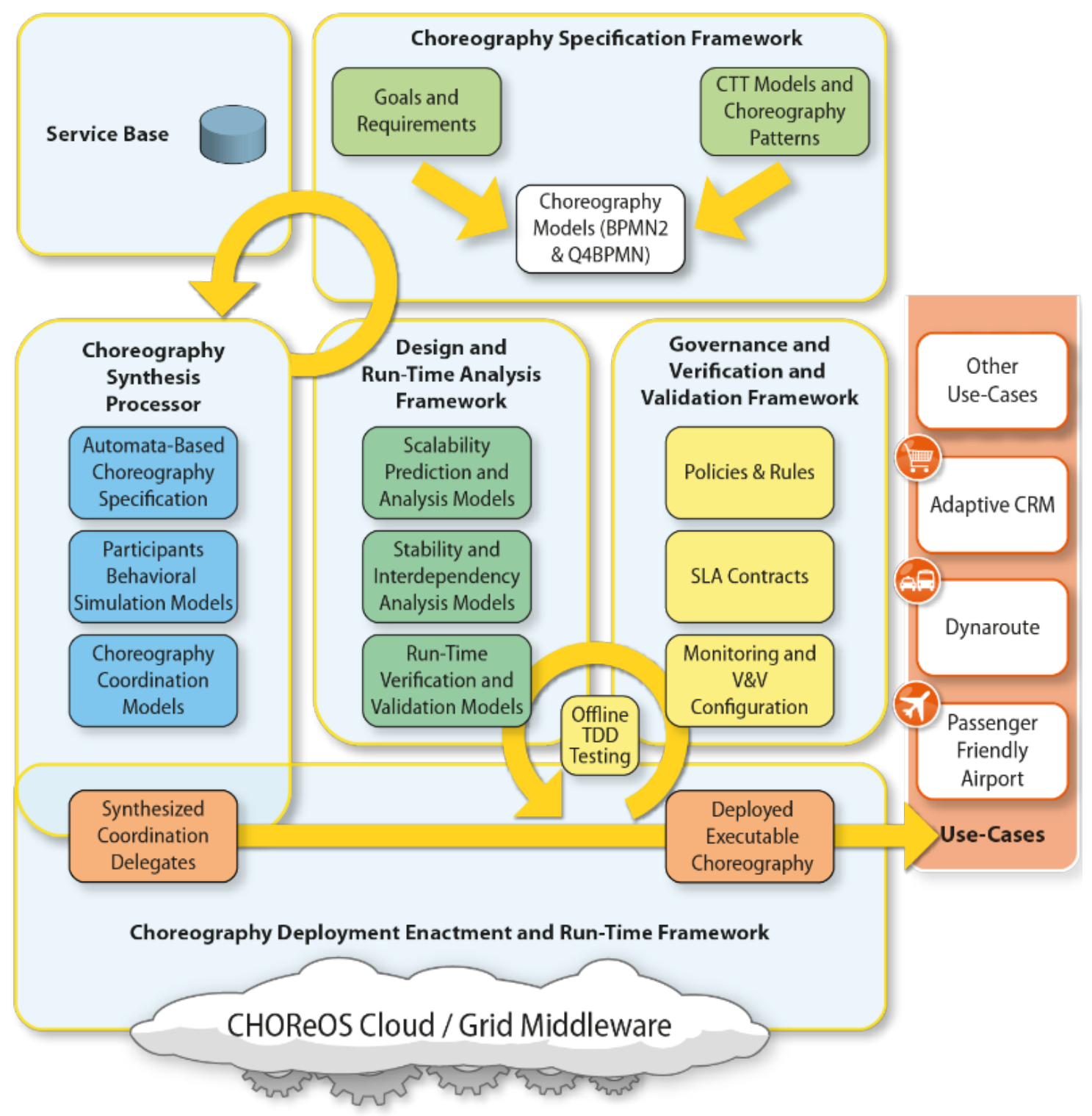

Figura 1.1: Visão geral da arquitetura e componentes do arcabouço CHOReOS. 


\section{Capítulo 2}

\section{Conceitos Básicos}

Este capítulo apresenta conceitos básicos necessários para a compreensão da dissertação.

\subsection{Serviços Web}

Os serviços Web foram propostos para facilitar a comunicação entre componentes de arquiteturas heterogêneas, oferecendo uma visão destas arquiteturas baseada em serviços e totalmente compatível com a Internet. O surgimento dos serviços Web, e da SOA, implicaram o estabelecimento de novos mecanismos de B2B, B2C e B2E. A organização responsável pela definição de normativas e padrões que permitem que sistemas desenvolvidos em diferentes plataformas e diferentes linguagens de programação possam interagir é a WS-I [WSI05](Web Services Interoperability Organization).

A arquitetura de serviços Web permite que os serviços sejam descritos de forma dinâmica, publicados, descobertos e invocados em um ambiente de computação distribuída, utilizando os padrões $\mathrm{WSDL}^{1}, \mathrm{UDDI}^{2}, \mathrm{SOAP}^{3}$ e XML, respectivamente. Segundo [New02], os serviços Web representam o próximo passo na evolução da tecnologia orientada a objetos e representam uma revolução, afastando-se da tradicional arquitetura cliente-servidor para as novas arquiteturas ponto a ponto.

Os serviços Web são aplicações auto-contidas e modulares que podem ser:

- Descritas por uma linguagem de descrição de serviços, como a linguagem WSDL.

- Publicadas, incluindo as descrições e as políticas de uso em um registro conhecido, utilizando o método de registro UDDI.

- Descobertas, também usando o padrão UDDI, para enviar requisições para o registro e receber os detalhes necessários para a localização e ligação (binding) do serviço que atenda os parâmetros de busca.

- Associadas, quando as informações contidas na descrição do serviço são utilizadas para criar uma instância do serviço disponível.

- Invocadas sobre a rede, utilizando as informações contidas nos detalhes da descrição do serviço, em um documento WSDL. Durante a invocação se utiliza o protocolo SOAP.

- Composta com outros serviços para integrar novas aplicações e serviços, o que é a base da SOA.

A Figura 2.1 ilustra os componentes que estão envolvidos no modelo de uma arquitetura de serviços Web. A seguir a descrição desses elementos [TPM06]:

\footnotetext{
${ }^{1}$ WSDL : http://www.w3.org/TR/wsdl

${ }^{2}$ UDDI: http://uddi.xml.org/

${ }^{3}$ SOAP:www.w3.org/TR/soap/
} 
- Serviço: A aplicação publicada para ser utilizada pelos solicitantes que cumpram os requisitos especificados pelo provedor de serviços. Obviamente, a execução é realizada em uma plataforma acessível via rede.

- Provedor do serviço: Do ponto de vista comercial, é quem fornece o serviço. Do ponto de vista da arquitetura, é a plataforma que fornece o serviço.

- Registro de serviços : É um repositório de descrições, em que os provedores publicam seus serviços e as formas de acessá-los. Também permite aos solicitantes realizarem diferentes tipos de buscas.

- Solicitante do serviço: Do ponto de vista comercial, é a empresa que precisa de um determinado serviço. Do ponto de vista da arquitetura, é o aplicativo cliente que invoca um serviço de busca.

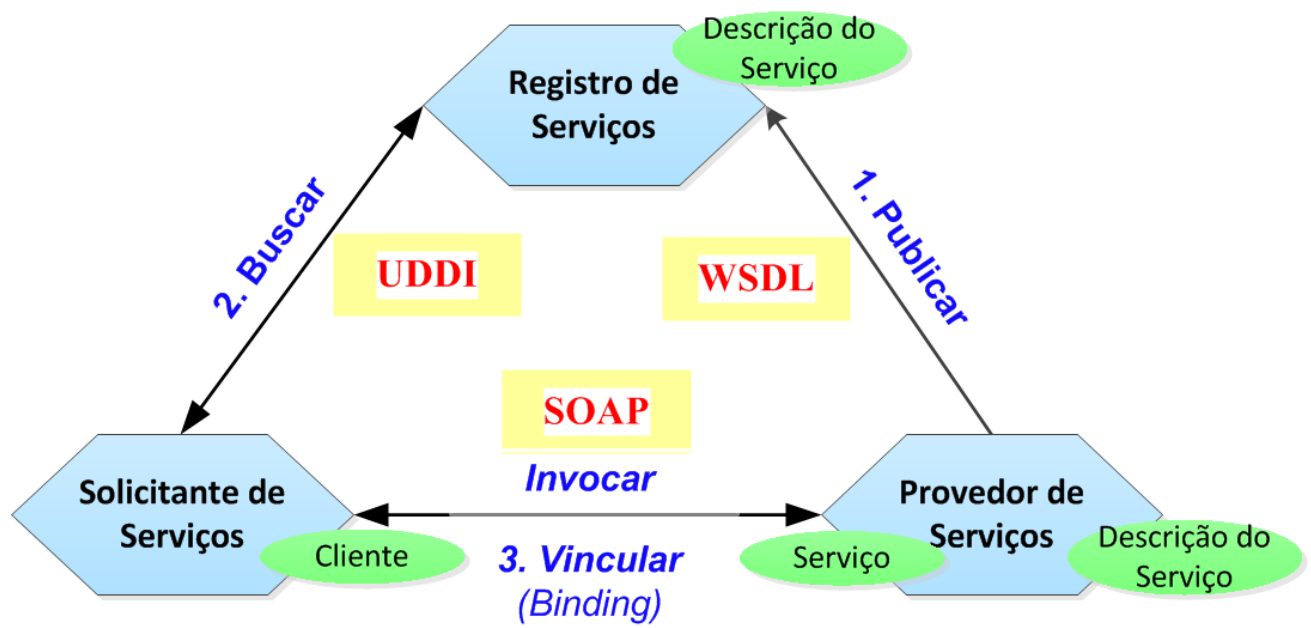

Figura 2.1: Modelo da arquitetura de serviços Web

As operações que podem ser realizadas com os serviços Web são:

- Publicar/Cancelar: Um provedor de serviços pode publicar um determinado serviço comercial em um ou mais registros de serviços e cancelar essa publicação em qualquer momento.

- Procurar: Os solicitantes dos serviços podem interagir com um ou mais registros para encontrar um conjunto de serviços que solucione seus problemas.

- Ligação (binding): Os solicitantes negociam com os provedores de serviços a forma de acesso e invocação dos seus serviços comerciais.

Atualmente, as aplicações que estão sendo desenvolvidas têm a capacidade de procurar e selecionar serviços de forma dinâmica em tempo real, com base em parâmetros como custos, qualidade ou disponibilidade. Isto é uma grande vantagem na hora de utilizar sistemas baseados em serviços Web, já que o sistema automaticamente escolhe o serviço que melhor se adapte às necessidades do solicitante [Wan04].

Entre as razões pelas quais os serviços Web possuem um papel importante na implementação de sistemas distribuídos estão [TPM06]:

- Interoperabilidade: Os serviços Web podem interagir com outro serviços. O protocolo padrão SOAP permite que os serviços possam ser oferecidos ou utilizados independentemente da linguagem ou ambiente em que são desenvolvidos. 
- Onipresença: Os serviços Web se comunicam usando HTTP e XML. Qualquer dispositivo que trabalha com estas tecnologias pode ser o cliente e acessar os serviços Web. Por exemplo, uma máquina de venda de refrigerantes pode se comunicar com o serviço Web de um provedor local e solicitar uma ordem de fornecimento através de uma rede de acesso sem fio existente.

- Barreira mínima de participação: Os conceitos por trás dos serviços Web são não dífíceis de compreender e existe uma gama de ferramentas de desenvolvimento, como os oferecidos pela IBM, Sun Microsystems, Apache, Systinet, entre outras. Tais ferramentas permitem que os desenvolvedores criem e implementem serviços Web de maneira rápida.

- Suporte da indústria: As principais empresas de TI suportam os serviços Web baseados em SOAP, e serviços Web baseados na arquitetura REST, conhecidos como serviços Web RESTFul [PML09], e tecnologias derivadas dos serviços Web.

A infraestrutura mínima exigida pelos serviços Web pode ser definida em termos de [Pel05]:

- O que é transferido pela rede: Formatos e protocolos de comunicação.

- O que é descrito para ser transferido via rede: Linguagens de descrição de serviços.

- O que permite encontrar e armazenar essas descrições: Descoberta de serviços.

Os serviços Web baseiam-se nas seguintes normativas e protocolos [ACKM04]:

- XML [W3C98], publicado em 1998, mudou e impactou a maneira de estruturar, descrever e trocar informação. Independentemente das muitas maneiras atuais de usar XML, ainda muitas das tecnologias de serviços Web são baseadas em XML apesar do acrescentamento dos serviços RESTful. É o padrão central desta arquitetura, sobre a qual o resto de padrões se apoiam. O projeto do XML deriva de duas fontes principais: SGML (Standard Generalized Markup Language) [ISO86].

- UDDI [UDD05], é um diretório que contém um registro/repositório de descrições de serviços Web. Este padrão permite que as empresas se registrem em um tipo de diretório da Internet, que as ajuda a anunciar seus serviços, de modo que outras empresas possam localizar os seus serviços e realizar transações na web. O processo de registro e consulta se realizam usando os mecanismos baseados em XML e HTTP(S). Portanto, a especificação UDDI tem dois objetivos principais, primeiro, servir de suporte aos desenvolvedores para encontrar informações sobre os serviços Web e poder construir os clientes; e por outro lado, facilitando a ligação dinâmica de serviços Web, permitindo consultar referências e acessar serviços de interesse.

- SOAP [HMG $\left.{ }^{+} 03\right]$, é um padrão do $\mathrm{W}^{2} \mathrm{C}^{4}$, que define um protocolo que dá suporte para a interação (dados + funcionalidade) entre aplicações em ambientes heterogêneos distribuídos. SOAP define a forma de organizar informações em XML para permitir a troca entre diferentes sistemas. O protocolo SOAP simplifica o acesso a objetos, permitindo que as aplicações possam invocar métodos de objetos ou funções que residem em sistemas remotos.

- WSDL [CCMW01], criada pela IBM, Microsoft e Ariba, tem papel e propósito semelhante à IDL (Interface Definition Language) das plataformas de middleware. Um arquivo WSDL é um documento XML que descreve os serviços Web, particularmente suas interfaces. Uma característica que o diferencia da IDL, é que a WSDL deve definir os mecanismos de acesso (protocolos) para os serviços web. Outra característica distintiva é a necessidade de definir na especificação a localização de um serviço (endpoints). A separação das interfaces e dos protocolos, e a necessidade de incluir as informações de localização, permite a definição de especificações modulares.

\footnotetext{
${ }^{4}$ www.w3.org/
} 


\subsection{Computação Orientada a Serviços}

Integrar produtos de diferentes provedores e de diferentes tecnologias é uma tarefa difícil, por isso cada vez mais as aplicações estão orientadas a serviços. Isto pode ser visto na Figura 2.2, na qual se apresenta a evolução das arquiteturas de software, paradigmas de programação, metodologias de desenvolvimento e também os modelos de computação tanto no hardware quanto via rede, convergindo para a SOC.

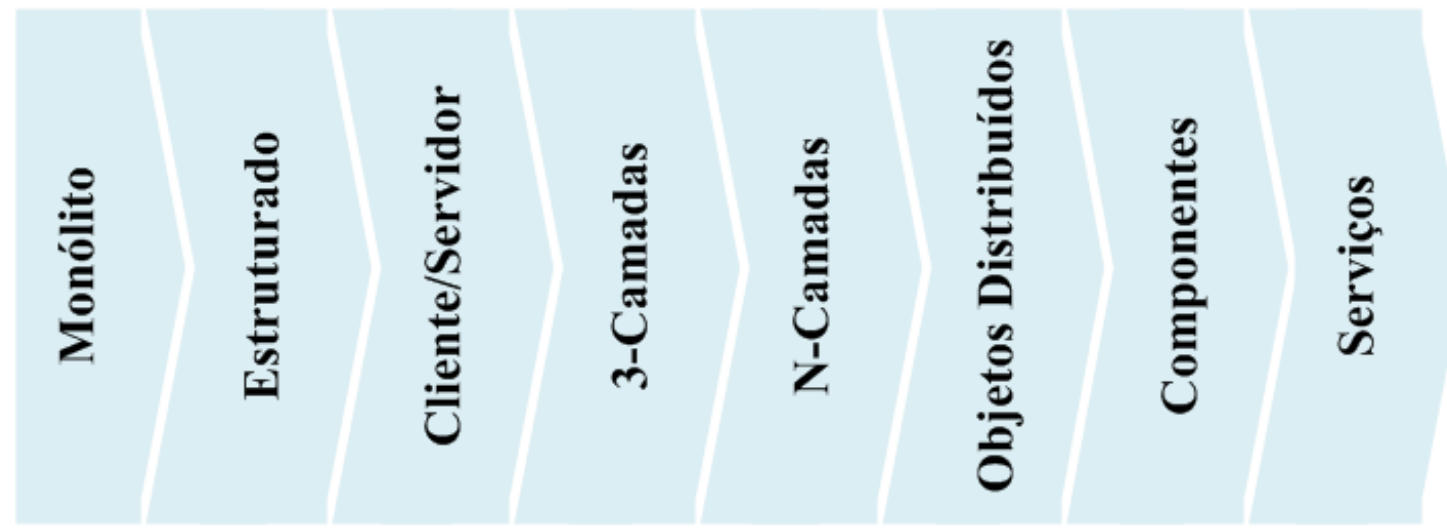

Figura 2.2: Evolução das arquiteturas de sistemas de software (traduzida de [Pel05])

O paradigma da SOC utiliza os serviços como blocos de construção para suportar o desenvolvimento de maneira rápida, interoperável, evolutiva, de baixo custo e de fácil composição de aplicações distribuídas. Os serviços desempenham funções que podem variar de responder requisições simples até a execução de processos de negócios sofisticados que exijam relações $\mathrm{P} 2 \mathrm{P}$ entre várias camadas de consumidores e provedores de serviços.

Trechos de código e componentes de algum aplicativo implantado em um sistema pode ser reutilizado e transformado em um serviço disponibilizado na rede. Os serviços geralmente são implementados de maneira independente do contexto em que serão utilizados. Isso significa que entre o provedor e o consumidor de serviços há um baixo acoplamento.

A abordagem orientada a serviços é independente de linguagens de programação ou sistemas operacionais. Isso permite que as organizações exponham suas funcionalidades essenciais por meio da Internet e de uma variedade de tecnologias de redes usando, por exemplo, linguagens baseadas em XML e protocolos padrão, e implementando uma interface auto-descritiva. A promessa visionária de SOC consiste em construir facilmente componentes de aplicação dentro de uma rede de serviços de baixo acoplamento, a fim de que se possa criar processos de negócios dinâmicos e aplicações ágeis que cubram diversas organizações e plataformas de computação [PTDL08].

\subsubsection{Conceito de SOA}

A chave para concretizar a visão da SOC é a SOA. A SOA descreve um maneira lógica com o objetivo de projetar sistemas de software para fornecer serviços para aplicações de usuário final ou para outros serviços distribuídos em uma rede, por meio de interfaces publicadas e detectáveis, isto é, que possam ser descobertas.

A SOA orienta os requisitos de baixo acoplamento, baseando-se em padrões e em computação distribuída independente de protocolos [PH07]. A Figura 2.3 mostra um roteiro para o desenvolvimento de SOA segundo [PTDL07]). A pirâmide da figura separa as funcionalidades da arquitetura em três planos. Serviços básicos na base da pirâmide, composição de serviços no meio e gerenciamento de serviços com monitoramento no topo da pirâmide. Esta divisão lógica está baseada na necessidade de separar:

- Capacidades de serviços básicos fornecidos por uma infraestrutura de middleware, e uma SOA convencional de funcionalidades de serviços avançadas necessárias para dinamicamente 
compor serviços.

- Serviços de negócio de serviços focados em sistemas.

- Composição de serviços de gerenciamento de serviços.

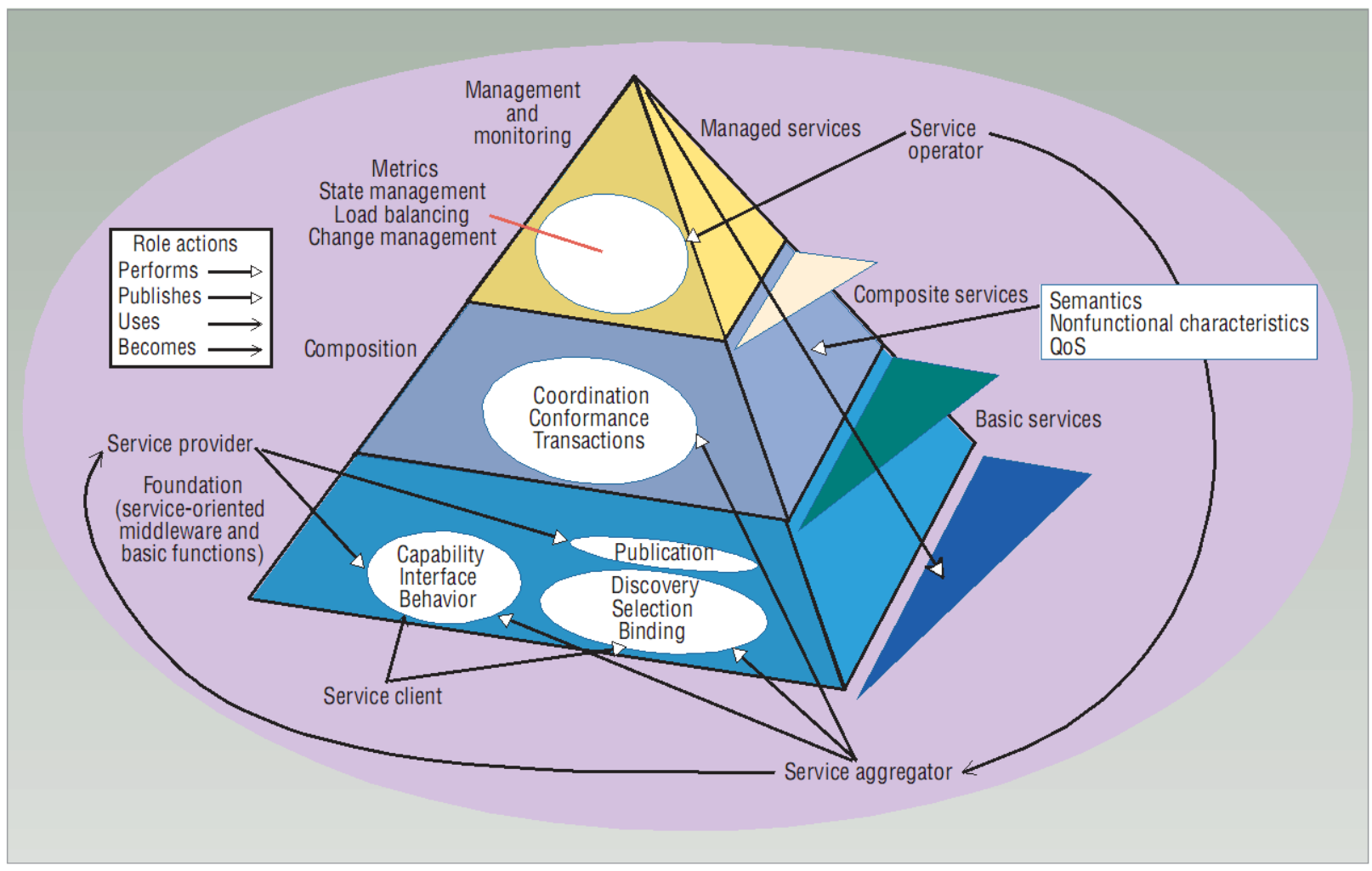

Figura 2.3: Roteiro para o desenvolvimento de SOA [PTDLO7]

\subsection{Composição de Serviços}

A composição de serviços Web em um novo serviço é um grande desafio. Há duas formas principais de compor serviços Web: orquestrações e coreografias. O Capítulo 3 entrará em detalhes sobre cada uma dessas duas formas. Resumidamente, composições baseadas em orquestrações possuem uma entidade central que controla a chamada a cada um dos serviços da composição. Composições baseadas em coreografias são colaborativas e não possuem nenhuma entidade central como existe nas orquestrações.

A Figura 2.4 apresenta uma arquitetura genérica para descrever o ciclo de vida em uma composição de serviços Web. Para iniciar um processo de composição, deve-se descrever e publicar um serviço (Etapa 1 da Figura 2.4). Em seguida deve haver uma solicitação para iniciar o processo de composição. O processo de definição e composição dos serviços (Etapa 2 da Figura 2.4) pode invocar a tradução de uma linguagem de design para uma linguagem mais formal, que é usada pelo gerador do processo de composição (Etapa 3 da Figura 2.4). Já que alguns serviços podem ter funcionalidades similares, pode ser gerado mais de um modelo de serviço de composição que atenda às requisições. Neste caso, os serviços compostos são avaliados (Etapa 4 da Figura 2.4), e finalmente o serviço composto escolhido é executado e monitorado (Etapa 5 da Figura 2.4).

A maioria das ferramentas que apoiam o projeto e definição da composição de serviços fazem uma distinção entre linguagens de especificação de serviços internas e externas. As linguagens externas, também chamadas de linguagens de design, permitem representar, geralmente em forma gráfica, a composição de serviços para que ela possa ser facilmente compreendida pelos interessados. Por outro 


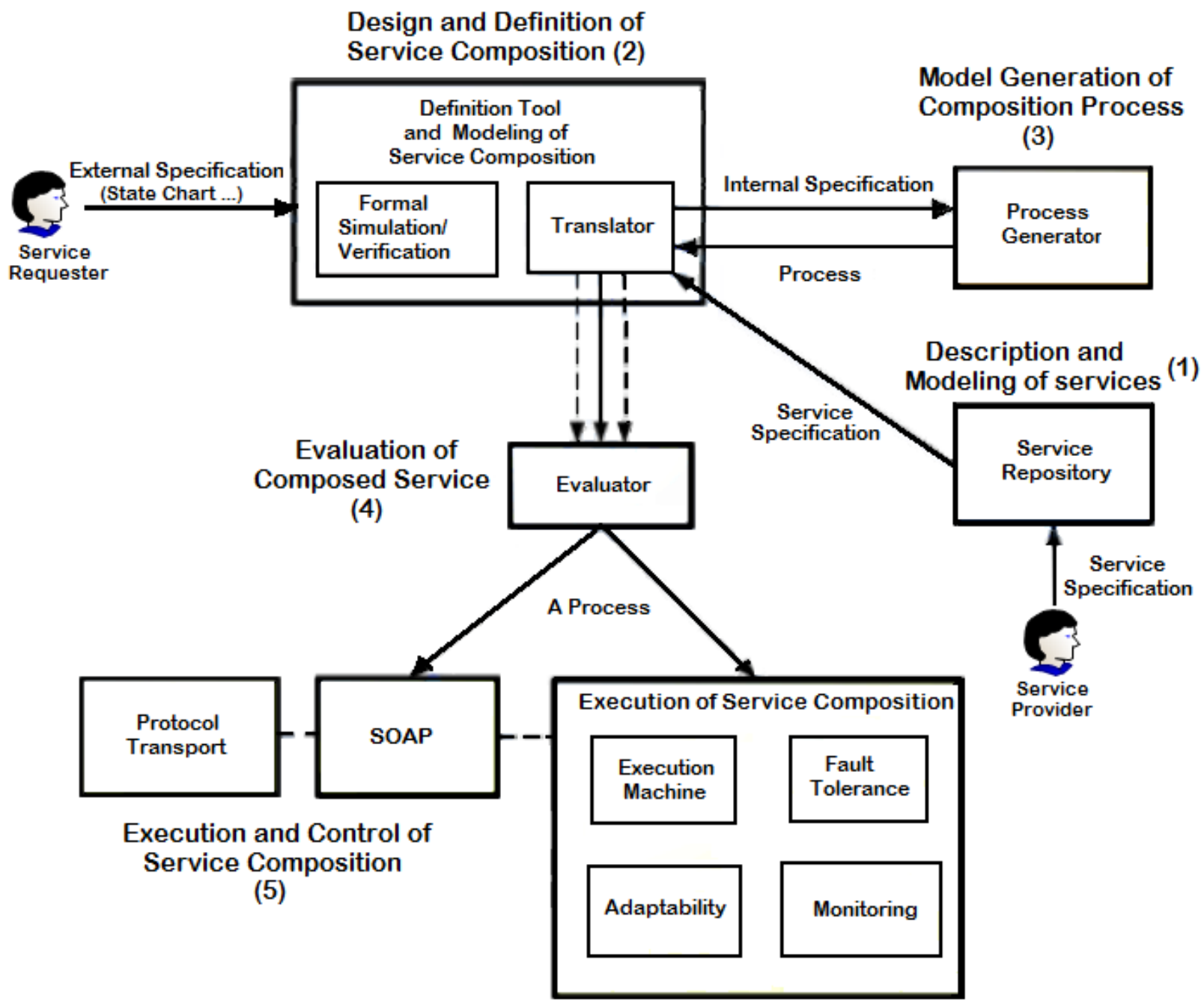

Figura 2.4: Arquitetura genérica para um sistema de composição de serviços Web [EA06]

lado, as linguagens internas, ou linguagens de composição de serviços, são linguagens geralmente mais precisas e formais, que são usados para gerar o processo de composição.

A lista a seguir apresenta algumas linguagens externas:

- WS-BPEL: É uma linguagem com uma sintaxe baseada em XML que suporta a especificação de processos de negócio, que por sua vez utilizam operações que envolvem um ou vários serviços Web. BPEL (nome curto do WS-BPEL) suporta a descrição de dois tipos de processos: abstrato e executável. A linguagem utiliza os conceitos desenvolvidos na área de gestão de fluxos de trabalho (workflows) e é relativamente expressiva, em comparação a algumas linguagens suportadas por sistemas de fluxos de trabalho existentes e padrões relacionados.

- ebXML BPSS: Electronic Business XML, é um conjunto de padrões com o objetivo de fornecer uma plataforma de implementação para a colaboração entre negócios. ebXML adota uma proposta baseada na coreografia para a composição de serviços. Especificamente, uma colaboração de negócios é descrita como um conjunto de Perfis de Protocolos de Colaboração $(\mathrm{CPP})$.

- BPML ${ }^{5}$ : O BPMi (Business Process Management Initiative) é um consórcio que tem como objetivo contribuir no desenvolvimento de padrões de descrição de processos. Esse consórcio publicou uma especificação para uma linguagem de descrição de processos chamada de BPML

${ }^{5}$ BPML: Atualmente é BPMN 
(Business Process Modeling Language), que é similar em algumas formas a WS-BPEL, e está voltada para a descrição de orquestrações de serviços Web. BPML se beneficia de um padrão prévio chamado de WSCI desenvolvido pelos interessados em BPMi. Embora descontinuada, a WSCI integra alguns dos modelos encontrados no BPML e BPEL, por exemplo, a sequência, a execução paralela e as primitivas para enviar/receber, e é usada também para descrever coreografias de serviços Web.

As linguagens externas possuem limitações para o projeto e análise de uma composição de serviços, por exemplo, para permitir técnicas de simulação, e para garantir a verificação de propriedades como segurança, gerenciamento de recursos e satisfação das restrições de negócio. Por causa disso, alguns grupos de pesquisa têm proposto algumas linguagens formais de composição de serviços. A seguir, descrevem-se algumas das linguagens formais para compor serviços Web, ou seja, linguagens internas.

- OWL-S ${ }^{6}$ : É uma ontologia de serviços que permite a descoberta, invocação, composição, interoperação e monitoramento da execução de maneira automática. OWL-S modela os serviços utilizando uma ontologia, que consiste em três partes: (1) service profile: descreve aquilo que o serviço requer dos usuários, (2) service model: especifica como funciona o serviço, e (3) service grounding: oferece informações sobre como usar o serviço.

- Componentes Web: Esta proposta trata os serviços como componentes para dar suporte a princípios básicos de desenvolvimento de software, tais como reutilização, especialização e extensão. A ideia principal é encapsular a lógica de informação composta dentro de uma definição de classe, o que representa um componente Web. A interface pública de um componente Web pode então ser publicada e utilizada para a descoberta e reutilização.

- Álgebra de Processos : Tem como meta introduzir descrições muito mais simples do que outras propostas, e modelar os serviços como processos móveis para garantir a verificação de propriedades, tais como segurança e gerenciamento de recursos. A teoria de processos móveis está baseada no Pi-Calculus, no qual a entidade básica é o processo, que pode ser um processo vazio, ou uma escolha entre várias operações de entrada/saída, uma composição paralela, uma definição recursiva ou uma invocação recursiva.

- Redes de Petri: As Redes de Petri são uma proposta de modelagem de processos bem estabelecida. Uma rede de Petri é um grafo orientado, conectado e bipartido, no qual os nós representam localizações e transições, e existem tokens que ocupam os estados. Os serviços podem ser modelados como redes de Petri, atribuindo transições para métodos e localizações para os estados. Cada serviço tem uma rede de Petri atribuída que descreve o comportamento e possui uma localização de entrada e uma de saída.

- Inspeção de Modelos: Uma inspeção de modelos é usada para verificar formalmente sistemas concorrentes de estado finito. A especificação do sistema é descrita usando lógica temporal, e para saber se a especificação é correta, realiza-se um teste no modelo. Pode-se aplicar a inspeção de modelos para a composição de serviços Web, verificando a corretude da especificação dos serviços. Dentre as propriedades que podem ser verificadas estão a consistência dos dados e a satisfação de restrições de negócio.

- Roman Model (Ações com modelo de processos baseado em autômatos): Com esta proposta, os serviços são modelados de uma forma mais abstrata, baseada na noção de atividades. Basicamente, há um alfabeto finito de nomes de atividades, mas não é modelada a estrutura interna (entradas, saídas ou interação com o mundo).

- Máquinas de Mealy (máquinas de estado finito): São máquinas de estado finito com entradas e saídas. Os serviços se comunicam através do envio de mensagens assíncronas,

${ }^{6}$ OWLS foi anteriormente conhecido como DAML-S 
onde cada serviço tem uma fila. Um "observador" global faz acompanhamento de todas as mensagens. A conversa é vista como uma sequência de mensagens.

\subsection{Internet do Futuro: A Internet das Coisas}

Atualmente, a maioria das conexões à Internet são realizadas por dispositivos utilizados diretamente por pessoas, tais como computadores e telefones celulares. A principal forma de comunicação é de humano a humano. Em um futuro não muito distante, os objetos estarão conectados. As "coisas" poderão trocar informações por si mesmas e o número de coisas conectadas à Internet será muito maior do que o número de pessoas, e os humanos podem tornar-se a minoria como geradores e receptores de tráfego. O mundo físico e o mundo da informação parecerão um só [TW10]. Nessa "Internet das Coisas" (IoT) serão realizadas novas formas de comunicação entre pessoas e coisas, e entre coisas entre si.

Não há nenhum padrão para definir a IoT. Considerando a funcionalidade e a identidade como central, a IoT pode ser definida como "Coisas que possuem identidades e personalidades virtuais movimentando-se em espaços inteligentes utilizando interfaces inteligentes para se conectarem e se comunicarem dentro de contextos de tipo social, de ambiente e de usuário". Uma definição diferente com foco na integração poderia ser formulada como "Objetos interconectados com um papel ativo no que pode ser chamado de 'Internet do Futuro'" [TW10]. Do ponto de vista conceitual, a IoT baseiase em três pilares que estão relacionados com a capacidade dos objetos inteligentes de: (i) serem identificáveis, (ii) se comunicarem e (iii) interagirem, construindo redes de objetos interconectados, ou com usuários finais ou com outras entidades na rede [MSDC12].

De uma perspectiva de nível de serviço, a questão principal tem a ver com como integrar ou compor as funcionalidades e/ou recursos fornecidos por objetos inteligentes dentro de serviços. Isto requer a definição de: (i) arquiteturas e métodos para virtualizar objetos criando um padrão para representar objetos inteligentes no domínio digital, capaz de ocultar a heterogeneidade dos dispositivos e (ii) métodos para a integração e composição contínua de serviços de objetos inteligentes em serviços de valor agregado para usuários finais [MSDC12]. As coreografias de serviços Web surgem como tecnologia facilitadora para permitir a integração das diversas coisas na IoT. Além disso, mecanismos como o proposto nesta dissertação são necessários para que as composições de serviço entre as diversas coisas atendam aos requisitos de QoS.

O termo IoT é amplamente utilizado para se referir a: (1) o resultado de interconectar objetos inteligentes em uma rede global por meio de tecnologias da Internet, (2) o conjunto de tecnologias de suporte necessárias para concretizar essa visão, incluindo, por exemplo, RFID ${ }^{7}$, sensores/atuadores, dispositivos de comunicação máquina a máquina, etc e (3) os conjuntos de aplicações e serviços, aproveitando essas tecnologias para criar novos negócios e oportunidades de mercado [MSDC12].

A tendência de desenvolvimento da IoT inclui três etapas de evolução dos dispositivos: inteligência embarcada, conectividade e interação. Atualmente, existe inteligência embarcada em diversos dispositivos e domínios como sistemas de voo e eletrodomésticos para casa. Porém, esses dispositivos inteligentes apenas trabalham sozinhos e localmente, sem haver comunicação via rede.

Dessa maneira, o próximo passo seria conectar esses dispositivos inteligentes. No entanto, do ponto de vista de "dispositivos inteligentes conectados", esses dispositivos não são inteligentes porque são apenas dotados com recursos de agentes e todas as ações são preconcebidas por humanos. As coisas podem ser conectadas com fio ou sem fio. Na Internet das Coisas, a conexão sem fio será a principal. Com base na infraestrutura existente, há muitas maneiras de conectar uma coisa: RFID, ZigBee, WPAN, WSN, 3G, etc. Conectar coisas inteligentes torna possível a interação.

Mesmo que seja possível conectar qualquer coisa, não significa que as coisas possam se comunicar por decisões próprias. Assim, novas coisas inteligentes devem ser criadas com a capacidade de processar informação, se autoconfigurar, se auto-manter, se auto-reparar, tomar decisões de forma independente e, eventualmente, desempenhar um papel ativo na sua própria remoção.

${ }^{7}$ RFID: Identificação por radiofrequência do inglês "Radio-Frequency IDentification" 


\section{Capítulo 3}

\section{Coreografias de Serviços Web}

Como explicado no Capítulo 2, orquestração e coreografia são dois tipos de composição de serviços. Não existe um consenso acerca da definição formal de uma coreografia de serviços Web [Rt05]. O conceito, junto com os padrões, ferramentas e a tecnologia que a suportam, têm evoluído junto com a maturidade da SOA e dos serviços Web [CDMV09].

Em [Lie11], são apresentadas várias definições de "coreografia de serviços" agrupadas segundo camadas de domínios. Na camada de "Composição de serviços e coordenação" uma coreografia de serviços é definida como uma forma de composição de serviços na qual o protocolo de interação entre os diversos serviços participantes é descrito de uma perspectiva global. Em [BDO05], apresenta-se uma definição genérica, na qual uma coreografia de serviços é um processo colaborativo que envolve múltiplos serviços e em que a interação entre eles é vista de uma perspectiva global.

A definição informal de coreografia de serviços pode ser resumida como [CHY07]:

"Os dançarinos dançam seguindo um cenário global, sem um único ponto de controle".

Isto é, em tempo de execução, cada participante em uma coreografia executa sua parte (chamada de papel), de acordo com o comportamento dos outros participantes. O papel da coreografia especifica o comportamento esperado na troca de mensagens dos participantes, em termos do sequenciamento e tempo das mensagens que eles consomem e produzem [SBFZ07].

Em [ADHR05] é apresentada uma definição de uma "coreografia real" sem fazer uma distinção entre uma coreografia e uma orquestração, porque ambos os termos são utilizados para se referir ao problema de acordo de um processo comum. Em [ADHR05], assume-se que uma coreografia define colaborações entre participantes que interagem, isto é, que no processo de coordenação dos serviços Web interconectados, todos os participantes precisam estar de acordo. A Figura 3.1 mostra essa noção de coreografia, onde os participantes interagem entre si sem um ponto de controle único. O acordo do ponto de vista global da coreografia está baseado no comportamento observável dos participantes, e o comportamento interno de cada um deles está especificado por meio de uma orquestração (BPEL).

\subsection{Padrões e Linguagens}

Diversas propostas para definir e especificar coreografias têm surgido. A seguir são apresentadas as definições de coreografia de serviços segundo alguns dos padrões mais utilizados.

- WSCI ${ }^{1}$ : A sua especificação não tem uma definição explícita de coreografia de serviços, mas a palavra coreografia e as palavras derivadas aparecem no documento. Coreografia de mensagens é descrita como a ordem na qual as mensagens podem ser enviados ou recebidos em uma dada troca de mensagens, as regras que governam tal ordem e quando as mensagens começam e terminam.

\footnotetext{
${ }^{1}$ WSCI (Web Services Choreography Interaction): www.w3.org/TR/wsci/
} 


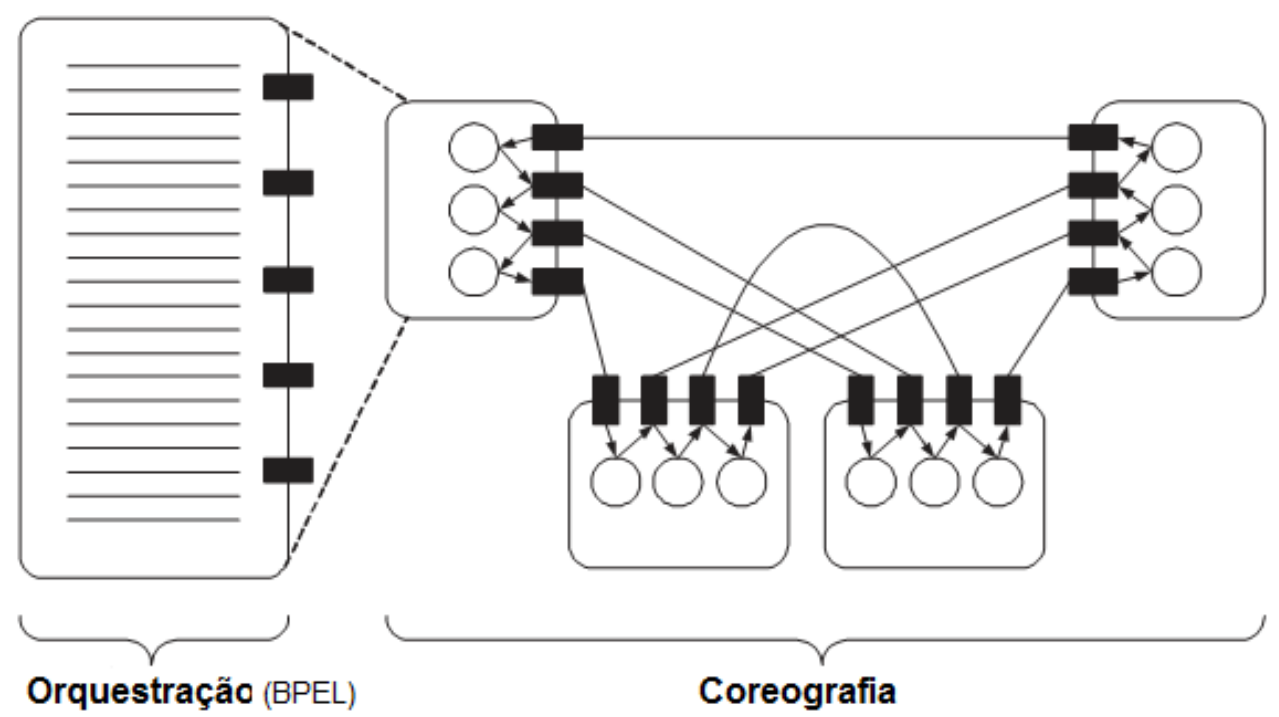

Figura 3.1: A coreografia define colaborações entre participantes que interagem entre si [ADHR05]

- WS-CDL: Em [W3C05], coreografia é definida como um contrato multi-participante visto de uma perspectiva Global. Na sua especificação, não há uma definição explícita de coreografia de serviços web, mas a camada de coreografia é descrita como o componente que descreve colaborações entre participantes, definindo de um ponto de vista global seus comportamentos e onde a troca de informação acontece.

- BPMN: No documento de especificação do BPMN $2.0^{2}$ uma coreografia é definida como uma sequência ordenada de troca de mensagens B2B (Negócio a Negócio) entre dois ou mais participantes. Uma coreografia não possui controlador central, entidade responsável e nem observador do processo.

- BPEL4Chor[DKLW07]: Uma coreografia descreve a troca de mensagens entre serviços da perspectiva de um observador que é capaz de ver todas as interações e o fluxo de dependências

- Let's Dance[ZBDH06]: Em uma perspectiva global (coreografia), as interações são descritas da perspectiva de uma coleção de serviços abstraídos como papéis.

\subsection{Orquestração e Coreografia de serviços}

Tanto orquestrações quanto coreografias de serviços fundamentam a área da engenharia de software orientada a serviços, e assim, representam diferentes escolhas de projeto na hora de implementar sistemas orientados a serviços [Ros09].

Os fluxos de trabalho (workflows) podem ser descritos usando WS-BPEL, ou outra linguagem de orquestração, ou podem ser descritos por uma linguagem de coreografia de serviços como o WS-CDL. É frequente o caso em que as duas linguagens são necessárias. Por exemplo, um fluxo de trabalho pode ser descrito como uma coreografia, e este pode se realizar como um conjunto de fluxos de trabalho executáveis. Nesse cenário os serviços podem ser orquestrados, usando por exemplo WS-BPEL, de modo que o comportamento externo observável é definido e gerado a partir de uma coreografia, usando por exemplo WS-CDL. Assim, a coreografia é uma guia para o sistema todo, e a orquestração é uma maneira para realizar e implementar o sistema sem a introdução de um intermediário de serviços global [Rt05].

\footnotetext{
${ }^{2}$ BPMN 2.0: http://www.bpmn.org/
} 
A Figura 3.2 mostra a relação em alto nível que existe entre orquestração e coreografia. Orquestração se refere a um processo de negócio executável que interage com serviços Web internos e externos. As interações acontecem no nível de mensagens. Elas incluem lógica de negócios e a ordem da execução de tarefas, e podem estender as aplicações e as organizações para definir um modelo de processos de longa duração, transacional e de várias etapas. A orquestração sempre representa o controle da perspectiva de um participante. A coreografia é mais colaborativa e permite que vários participantes estejam envolvidos para que descrevam sua parte na interação. A coreografia acompanha a sequência de mensagens de múltiplos participantes e fontes, em vez de apenas um processo de negócio específico.

Como o objetivo desta pesquisa é propor mecanismos relacionados com coreografia de serviços Web, a partir deste ponto este texto focará nesse tipo de composição.

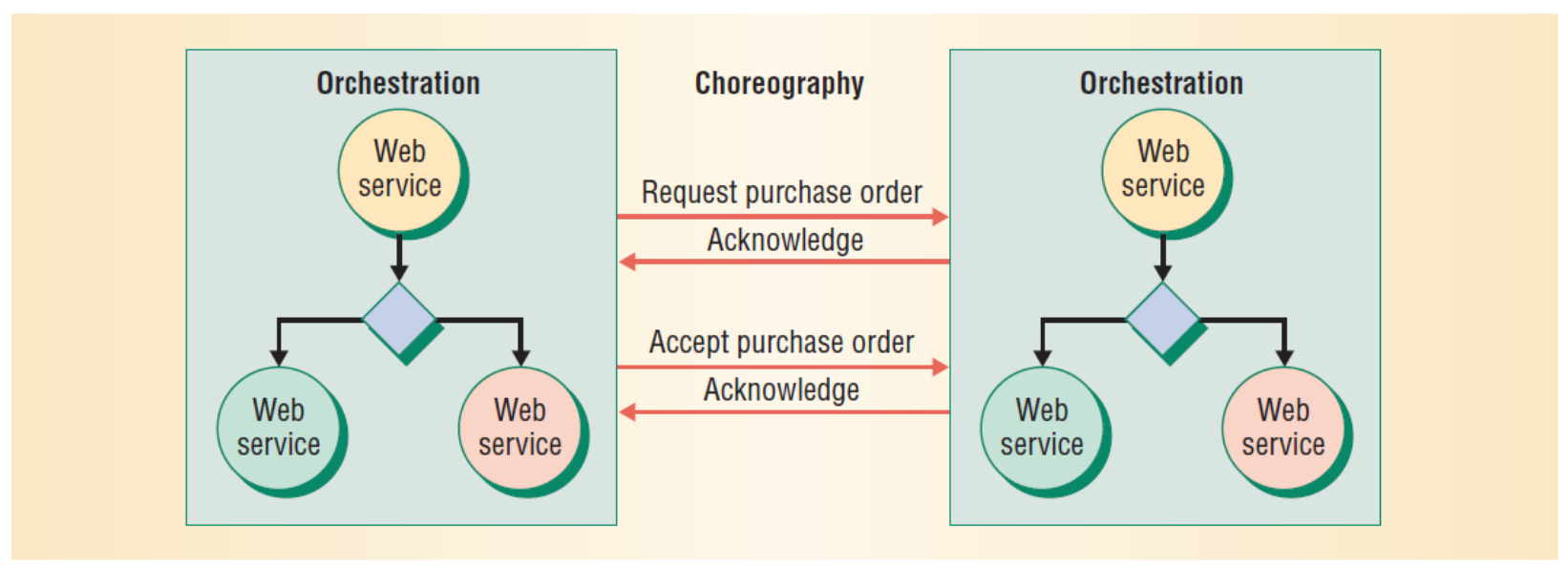

Figura 3.2: Orquestração Vs. Coreografia [Pel03]

\subsection{Processos de Negócio}

Um processo de negócio inter-organizacional (IOBP) é um grupo organizado de atividades realizadas por duas ou mais organizações para atingir um objetivo de negócio. Como consequência disso, a modelagem e o projeto de processos de negócios usados dentro de uma organização tem que ser melhorada e estendida para lidar com particularidades de negócios inter-organizacionais [BA11].

Do ponto de vista de processos de negócios, as coreografias descrevem o comportamento externamente observável de uma entidade de negócios em processos de negócio inter-organizacionais. A ideia por trás das coreografias está relacionado ao fato de que as entidades de negócios frequentemente consideram seus processos intra-organizacionais como ativos, por exemplo, visão baseada em recursos em gestão estratégica [MH05]. No entanto, as empresas querem se beneficiar de fortes colaborações com os seus parceiros (participantes). Assim, as linguagens de coreografias são maneiras de definir regras de colaborações entre vários participantes sem revelar as suas operações internas [MH05].

Além disso, a modelagem de processos de negócio inter-organizacionais envolve novos desafios, principalmente a capacidade de lidar com autonomia, privacidade, heterogeneidade e com suporte de coordenação por meio de contratos. Nesse contexto, as coreografias são uma abordagem para modelar processos ou workflows inter-organizacionais do ponto de vista global (ver Figura 3.3). Nesse esquema os processos ficam descritos de maneira "privada" (orquestração, interna ou executável), "pública" (coreografia local, abstrata ou vista), e "colaborativa" (coreografia global, interorganizacional ou cross-organizacional), a fim de separar melhor a densidade de informação de diferentes áreas. 


\section{Processos de Negócio Inter-Organizacionais}

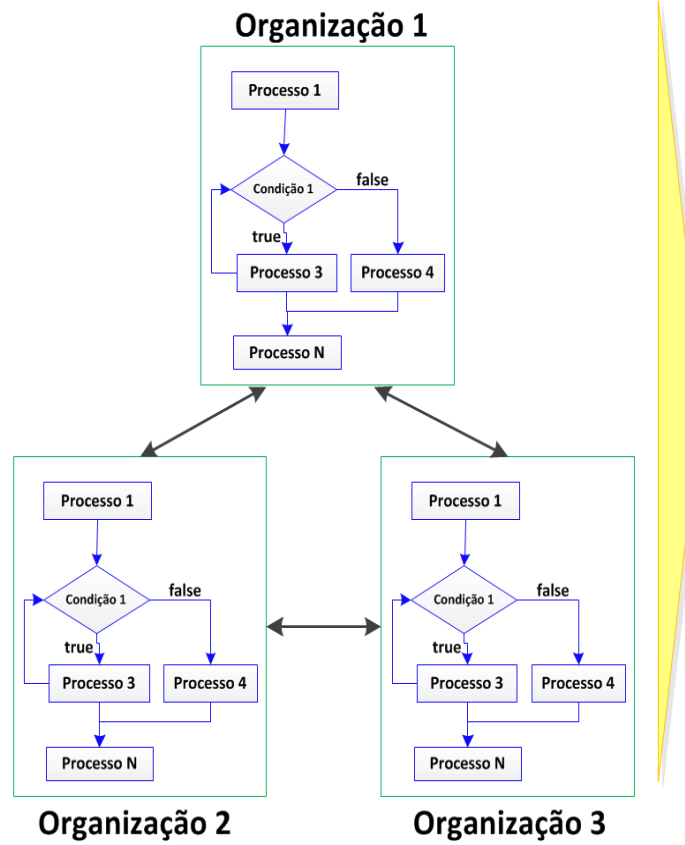

\section{Coreografia de Serviços}

Participante 2

Participante

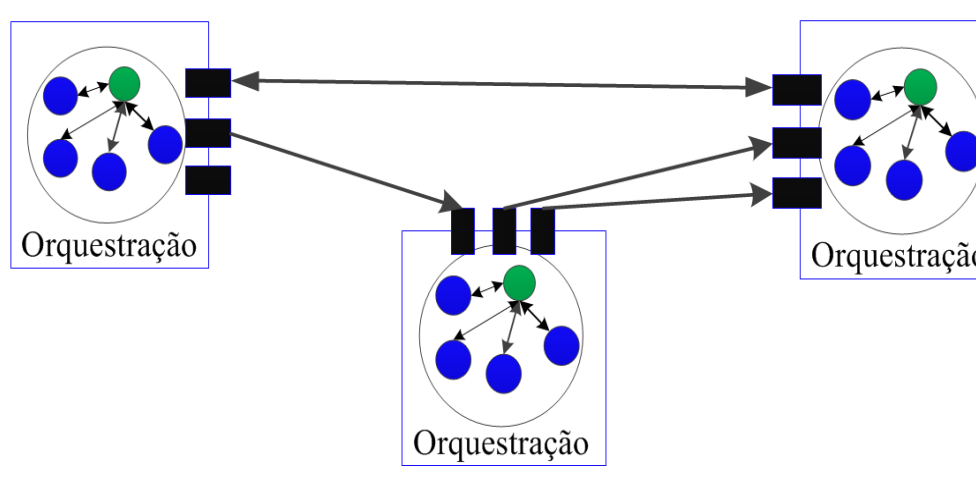

Participante 1

Figura 3.3: Coreografia como solução para modelagem de processos de negócio inter-organizacionais

\subsection{Elementos de um Modelo de Coreografia}

Segundo [SBFZ07], uma linguagem de modelagem de coreografias fornece os meios para definir um modelo de coreografia, isto é, coreografias, implementação de serviços e semântica, incluindo mecanismos para comparar a coreografia com o comportamento global das implementações dos seus serviços. Assim, pode-se entender informalmente uma linguagem de modelagem de coreografias $L$ como uma coleção de modelos de coreografias:

$$
L=\{(C, I) \mid C \text { é uma coreografia e I é sua implementação mediante serviços }\}
$$

Onde $C$ é a coleção de coreografias e $I$ é a coleção de implementações de serviços. Em tempo de execução, cada participante é responsável pela correta execução do seu papel na coreografia, isto é, seu comportamento esperado na troca de mensagens em relação ao comportamento dos outros participantes. Quando os participantes realizam ou executam seus papéis segundo o acordo comum entre eles, isto é chamado de enactment da coreografia [MPRW10], [Bul08].

Uma coreografia pode ser definida utilizando dois tipos básicos de elementos [SBFZ07]:

1. Um conjunto de ações observáveis que acontecem nos serviços individuais localmente.

2. Conjunto de restrições globais de sequência de atividades em (1).

As ações observáveis tipicamente são de dois tipos: Ações por meio de mensagens para se comunicar com outros serviços, e as ações locais, que são realizadas nos serviços individuais independentemente de outros serviços. As restrições de sequência restringem a ordem das ações dos participantes ou serviços. Além disso, os serviços devem utilizar um modelo de mensagens para se comunicar, que tipicamente são os modelos síncrono e assíncrono. No caso do modelo assíncrono, é comum utilizar uma fila $\mathrm{FIFO}^{3}$ no receptor para armazenar por ordem de chegada as mensagens que ainda não foram consumidas [MPRW10]. Dadas estas definições, os modelos de coreografia de serviços têm que lidar com os seguintes problemas [Bul08], [MPRW10]:

\footnotetext{
${ }^{3}$ FIFO: Acrônimo em inglês para Primeiro em Entrar Primeiro em Sair.
} 
- Ausência de deadlock: Um deadlock ocorre quando o enactment de uma coreografia atinge um estado que, (1) não é o final e que (2) não pode deixar sem violar a ordem das mensagens na coreografia. As análises de coreografias para a ausência de deadlocks geralmente são construídas sobre técnicas de verificação de modelos [MPRW10].

- Conformidade: Um participante está em conformidade com uma coreografia se seu protocolo de negócio, isto é, o atual comportamento da troca de mensagens do participante como é percebido pelos outros, é equivalente ao papel especificado por esse participante na coreografia [MPRW10].

- Realizability: Realizability indica se peers podem ser gerados a partir de uma especificação de coreografia, de maneira que as interações dos peers gerados coincidam com a especificação da coreografia [BR09]. Em outras palavras, realizability é a possibilidade de que uma especificação de coreografia possa ser realizada pelos serviços ou participantes [SBFZ07].

- Síntese: A síntese de uma coreografia denota a derivação de processos de orquestração executáveis a partir de uma especificação de coreografia [ZWPZ10]. Uma síntese ideal pode tomar um documento WS-CDL válido para derivar um conjunto de processos de orquestração, os quais são semanticamente equivalentes à coreografia original dada. Portanto, o problema da síntese é decidir se uma coreografia pode ser realizada por algumas orquestrações e sintetizar uma combinação de orquestrações se for possível [SLD $\left.{ }^{+} 10\right]$.

- Sincronização: A análise da sincronização visa avaliar os efeitos da comunicação síncrona e assíncrona para melhorar a eficiência da interação. Assim, um conjunto de peers que se comunicam assincronamente são sincronizáveis, se seu conjunto de mensagens não muda quando a comunicação assíncrona é substituída por uma comunicação síncrona [MPRW10].

- Compatibilidade: A compatibilidade de uma coreografia de serviços é a capacidade de um conjunto de serviços Web interagir por meio de troca de mensagens de uma forma confiável. O conjunto de serviços compatíveis não somente depende da sequência de mensagens, mas também depende de propriedades quantitativas como o tempo [GG11].

- Reconfiguração Dinâmica: Tais reconfigurações correspondem à adição ou remoção de algumas interações em tempo de execução por conta de eventos como perda do serviço, extensão de funcionalidades, substituição de um serviço, entre outros [SR09]. Assim, é importante formalizar a reconfiguração para verificar se um conjunto de peers, podem ser reconfigurados com relação a uma segunda especificação de coreografia, a qual consiste de uma extensão (adição de algumas interações) ou uma simplificação (remoção de algumas interações) da coreografia original. Se essas reconfigurações são possíveis, novos peers são gerados.

As linguagens de coreografia, segundo [SBFZ07], podem ser divididas em três categorias baseadas em seus arcabouços associados: autômatos de estado finito, redes de Petri e álgebra de processos.

\subsubsection{Modelos baseados em Autômatos}

Os modelos baseado em autômatos representam a coreografia e a implementação de serviços como uma maquina de estado finito, isto é, especificam uma coreografia por meio de estados e transições. Desta maneira, capturam explicitamente um instantâneo da execução do serviço composto como um estado, e os comportamentos locais e globais podem ser capturados como uma sequência de estados, nos quais cada estado de transição está associado a uma mensagem ou uma atividade [SBFZ07].

Este grupo de linguagens de modelagem de coreografias inclui: protocolos de conversação, serviços Mealy [BFHS03], diagramas de colaboração UML [BF08], e o modelo de composição de serviços Colombo $\left[\mathrm{BCG}^{+} 05\right]$. A linguagem Let's Dance [ZBDH06] também pertence a esse grupo, e fornece um conjunto de primitivas de restrição de sequências para permitir a especificação de uma coreografia com uma notação gráfica. 


\subsubsection{Modelos baseados em Redes de Petri}

São amplamente utilizados para modelar, entre outras coisas, fluxos de controle, e por conta disso, são candidatos adequados para linguagens de modelagem de coreografias. Por exemplo, IPN (Interaction Petri Net), uma linguagem de modelagem de coreografias baseada em Redes de Petri, trata uma troca de mensagem como o disparo de uma transição. O uso de redes de Petri permite que comunicações concorrentes sejam explicitamente separadas, ao contrário do que permitiria um diagrama de colaboração UML [SBFZ07]. Os serviços ou participantes são representados por "interfaces de comportamento", que são redes de Petri com entrada e saída. Os serviços ou participantes se comunicam com outros no modelo de mensagens síncronos, em lugar de uma fila FIFO, que utilizam as linguagens baseadas em autômatos.

\subsubsection{Modelos baseados em Álgebra de Processos}

São menos intuitivos e não possuem representação gráfica, e assim como os modelos baseados em redes de Petri, fornecem um formalismo para a verificação das propriedades de uma especificação. Existem várias propostas no desenvolvimento de linguagens de modelagem de coreografias baseadas em álgebra de processos [SBFZ07], muitas dessas propostas estão baseada em cálculo Pi. O cálculo Pi é uma álgebra de processos que tem como intuito ser uma teoria formal para modelagem de processos. Exemplos de linguagens deste tipo são XLANG, WS-CDL e as baseadas nela, tais como CDL [PSW $\left.{ }^{+} 07\right]$ e Chor [ZXCH07], o modelo "Bologna" [SBFZ07], entre outras.

\subsection{Linguagens de Coreografias de Serviços}

As linguagens de coreografia de serviços podem ser categorizadas utilizando dois critérios [DKB08]: as independentes de implementação e as específicas de implementação. As linguagens independentes de implementação são utilizadas principalmente para descrever processos da perspectiva de negócios. A definição de formatos de mensagens concretas ou protocolos de comunicação é realizada no escopo das linguagens específicas de implementação.

Basicamente existem duas abordagens de modelagem para linguagens de coreografia de serviços [BWR09]: modelos de interação e os modelos de interconexão. Os modelos de interação usam interações atômicas como blocos de construção básicos e os fluxos de dados e de controle estão baseados nas dependências entre essas interações de uma perspectiva global. Os modelos de interconexão definem o fluxo de controle por participante ou por papel do participante, e as respectivas atividades de envio e recepção são conectadas usando fluxos de mensagens, representando deste modo as interações. A Figura 3.4 mostra a categorização das linguagens de coreografia segundo os critérios e as abordagens citados. A seguir, essas linguagens são descritas resumidamente.

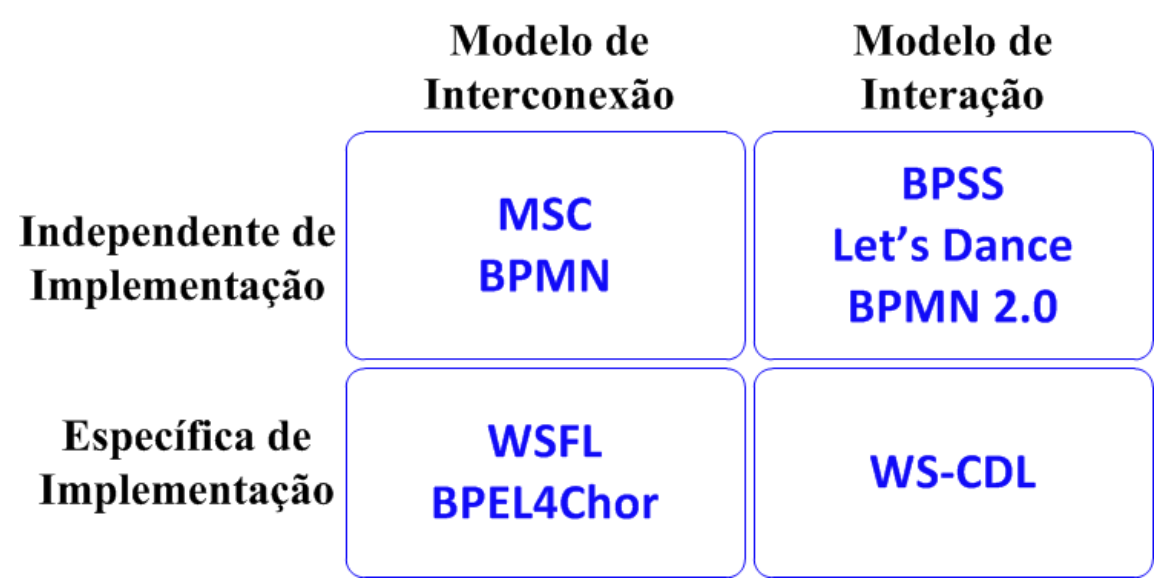

Figura 3.4: Categorização de linguagens de coreografias de serviços Web (baseada em [Eng09]) 
O BPMN é uma linguagem de modelagem gráfica e é o padrão $\mathrm{OMG}^{4}$ para modelar processos. Esta linguagem realiza a distinção explícita entre o fluxo de controle e o fluxo de mensagens. Todas as atividades conectadas por meio de fluxos de controle pertencem ao mesmo processo e o fluxo de mensagens é utilizado para interconectar processos diferentes. O MSC (Tabela de Sequência de Mensagens) é uma linguagem mais adequada para modelar sequências de interações simples ao invés de coreografias complexas, já que não suporta ramos condicionais, ramos paralelos e nem iterações [DKB08].

O protocolo BPSS ${ }^{5}$ pode definir coreografias e comunicação entre serviços baseadas em XML, e pertence ao grupo de especificações do $e b X M L$ da OASIS. Sua principal desvantagem é suportar somente coreografias entre dois participantes. Let's Dance é uma linguagem de modelagem gráfica e, assim como BPMN, está focado na análise de negócios e captura de requisitos, em lugar de detalhes de implementação. Let's Dance suporta mais cenários de coreografias do que BPMN [ZBDH06] e suporta também todos os padrões de coreografia comuns [BDH05]. BPMN $2.0^{6}$ é a versão atual do BPMN e ela introduz dois novos tipos de diagrama: diagramas de coreografia e diagramas de colaboração. O primeiro permite modelar fluxos entre distintas interações, enquanto que o segundo fornece uma visão geral em cenários complexos com diversos participantes.

O WSFL é uma linguagem baseada em XML que consiste de várias vistas locais, também chamadas de modelos de fluxo, para especificar processos de negócio executáveis, e um modelo global para especificar colaborações e interações entre os participantes de negócio. O BPEL4Chor [DKLW07] é uma proposta que adiciona uma camada sobre o BPEL para mudar de uma linguagem de orquestração para uma linguagem de coreografia completa. No BPEL4Chor os processos BPEL abstratos são utilizados para descrições de comportamento entre participantes, as quais são unidas por meio de mensagens formando uma topologia de participantes. Assim como Let's Dance, o BPEL4Chor suporta todos os padrões de coreografia comuns [DKB08].

O WS-CDL é uma recomendação candidata pela W3C para se tornar a linguagem padrão para coreografias de serviços Web. Ela é baseada em Pi-calculus, uma linguagem formal que permite a descrição de algoritmos de programação concorrente. As dependências entre as interações são definidas por meio de um conjunto de construções de fluxo de controle que são difíceis de mapear para processos BPEL, sendo este ponto um dos aspectos mais criticados desta linguagem [BDO05]. A WS-CDL é muito utilizada em vários trabalhos sobre coreografias de serviços Web, e inclusive foram propostas linguagens derivadas dela, tais como Chor [ZXCH07] e WSCDL + [KWH07]. Contudo, atualmente a especificação do WS-CDL está descontinuada [Web05].

\subsection{Ferramentas e Arcabouços}

Existem várias ferramentas e arcabouços para apoiar diversos aspectos da coreografia de serviços, tais como modelagem, verificação e validação, simulação, síntese e mapeamento para processos executáveis como BPEL e enactment. Alguns arcabouços abrangem muitos desses aspectos dentro de uma metodologia de desenvolvimento, por exemplo, o projeto Savara [SAV09] do JBoss. A seguir, são resumidas algumas dessas ferramentas e arcabouços.

WS-CDL Eclipse [Dou05] e Pi4SOA [ZTW $\left.{ }^{+} 06\right]$ foram algumas das primeiras implementações para suportar modelagem, simulação e verificação de coreografias de serviços Web baseadas em WS-CDL. Estas três ferramentas são indicadas na especificação WS-CDL [Web05].

WS-CDL Eclipse é uma ferramenta baseada em Eclipse para produzir, visualizar e simular coreografias de serviços Web a partir de um documento WS-CDL. Pi4SOA fornece uma ferramenta baseada em Eclipse para modelar coreografias, além de possibilitar a geração de serviços a partir de um documento WS-CDL. Atualmente, o desenvolvimento de Pi4SOA está descontinuado, e nesse contexto apareceu o projeto Savara [SAV09]. O Savara faz parte da comunidade do JBoss e propõe uma nova metodologia de desenvolvimento chamada de arquitetura testável [Kum09].

\footnotetext{
${ }^{4}$ OMG: Object Management Group

${ }^{5}$ BPSS: Business Process Specification Schema

${ }^{6} \mathrm{BPMN}$ 2.0: http://www.omg.org/spec/BPMN/2.0/
} 
Em [LK08] é apresentado um conjunto de ferramentas para suportar modelagem, verificação, validação e transformação para processos executáveis BPEL dentro do contexto do BPEL4Chor.

OpenKnowledge $\left[\mathrm{BPB}^{+} 09\right]$ é uma plataforma baseada em uma arquitetura ponto a ponto $(\mathrm{P} 2 \mathrm{P})$ para especificar e executar ${ }^{7}$ coreografias de serviços. Cada peer representa um participante da coreografia. Esse peer é uma wrapper que separa o comportamento observável de um participante da sua implementação, a qual pode ser um serviço Web, um serviço composto, entre outros. Essa plataforma utiliza o LCC (Lightweight Coordination Calculus) [Rob05] como a linguagem executável baseada no Process-Calculus para especificar e executar as coreografias. A sua arquitetura é capaz de lidar com a heterogeneidade semântica dos seus participantes e a descoberta deles.

\subsection{Coreografias em BPMN}

\subsubsection{BPMN}

O BPMN (Notação de Modelagem de Processos de Negócio) é um padrão que surgiu como uma notação para capturar processos de negócio, especialmente no nível da análise de domínios e design de sistemas de alto nível. A notação herda e combina elementos a partir de uma série de anotações previamente propostas para modelagem de processos de negócios, incluindo a XPDL ${ }^{8}$ e diagramas de atividades do UML.

O BPMN fornece uma notação gráfica para modelagem de processos de negócios, com ênfase em controle de fluxo. Ele define um Diagrama de Processos de Negócio (BPD), uma espécie de fluxograma que incorpora construções adaptadas para a modelagem de processos de negócios, tais como AND-split, AND-join, XOR-split e XOR-join. A Figura 3.5 mostra um subconjunto do núcleo de elementos de BPMN. Há objetos e fluxos de sequência. Um objeto pode ser um evento, uma atividade ou um gateway. Uma fluxo de sequência liga dois objetos em uma BPD e mostra a relação do fluxo de controle, ou seja, a ordem de execução.

Um evento pode sinalizar o início de um processo (evento de inicio), o final de um processo (evento de finalização), e pode também ocorrer durante o processo (evento intermediário). Um evento de mensagem é usado para enviar ou receber uma mensagem. Um evento temporizador (timer) indica um tempo ou data específico a ser atingido, e um evento de erro sinaliza um erro a ser detectado durante a execução de um processo.

Uma atividade pode ser uma tarefa ou um subprocesso. Uma tarefa é uma atividade atômica e significa trabalho a ser executado dentro de um processo. Há sete tipos de tarefa: serviço, de recebimento, de envio, de usuário, um script manual, e de referência. Por exemplo, uma tarefa de recebimento é utilizada quando um processo aguarda por uma mensagem de um participante externo. Um subprocesso é uma atividade composta que é definida como o fluxo de outras atividades. Existem subprocessos embarcados e subprocessos independentes. A diferença é que um subprocesso embarcado é parte de um processo, enquanto um subprocesso independente pode ser chamado por diferentes processos. Um subprocesso pode ser invocado via uma atividade de invocação de subprocessos.

Um gateway é uma construção de roteamento utilizada para controlar a convergência e divergência do fluxo de sequência. A seguir a descrição dos principais tipos de gateways:

- De divisão em paralelo ( $\boldsymbol{A} N \boldsymbol{N}$-split): para a criação de fluxos de sequência concorrentes.

- De junção paralela ( $A N D$-join): para a sincronização simultânea de vários fluxos de sequência.

- De escolha XOR baseados em dados/eventos (data/event-based XOR decision): para a seleção de um conjunto de fluxos de sequência mutuamente excludentes. Onde a escolha está baseada ou nos dados do processo (data-based, isto é, XOR-split) ou de eventos externos (event-based).

\footnotetext{
${ }^{7}$ Neste caso, o termo executar é válido, já que o LCC é uma linguagem executável de coreografias .

${ }^{8}$ XPDL: Linguagem de Definição de Processo XML
} 


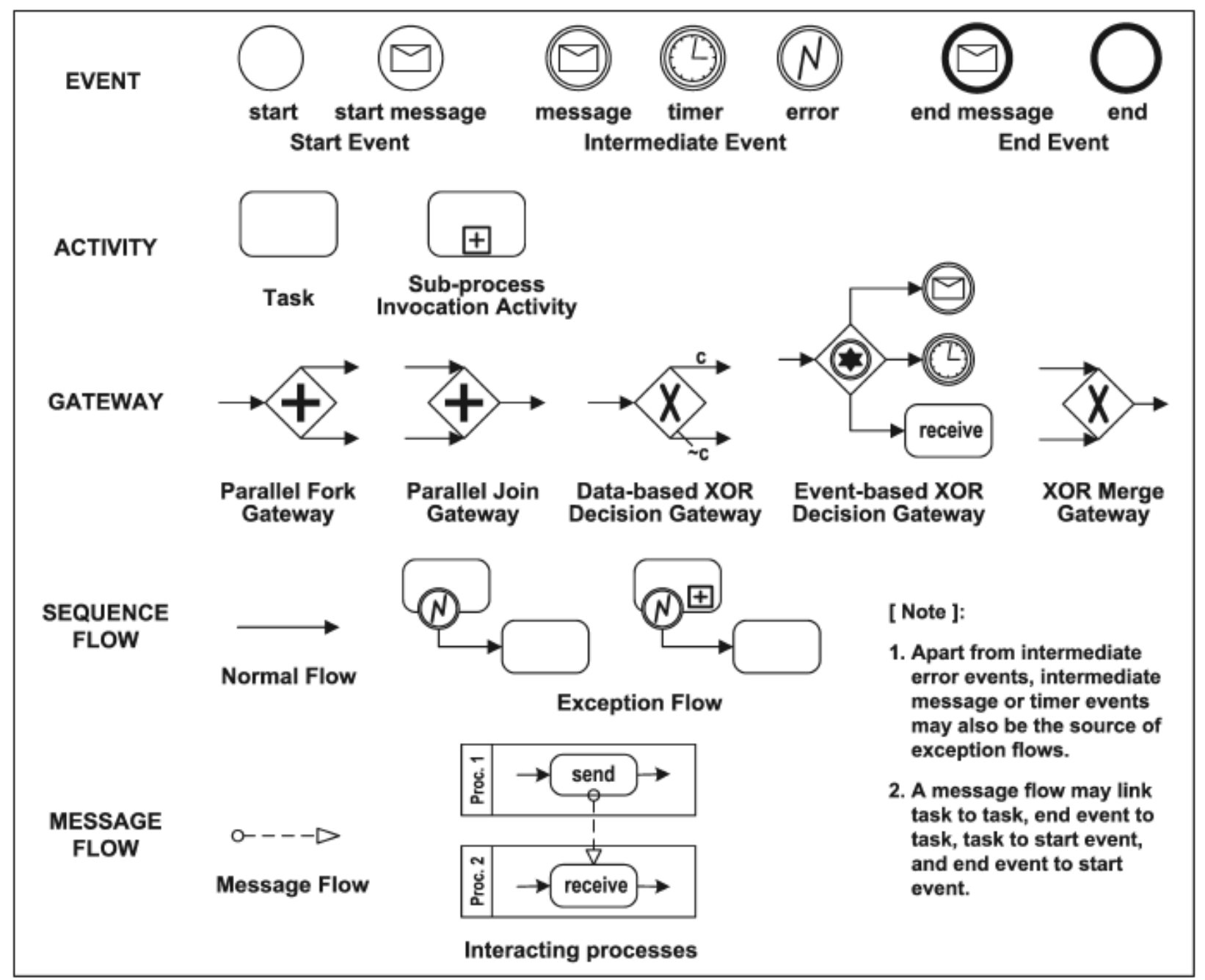

Figura 3.5: Conjunto dos principais elementos do BPMN [DDO07]

- De junção XOR (XOR-join): para unir um conjunto de fluxos de sequência mutuamente excludentes dentro de um único fluxo de sequência.

\subsubsection{Coreografia de Processos}

O BPMN é uma linguagem independente da implementação e, especialmente, permite a definição de coreografias interligando diferentes processos utilizando fluxos de mensagens. Essas coreografias são de alto valor, principalmente em contextos inter-organizacionais, onde diferentes parceiros ou participantes de negócios acordam seu comportamento de interação antes de interconectar seus sistemas de informação. Descrições de comportamento dos participantes são primeiro utilizadas como vistas de coreografia de acordo com a perspectiva de um participante individual. Depois disso, elas servem como especificações para a implementação de novos serviços ou a adaptação de serviços existentes [PDKL08].

Como já descrito na Seção 3.5, existem duas maneiras de especificar coreografias de serviços, com modelos de interação e com modelos de interconexão. Em ambos os estilos de modelagem, os participantes interagem entre si e as atividades são conectadas. O modelo de interconexão conecta atividades de comunicação pertencentes a dois participantes. Assim, cada troca de mensagem é expressa usando uma conexão entre os participantes [KLW11]. O modelo de interação expressa cada troca de mensagem como interações atômicas. Em geral, os termos "modelo de interconexão" e "modelo de interação" são derivadas da maneira como cada paradigma de modelagem expressa a troca de mensagens e não do fato de se as atividades são conectadas ou se são interações gerais 
entre os processos que são apresentados [KLW11].

\section{O Modelo de Interconexão}

Os modelos de interconexão modelam cada participante como um processo separado, e podem fornecer o comportamento interno dos participantes. Exemplos para linguagens de coreografia neste modelo são colaborações em BPMN 2.0, modelos com vários pools em BPMN 1.2, BPMN + ou BPEL4Chor. O comportamento de cada participante pode ser expresso como um único elemento pool do BPMN ou um processo BPEL abstrato [KLW10]. Outras possibilidades adicionais para especificar o comportamento de um participante incluem a abordagem Open Net [KLW10].

Em BPMN 2.0 os modelos de interconexão são implementados por diagramas de colaboração. Estes diagramas consistem em dois ou mais pools, em que cada um deles representa um participante na colaboração global. Dentro de um pool, o comportamento do processo interno de um participante é modelado com elementos comuns do BPMN, por exemplo, atividades, eventos, e os fluxos de sequência [KLW11]. Alternativamente, os pools podem ser descritos como caixas pretas.

A Figura 3.6 apresenta um exemplo de coreografia especificada de acordo com o modelo de interconexão. O exemplo é acerca de oferta de investimentos e está especificada utilizando a notação BPMN 1.2. Primeiro, um consultor financeiro (participante) oferece um produto a um cliente (outro participante). Posteriormente, o cliente tem 24 horas para decidir se aceita a proposta de investimento. Cada participante é representado por meio de pools nos quais se interconectam atividades.

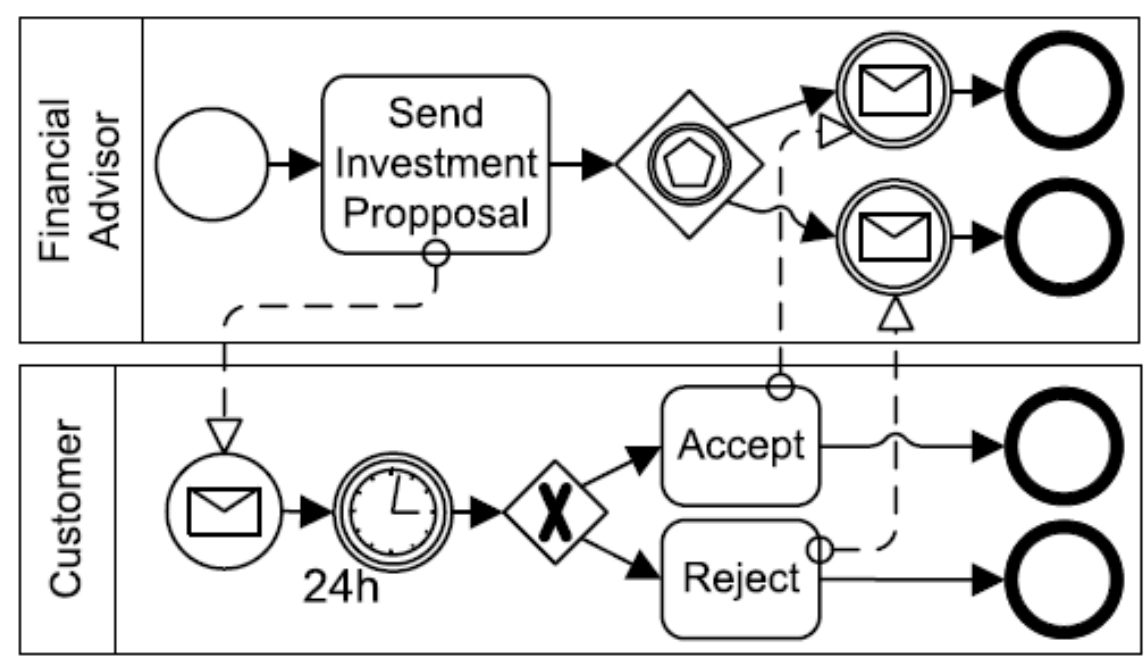

Figura 3.6: Exemplo de modelo de interconexão de coreografias: oferta de investimento [KLW10].

É importante observar que essa abordagem de modelagem leva as dependências de fluxos de controle a serem redundantes e ter mais chances de processos incompatíveis. Um exemplo para essa incompatibilidade seria um provedor que aguarda a realização de um pagamento antes de entregar os bens adquiridos. O comprador, por outro lado, espera que as mercadorias possam ser entregues antes de ter pago. Ambos os parceiros iriam esperar indefinidamente - uma clássica situação de deadlock. Os modelos de interação evitam esses problemas por meio da descrição de dependências de fluxos de controle entre as interações [DB08]. Outra desvantagem de redundância é que os modeladores precisam de mais tempo para criar e entender os modelos. Em [DB08], verificou-se que o modelo de interação permite uma rápida criação e compreensão para modeladores humanos.

\subsubsection{O Modelo de Interação}

O modelo de interação tem como bloco de construção de coreografias as interações atômicas entre participantes por meio de troca de mensagens. O modelo de interação é considerado nesta dissertação. 
O bloco básico de construção nos modelos de interação são as "atividades" de interação. Cada atividade descreve uma troca de mensagem entre dois participantes de maneira atômica na especificação de uma coreografia. Os modelos de interação fornecem uma visão de alto nível das colaborações e a maioria das linguagens de coreografia neste modelo ocultam o comportamento interno dos participantes [KLW10]. BPMN 2.0, iBPMN e BPELGold são linguagens que suportam o modelo de interação, das quais apenas o BPMN 2.0 é padrão. Para especificar ou modelar coreografias nesta abordagem utilizam-se "diagramas de coregrafias" suportados a partir de BPMN 2.0

Alguns elementos BPMN são comuns para os diagramas de processos normais e para os diagramas de coreografias (modelo de interação), bem como colaborações (modelos de interconexão). Tais elementos comuns incluem principalmente eventos, gateways, e fluxos de sequência e não incluem os pools. As interações entre os participantes são representadas mediante atividades de coreografias (choreography activity). Uma atividade de coreografia representa um ponto no fluxo de uma coreografia, em que uma interação acontece entre dois ou mais participantes. Uma atividade de coreografia pode se referir a elementos como "subcoreografia", "chamada a outra coreografia" (callchoreography) e uma "tarefa de coreografia" (choreography task), das quais a última será levada em consideração nesta dissertação.

Uma tarefa de coreografia é uma atividade atômica em uma coregrafia de processos. Ela representa uma interação em que uma ou duas trocas de mensagens acontecem entre dois participantes. A Figura 3.7 mostra uma tarefa de coreografia, em que as duas faixas, "Participant A" e "Participant B", representam os participantes. A faixa em cor branca é do participante que inicia a interação e a faixa em cor escura é do participante dono da tarefa. A tarefa está representada pela faixa interna chamada de "Choreography Task Name" na figura.

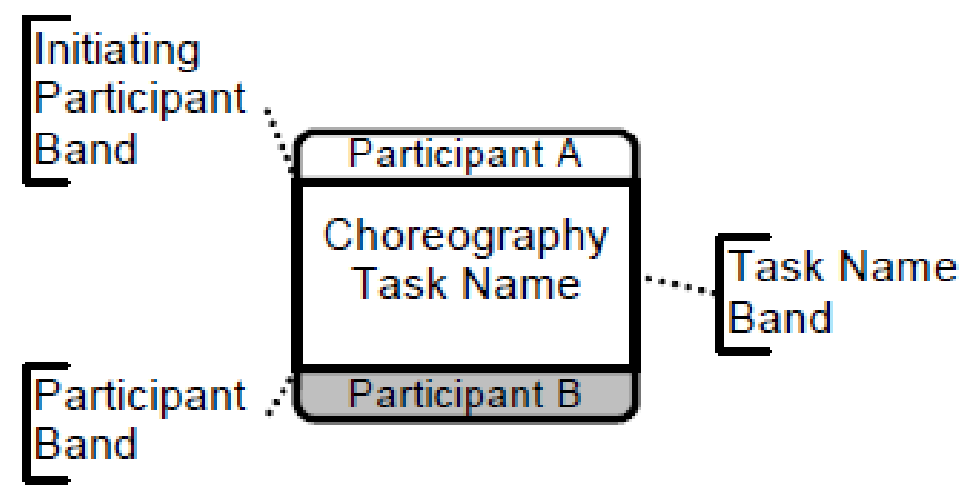

Figura 3.7: Representação de uma tarefa de coreografia [NF10]

As tarefas de coreografias são de um ou de dois sentidos. A tarefa de coreografia da Figura 3.7 é de um sentido e captura interações onde ocorrem apenas um envio de mensagem sem resposta, o que pode ser visualizado melhor no seu respectivo diagrama de colaboração (Figura 3.8). Uma tarefa de coreografia de dois sentidos captura interações atômicas em que existe resposta. A sua representação contêm as duas mensagens enviadas, como mostrado no diagrama de colaboração da Figura 3.9. A mensagem de cor branca é a iniciadora e a mensagem de cor escura é a resposta.

A Figura 7.1 apresenta o modelo de interação equivalente ao modelo de interconexão apresentado na Figura 3.6. Nesse caso, o fluxo de controle é representado entre os pools e as atividades de mensagens locais foram substituídas por atividades de interações atômicas.

\subsection{Considerações}

Neste capítulo foram apresentados aspectos chave em coreografia de serviços Web. Para efetuar o enactment de coreografias, precisam serem mapeadas para processos de negócio executáveis tais como BPEL. Assim, o enactment de coreografias depende do motor de processos executáveis, 

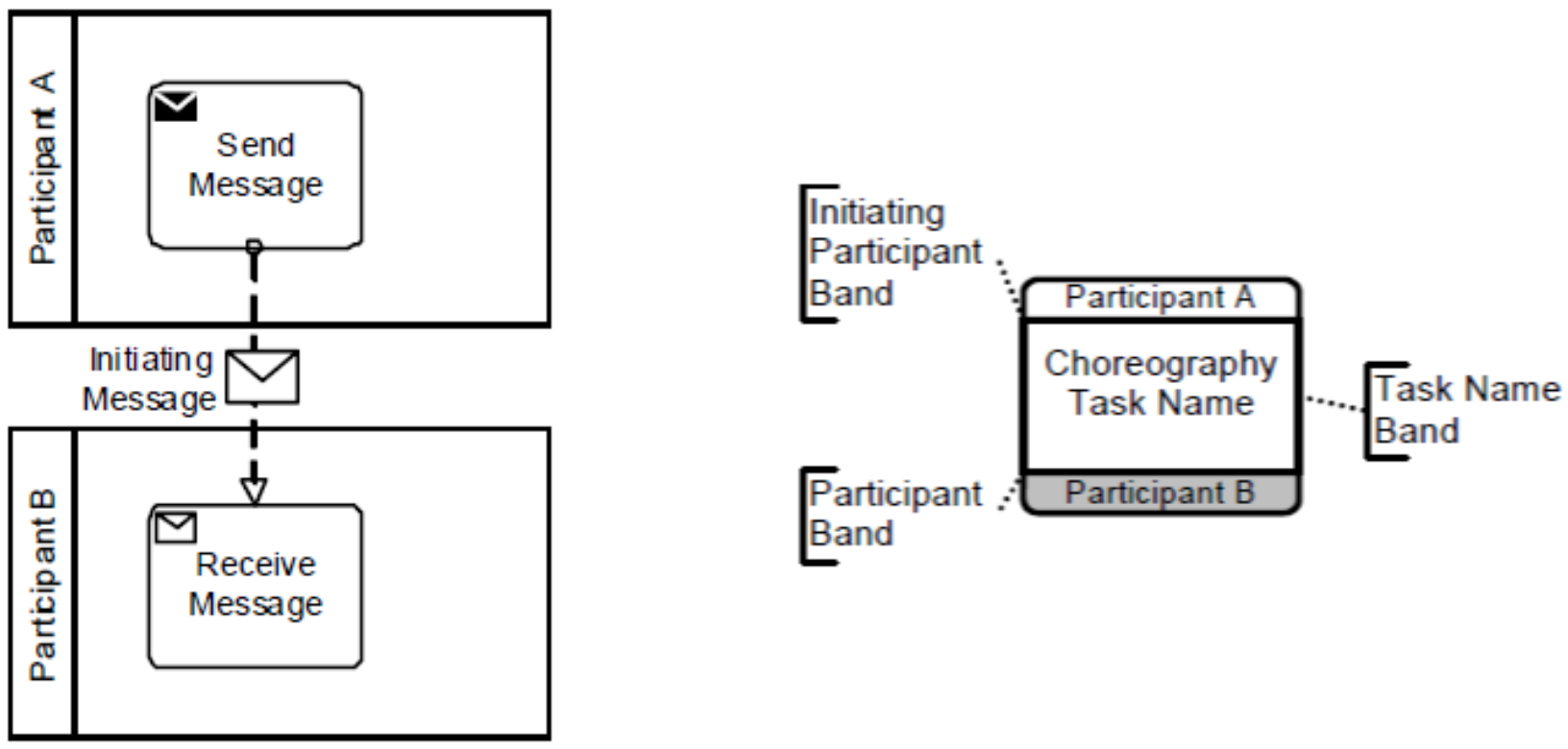

Figura 3.8: Uma tarefa de coreografia de um sentido e seu diagrama de colaboração [NF10]
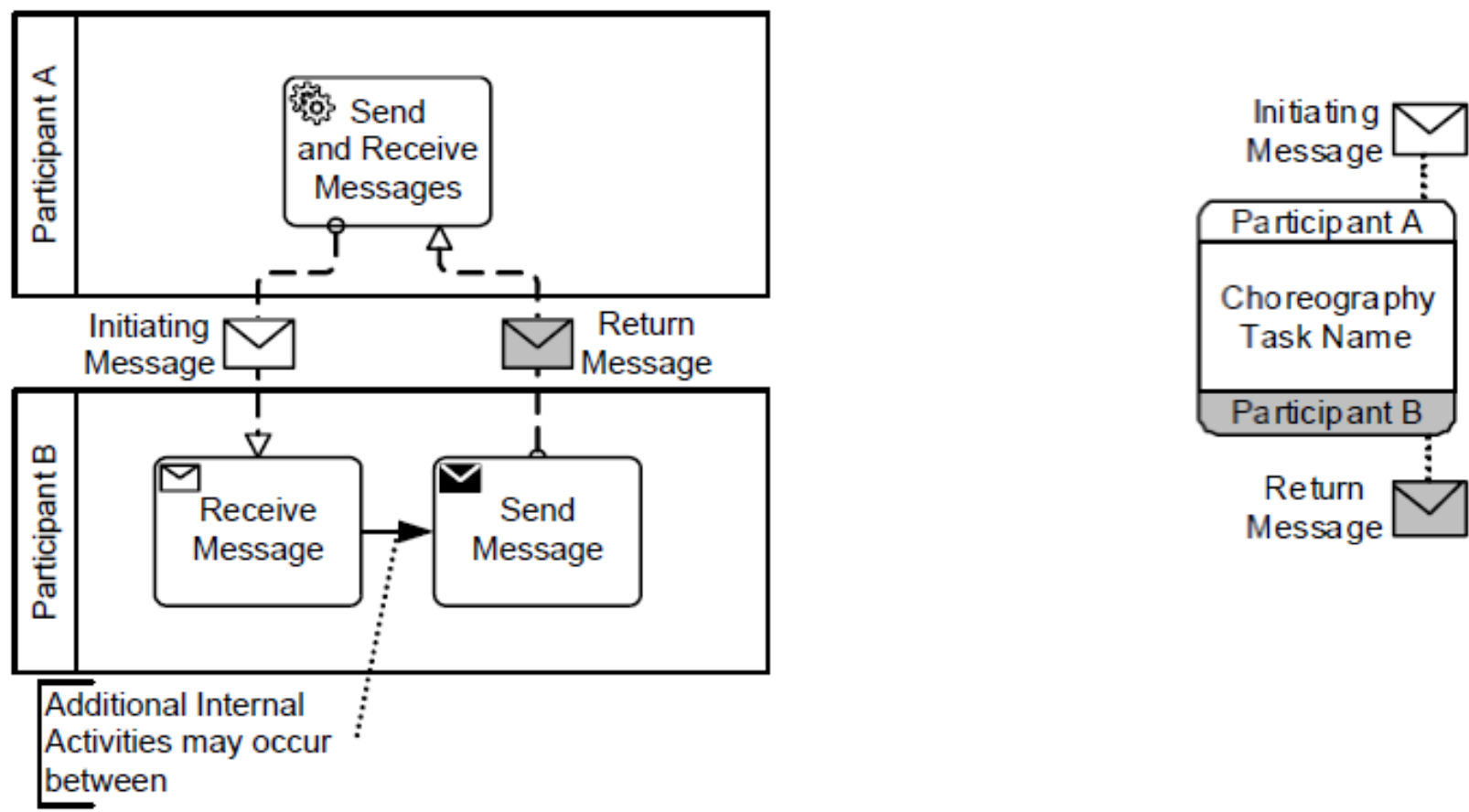

Figura 3.9: Uma tarefa de coreografia de dois sentidos e seu diagrama de colaboração [NF10]

mas, atualmente, esses motores não são cientes de coreografia. Em consequência, deveriam existir motores cientes dos aspectos envolvidos nas coreografias de serviços Web. Assim, as atuais implementações de ESB não oferecem características específicas das coreografias ([KLN08]), por exemplo, as implementações de ESB não verificam se as mensagens estão trafegando de acordo à descrição da coreografia, isto é, não há condições de realizar um monitoramento de forma trivial. A linguagem BPEL gold em [KELL10] visa superar as desvantagens mencionadas, e aborda o problema da necessidade de um ESB ciente de coreografias. WS-CDL + [KWH07] é outro trabalho que visa ser um motor de execução de coreografias.

Portanto, já que os atuais motores não são cientes de de coreografias, neste trabalho desenvolveuse um simulador para possibilitar o enactment de coreografias. O simulador possibilita a pesquisa em QoS e monitoramento em coreografias, os quais são alvo desta dissertação. 


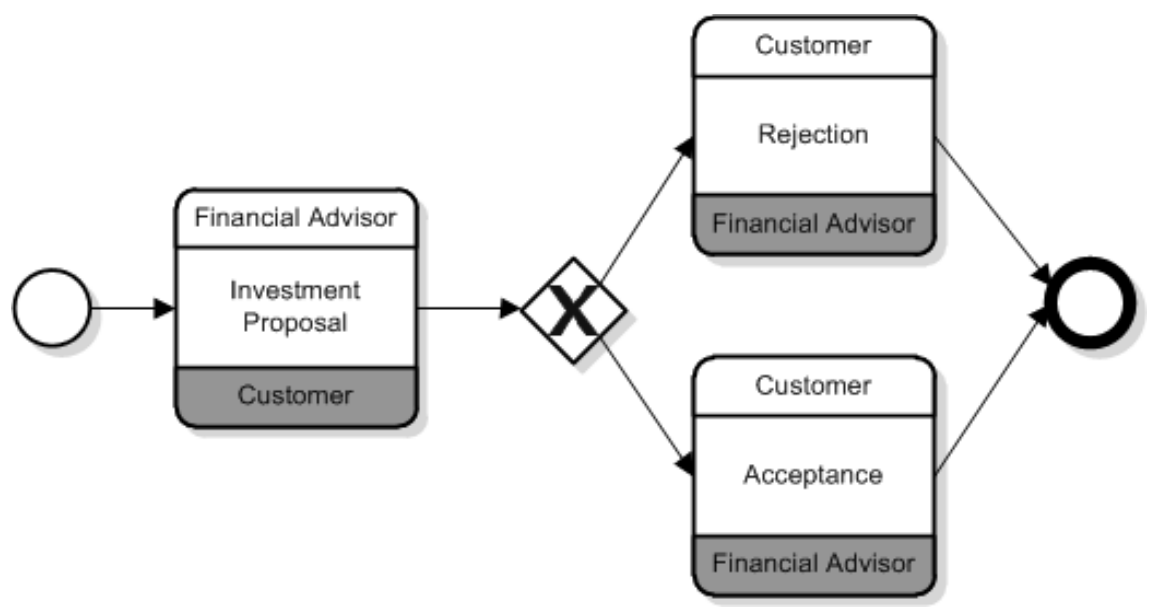

Figura 3.10: Exemplo de modelo de interação de coreografias: oferta de investimento [KLW10]. 


\section{Capítulo 4}

\section{QoS e Monitoramento em Coreografias de Serviços Web}

Um fator chave para possibilitar um comportamento adaptativo em sistemas orientados a serviços, e especificamente em composição de serviços, é a disponibilidade de métricas de Qualidade de Serviço (QoS) [Ros09]. O termo QoS surge no escopo das redes de computadores, onde é definido em [CRBS98] como um "conjunto de requisitos de serviços a serem cumpridos pela rede enquanto ela realiza o transporte de um fluxo". Na comunidade de SOC, a QoS abrange todos os atributos ou propriedades não funcionais de um serviço, por exemplo, atributos que tem relação com desempenho, confiabilidade, segurança e custos.

QoS tem um papel crucial em sistemas orientados a serviços, por exemplo, nas seguintes linhas [MRLD09]: seleção, descoberta, adaptabilidade, monitoramento e composição de serviços ciente de QoS (QoS-aware). Uma qualide do serviço permite a otimização de serviços compostos, em termos da QoS de toda a composição e da adaptação dinâmica de serviços quando acontecerem mudanças [Ros09].

Os atributos de QoS podem ser classificados como determinísticos e não determinísticos [HGDJ08]. Os atributos determinísticos indicam que o valor do atributo é conhecido antes que o serviço seja invocado (p. ex.: custo e segurança), enquanto que nos atributos não determinísticos os valores não são conhecidos antes da invocação do serviço (p. ex.: tempo de resposta e disponibilidade). Tratar com atributos não determinísticos é mais complexo, dado que requerem a realização de cálculos baseados na coleta de dados feita em um monitoramento em tempo de execução. Esses atributos não determinísticos são o foco nesta dissertação, dado que são fatores importantes para a realização da adaptação dinâmica em sistemas orientados a serviços [Ros09]. Para os atributos de QoS não determinísticos, abordagens de monitoramento são necessárias para avaliar continuamente os valores de atributos de QoS.

Um atributo de QoS pode ser também estático ou dinâmico [SSDS10]. O valor de um atributo de QoS estático é definido na especificação ou no projeto, enquanto que o valor de um atributo de QoS dinâmico requer medição e atualização periódica.

A Figura 4.1 exibe uma taxonomia de atributos de QoS que será utilizada como referência nesta dissertação. O foco do trabalho será em atributos de desempenho como o tempo de resposta, atraso e largura de banda. Para o cálculo e estimativa de valores dos atributos de desempenho serão utilizados os instantes de tempo mostrados na Figura 4.2, que representa a linha do tempo da invocação de um serviço. A lista a seguir descreve os principais atributos de desempenho de QoS relacionados com a Figura 4.2:

- Tempo de Processamento: Tempo necessário para executar uma operação de um serviço. Dado um serviço $s$ e uma operação $o$, o tempo de processamento é dado por:

$$
q_{p t}(s, o)=t_{p 2}-t_{p 1}
$$




\section{Classe de QoS}

Desempenho
— Tempo de Processamento
— Tempo de Execução
— Tempo de Resposta
— Atraso
— Tempo de embalagem
(wrapping time)
- Round Trip Time (RTT)
- Taxa de Transferência
Escalabilidade
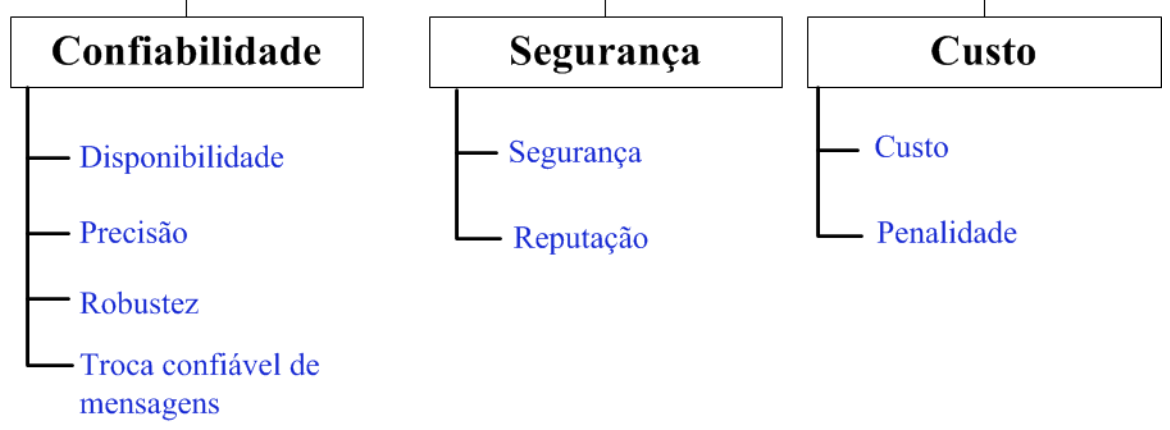

Figura 4.1: Classificação de atributos de QoS (traduzida de [ADHR05])

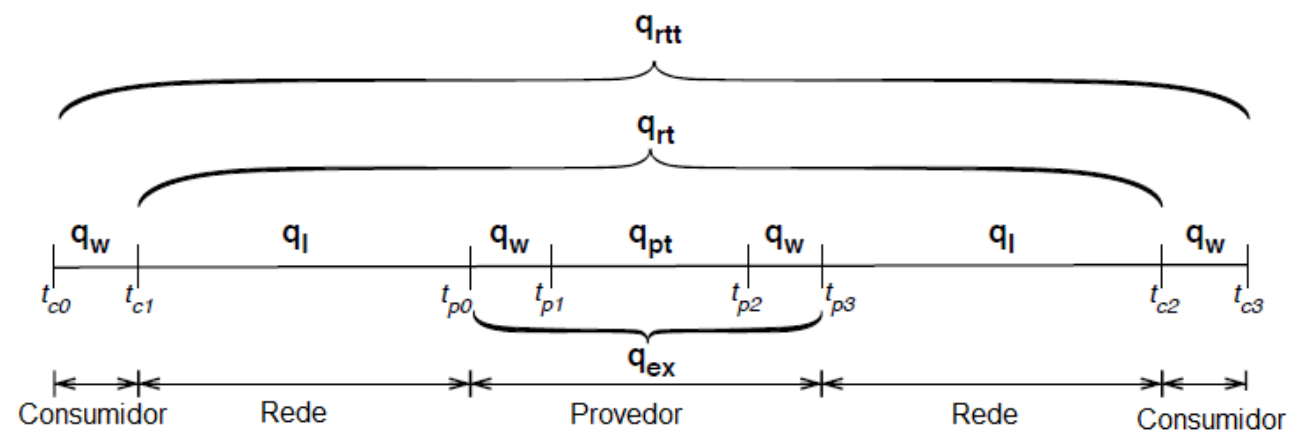

Figura 4.2: Tempos na invocação de serviços (traduzida de [MRLD09])

- Wrapping Time: É o tempo para encapsular ou desencapsular uma mensagem.

- No lado do Provedor:

$$
q_{w p}(s, o)=t_{p 1}-t_{p 0}+t_{p 3}-t_{p 2}
$$

- No lado do Cliente:

$$
q_{w p}(c, s, o)=t_{c 1}-t_{c 0}+t_{c 3}-t_{c 2}
$$

- Tempo de execução: Tempo que o provedor de serviço gasta para processar uma requisição.

$$
q_{e x}(s, o)=q_{p t}+q_{w p}
$$

- Atraso ou atraso de rede médio: Representa o tempo que uma requisição de um serviço demora desde o cliente até o provedor. É influenciado pelo tipo de conexão de rede, roteamento, utilização da rede, largura de banda e tamanho da requisição.

$$
q_{l}(c, s, o)=\frac{t_{p 0}-t_{c 1}+t_{c 2}-t_{p 3}}{2}
$$

- Tempo de Resposta: Tempo necessário para enviar uma mensagem de um cliente $c$ até um fornecedor do serviço $s$ e até que a mensagem de resposta retorne para o cliente.

$$
q_{r t}(c, s, o)=q_{e x}(s, o)+2 * q_{l}(c, s, o)
$$

- Taxa de Transferência: Número de requisições $r$ por operação $o$ que foram processadas por 
$s$ e retornadas ao cliente $c$ com sucesso dentro de um intervalo $\left[t_{0}, t_{1}\right]$.

$$
q_{t p}(c, s, o)=\frac{r}{t_{1}-t_{0}}
$$

Depende principalmente do poder do hardware e da largura de banda do fornecedor de serviço.

A lista a seguir descreve os principais atributos de confiabilidade de QoS:

- Precisão: É a taxa de sucesso do serviço $s . r_{f}$ é a quantidade de requisições que obtiveram resultados incorretos e $r_{t}$ é a quantidade de requisições totais ao serviço.

$$
q_{a c}(s)=1-\frac{r_{f}}{r_{t}}
$$

- Robustez: Probabilidade de um sistema reagir adequadamente a mensagens de entrada inválidas, incompletas ou conflitantes.

$$
q_{r o}(s)=\frac{1}{r_{t}} \sum_{i=1}^{n} f\left(\operatorname{resp}_{i}(s)\right)
$$

Onde $\operatorname{resp}_{i}(s)$ é uma função auxiliar, que é a $i$ - sima resposta produzida por um serviço $s$. $n$ é o numero total de requisições para $s . f(m)$ representa se a resposta de uma mensagem $m$ é válida (retorna 1$)$ ou inválida (retorna 0$)$.

Além da taxonomia apresentada na Figura 4.1, os atributos de qualidade e métricas também podem ser classificados de diferentes perspectivas.

A partir de uma perspectiva de domínio, os atributos de qualidade são classificados como atributos independentes de domínio ou específicos de domínio [Hil09]:

- Atributos independentes de domínio: São aqueles que podem ser aplicados a qualquer tipo de serviço Web. Por exemplo, o tempo de resposta, a disponibilidade e o custo.

- Atributos específicos de domínio: São aqueles que podem ser aplicados apenas a um determinado ou determinados domínios. Por exemplo, em um domínio de previsão de tempo, um atributo de qualidade poderia ser a precisão da previsão.

As métricas de qualidade podem ser classificadas de acordo com o método em que os dados podem ser obtidos. Nesse sentido, três categorias foram identificadas [Hil09]:

- Métricas anunciadas pelo Provedor: Os valores dessas métricas são obtidos pelo anúncio do provedor. Um exemplo seria o custo do serviço.

- Métricas classificadas pelo Consumidor: Os valores valores dessas métricas são definidos a partir das opiniões de usuários. Por exemplo, a reputação do serviço obtido a partir de uma média de opiniões dos clientes.

- Métricas Observáveis: Os valores dessas métricas são obtidos mediante monitoramento ou testes. Um exemplo é o tempo de resposta ou a disponibilidade.

Outro tipo de classificação é a partir do fato de que algumas métricas de qualidade podem ser obtidas via alguma função de agregação que receba outras métricas de qualidade. Por exemplo, o tempo de resposta médio é a média de um conjunto de tempos de resposta atuais em diferentes intervalos de tempo. Essas métricas de qualidade são nomeadas métricas derivadas ou calculadas, enquanto as outras são nomeadas métricas básicas ou atômicas. 


\subsection{QoS em Sistemas Orientados a Serviços}

Na computação orientada a serviços (SOC), o fornecimento de serviços com garantia de qualidade exige mecanismos que incluam modelos de qualidade de serviço (QoS) como característica chave. De fato, os modelos de QoS fornecem uma base adequada para o cumprimento de QoS em ambientes orientados a serviços [MGI09].

Em tais ambientes, a garantia de QoS pode ser afetada por diversos fatores incluindo o hardware, a infraestrutura de rede, o nível de qualidade oferecido pelos serviços de aplicação e por características do usuário final como mobilidade, por exemplo. Isso implica que, a fim de se obter uma avaliação exata da QoS, nenhum destes aspectos devem ser negligenciados na fase de modelagem de QoS. Parâmetros que devem ser considerados em um modelo de QoS para coreografias são similares àqueles considerados em sistemas P2P [MGI09]: (i) o ambiente do serviço e o hardware e infraestrutura de rede subjacente, (ii) os serviços disponíveis, e (iii) os usuários finais.

Diferentes métodos e ferramentas para capturar e analisar o desempenho de serviços Web tem sido desenvolvidos. Em geral as abordagens para a avaliação da capacidade dos serviços Web diferem pelo conjunto de métricas de QoS definidas em tempo de projeto ou em tempo de execução. Isto pode dificultar a escolha de uma abordagem para a avaliação de QoS de uma aplicação.

No contexto de uma coreografia de serviços Web, é proposto em [Ros09] um modelo de QoS multi-camada que permite integrar coerentemente informação de QoS em vários níveis de abstração: a camada de coreografia, a camada de orquestração e a camada de serviços. A Figura 4.3 ilustra o modelo com todas as camadas. A seguir é apresentada uma descrição resumida de cada camada.

\section{Camada de Serviços}

Os serviços em sistemas orientados a serviços, podem ser invocados por usuários que na maioria dos casos são desconhecidos em tempo de projeto e implantação. Por isso, é importante que um serviço forneça uma descrição dos aspectos não funcionais, além dos funcionais, por exemplo, em um documento WSDL. Essa camada representa todos os serviços atômicos dentro de um sistema orientado a serviços. Nesta camada são definidos os atributos de QoS tais como tempo de resposta, disponibilidade, largura de banda, etc.

Os atributos definidos nesta camada serão utilizados nas camadas superiores (orquestração ou coreografia) para, através de cálculos de agregação de QoS, obter o QoS global e desta maneira definir políticas de QoS na orquestração e SLA na coreografia.

A Figura 4.4 descreve os componentes de um serviço Web usando um diagrama de classes UML. Esses componentes incluem o nome do serviço Web e suas mensagens, operações, port, portType e bindings associados. Os atributos de qualidade de serviço associados com o serviço, operação do serviço e as mensagens são resumidos na Tabela 4.1.

Nesse modelo, os atributos de qualidade no componente serviço são a confiabilidade e a disponibilidade. A confiabilidade está baseada no número esperado de falhas ao longo de um intervalo de tempo e tempo entre falhas. $\mathrm{O}$ atributo de disponibilidade é uma agregação de disponibilidade esperada, tempo para a reparação e o tempo entre a falha. O tempo de reparo é o tempo necessário para reparar o serviço após uma falha. A disponibilidade esperada pode ser calculada como a razão entre o tempo de atividade e o tempo total que inclui o tempo de uptime e down time. O atributo de qualidade na operação inclui a sua demanda e latência. A demanda pode ser computada em termos da taxa de chegada da requisição respectiva para essa operação. A latência pode ser especificada em termos do tempo de serviço e o tempo de ida e volta. O atributo de qualidade para mensagem depende do protocolo utilizado e do tipo de chaves utilizadas para criptografar mensagens.

\section{Camada de Orquestração}

Nesta camada as especificações dos SLA's são mapeadas para políticas concretas de QoS para cumprir o SLA no correspondente processo de negócio do participante [Ros09]. WS-QoSPolicy 

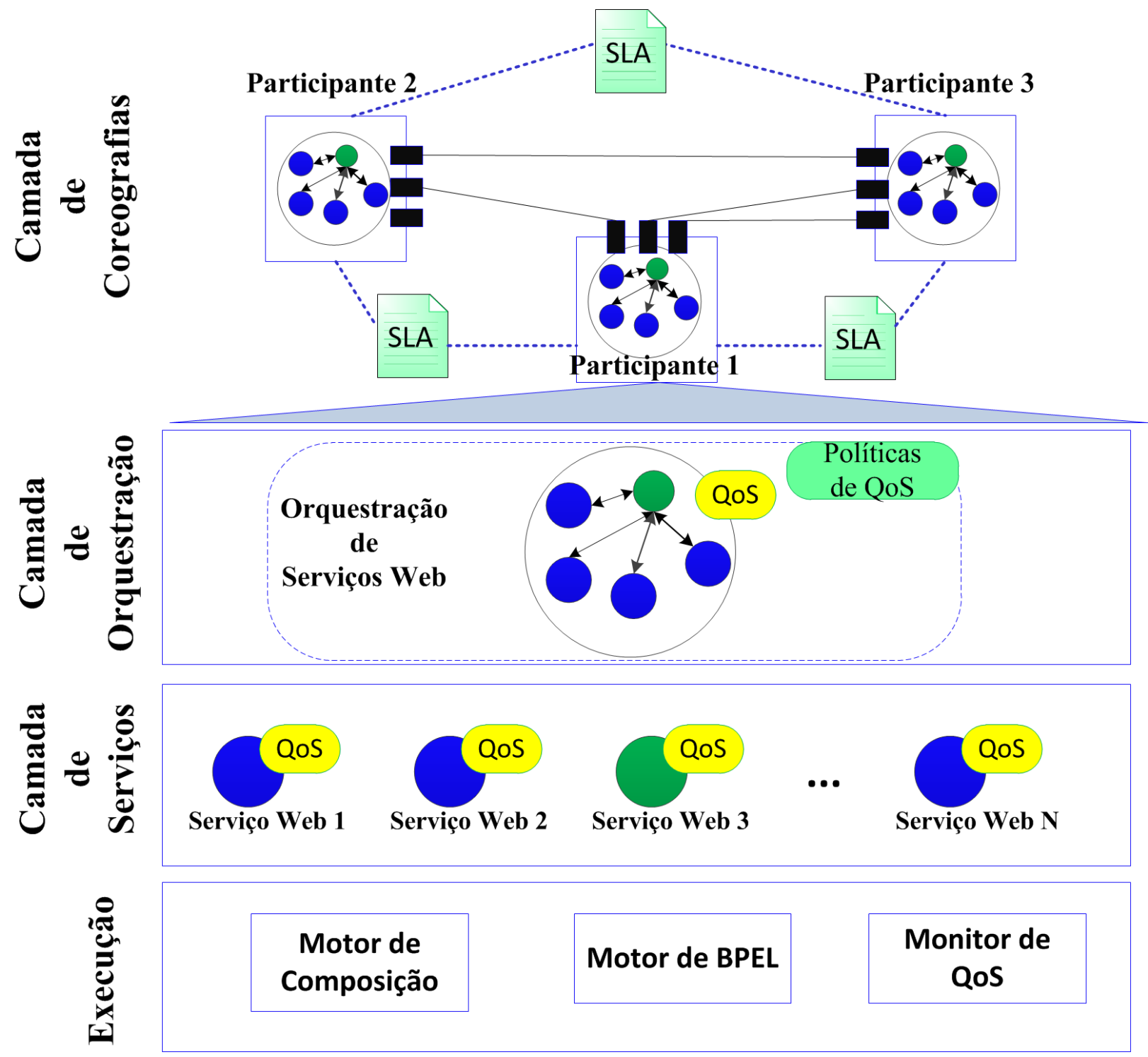

Figura 4.3: Modelo multi-camada de QoS para coreografias de serviços Web (baseada em [Ros09])

Tabela 4.1: QoS no modelo WSDL estendido

\begin{tabular}{|c|c|c|}
\multicolumn{2}{c}{ QoS em um serviço Web } \\
\hline Tipo & Parâmetro de QoS & Campo \\
\hline \multirow{3}{*}{ Serviço } & \multirow{2}{*}{ Disponibilidade } & TTR \\
& & TBF \\
& & ExpA \\
\cline { 2 - 3 } & \multirow{2}{*}{ Confiabilidade } & TBF \\
& Exp Failure \\
\hline \multirow{2}{*}{ Operação } & Latência & Tempo de serviço \\
& Demanda & TBF \\
\cline { 2 - 3 } & & Exp Failure \\
\hline \multirow{2}{*}{ Mensagem } & Protocolo & Enviar/Receber \\
\cline { 2 - 3 } & Tipo de Chave & Enviar/Receber \\
\hline
\end{tabular}

$\left[\mathrm{REM}^{+}\right.$07], que é uma extensão de WS-Policy ${ }^{1}$, pode ser usado para especificar as políticas de QoS.

\footnotetext{
${ }^{1}$ WS-Policy: recomendação pela W3C, http://www.w3.org/TR/ws-policy/
} 


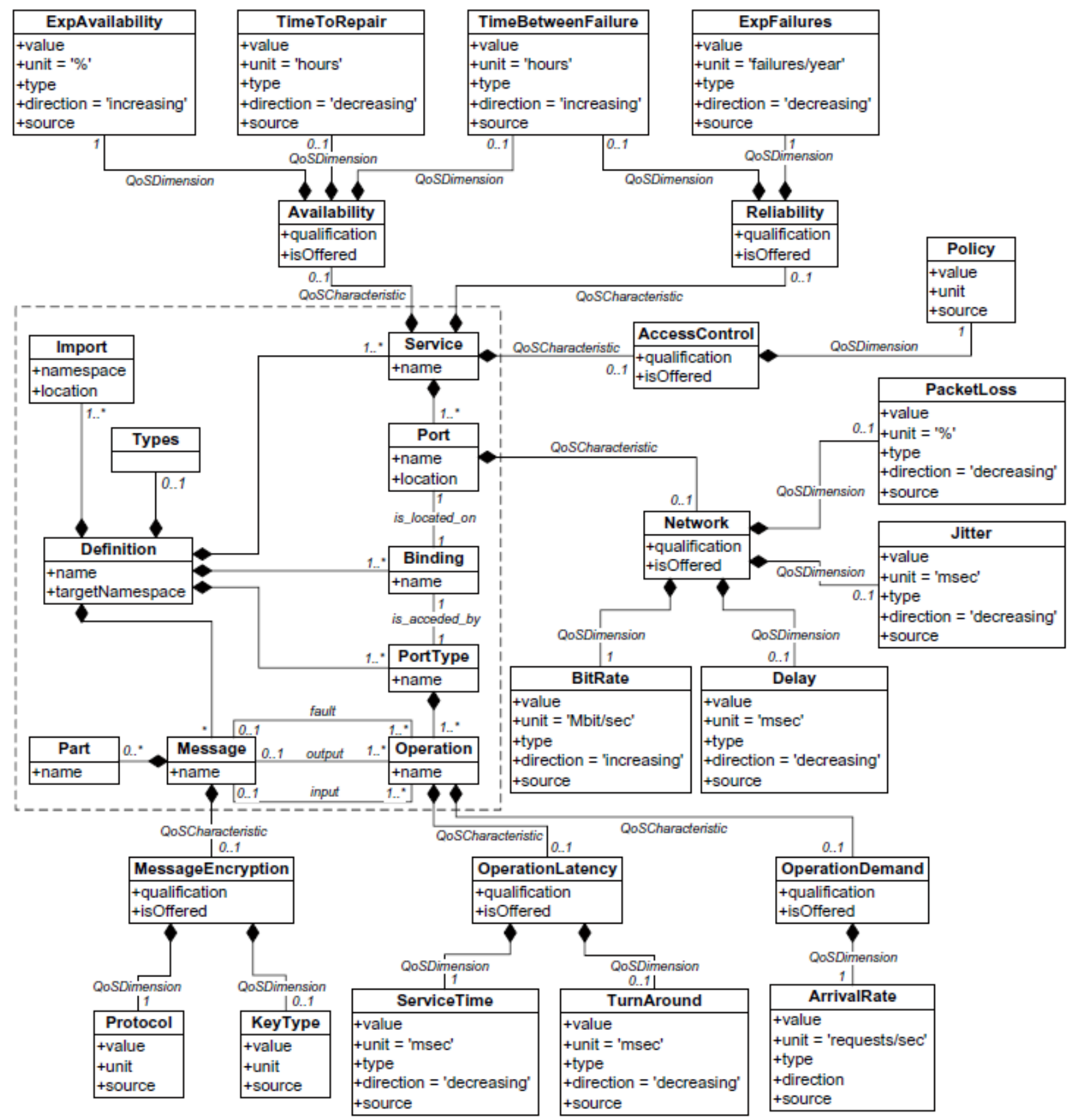

Figura 4.4: QoS do modelo de serviços Web de acordo com WSDL [Pan10]

WS-Policy é um arcabouço extensível definido na pilha de serviços Web, que é uma coleção de políticas em forma de asserções. Tais asserções de políticas definem requisitos, capacidades ou outras propriedades de um determinado objeto, por exemplo, mensagens, endpoints, operações, entre outros.

WS-QoSPolicy define um modelo de asserções para atributos de QoS na camada de serviços. Com essas asserções de políticas QoS, requisitos de QoS para serviços podem ser integrados em processos de negócio, cabendo ao motor de processos tratar essas asserções apropriadamente, por exemplo, disparando eventos para algum serviço ou entidade que tome as medidas necessárias quando um valor específico for violado.

Para avaliar e validar os valores no SLA, precisa-se de informação de QoS de cada serviço através de monitoramento, levando em consideração que os valores dos atributos de QoS medidos devem ser agregados para calcular a QoS da composição. A agregação de atributos de QoS é realizada por meio de um cálculo incremental baseado em padrões de fluxo de trabalho (workflows) bem 
definidos [Van03]. Para cada um desses padrões uma regra de agregação de QoS tem que ser aplicada para obter a QoS do padrão. Aplicando este processo recursivamente consegue-se a QoS global da composição.

\section{Camada de Coreografias}

É o topo do modelo de QoS multi-camada e tem como principal meta expressar as garantias e obrigações em termos de QoS entre as partes contratuais em um alto nível de abstração [Ros09]. O acordo contratual entre dois participantes é geralmente descrito como SLA (Acordo de Nível de Serviço) [JMS02]. O SLA é importante quando se integra serviços externos dentro de processos de negócio (coreografias, orquestrações ou workflows) [MRLD09]. Um SLA fornece um conjunto de operações, funções e predicados para definir restrições ou condições de QoS. Assim, um SLA define principalmente as seguintes três seções:

- Participantes: Identifica todas as partes contratuais, incluindo a identificação e todas as propriedades técnicas, tais como as descrições da interface ou o endpoint do serviço.

- Descrições de serviços: São definidas todas as características do serviço: as operações envolvidas e os parâmetros de SLA.

- Obrigações: Define as restrições para garantir valores nos parâmetros de SLA. São representadas e especificadas através de SLOs (Service Level Objectives) usando parâmetros de SLA. A listagem 4.1 mostra a definição de dois parâmetros de SLA: tempo de execução e a taxa de transferência. Para cada parâmetro se definem o nome, o tipo, a unidade de medida e a métrica de QoS.

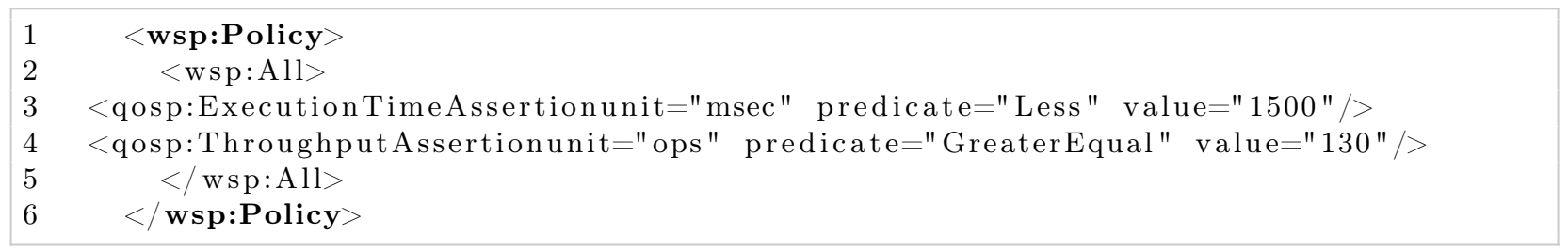

Listagem 4.1: Exemplo de parâmetro de SLA [KL03]

Toda vez que uma restrição é violada pelo provedor de serviços, eventos são disparados para notificar a violação. Após a notificação da violação podem ser tomadas ações como punições, adaptação ou mudança do provedor de serviços [MRLD09]. No lado do provedor, uma notificação de violação pode servir para tomar ações corretivas ou simplesmente selecionar um outro serviço com as mesmas funcionalidades e realizar uma substituição dinâmica. A Figura 4.5 apresenta um exemplo de um SLA e os elementos que a compõem.

A definição de SLA e QoS modifica os processos de negócios inter-organizacionais. Cada participante oferece serviços a outros participantes sobre a Internet, dos quais os últimos precisam executar seus negócios [REM $\left.{ }^{+} 07\right]$. Por isso, um certo grau de confiabilidade com relação ao tempo de resposta, vazão, uptime, entre outros, é desejado e tem de ser especificado e explicitamente expresso nas etapas iniciais da fase de modelagem. A Figura 4.6 ilustra uma coreografia com três participantes e seus respectivos relacionamentos. Para cada interação entre serviços um SLA é definido entre os participantes para definir o que os participantes precisam realizar para cumprir seus objetivos de negócio.

Dado que uma coreografia de serviços é um descrição de um ponto de vista global das interações dos seus participantes, ela não pode ser executada diretamente porque não envolve o aspecto interno de um participante. Assim, o SLA precisa ser cumprido também no aspecto interno, chamado de comportamento não-visível, de um participante. Em consequência, uma descrição SLA precisa ser mapeada em politicas concretas de QoS na camada de Orquestração. 


\section{SLA}

\begin{tabular}{|ll|}
\hline Partes & $\begin{array}{c}\text { Cliente X } \\
\text { Provedor Y }\end{array}$ \\
\hline \hline Operações & Comprar Passagem \\
Parâmetros & de SLA \\
& Tempo de Resposta \\
& Disponibilidade \\
Métricas de QoS \\
Tempo de Resposta, ms, número real
\end{tabular}

Figura 4.5: Exemplo de SLA [KLO3]

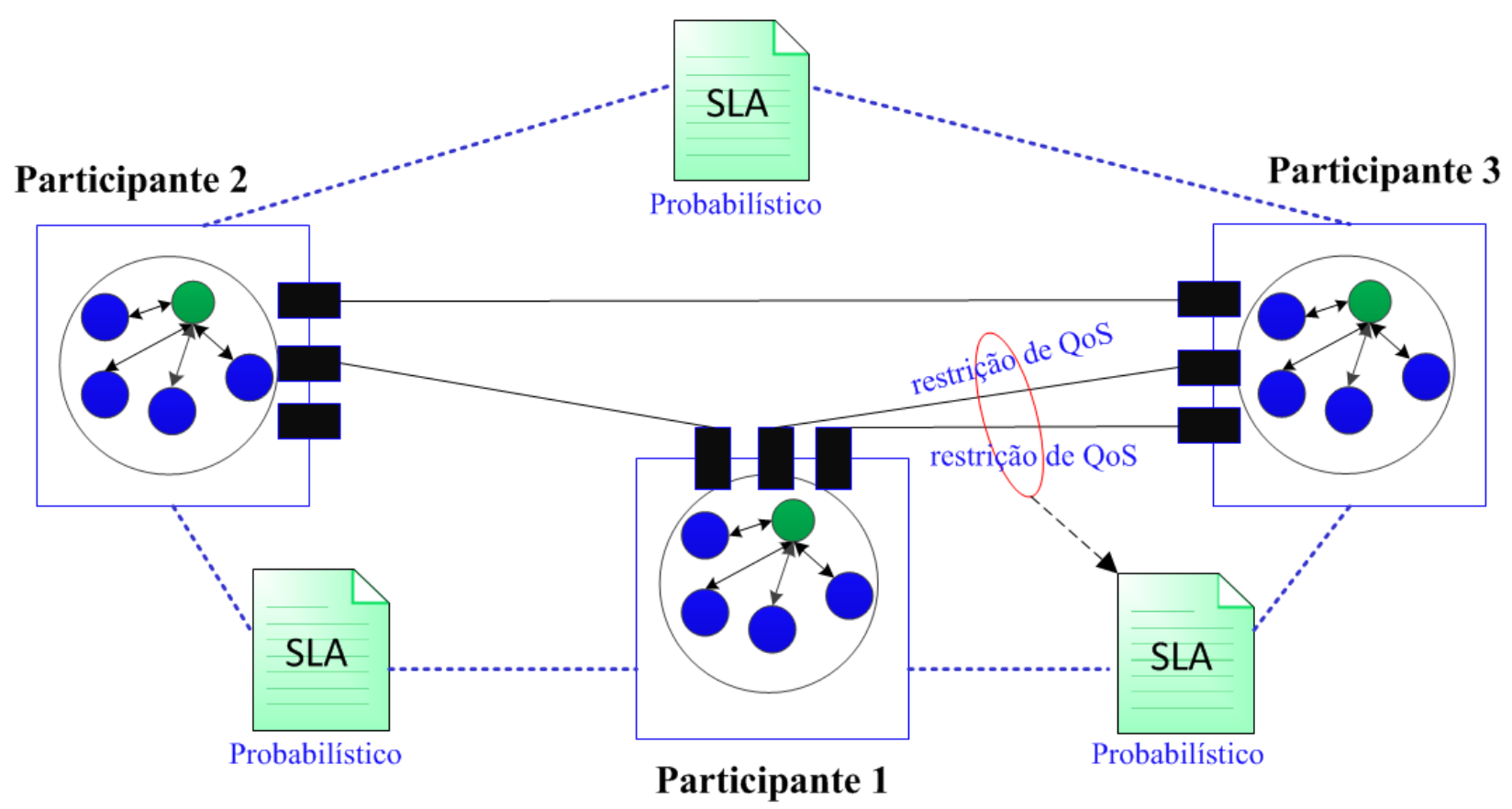

Figura 4.6: Definição de SLAs na camada de coreografias de serviços 


\subsection{SLAs Probabilísticos}

Tipicamente, as restrições de QoS são estabelecidas de maneira rígida, isto é, com limites absolutos [RBHJ08]. Por exemplo, o tempo de resposta de um serviço Web tem de ser menor que $10 \mathrm{~ms}$. Porém, o comportamento dinâmico de parâmetros de QoS, como o tempo de resposta, dificulta as suas representações por restrições rígidas. A Figura 4.7 mostra um histograma da distribuição de probabilidade dos tempos de resposta medidos para um serviço [RBHJ08], o que serve para ilustrar o comportamento dinâmico do tempo de resposta.

Assim, uma melhor maneira de representar o comportamento dinâmico dos parâmetro de QoS é através de restrições não rígidas, as quais não utilizam valores ou limites absolutos. Um exemplo de restrição não rígida é requisitar que o tempo de resposta seja menor do que $10 \mathrm{~ms}$, em $95 \%$ dos casos.

A restrição anterior ainda não é suficiente para refletir a dinâmica dos parâmetros de QoS. A solução é utilizar restrições não rígidas de QoS baseadas em distribuições de probabilidade, isto é, contratos probabilísticos [ZYZ10]. Uma restrição probabilística é da forma: "Para o parâmetro tempo de resposta, eu, provedor de serviço forneço a distribuição de probabilidade, e garanto que ela será respeitada".

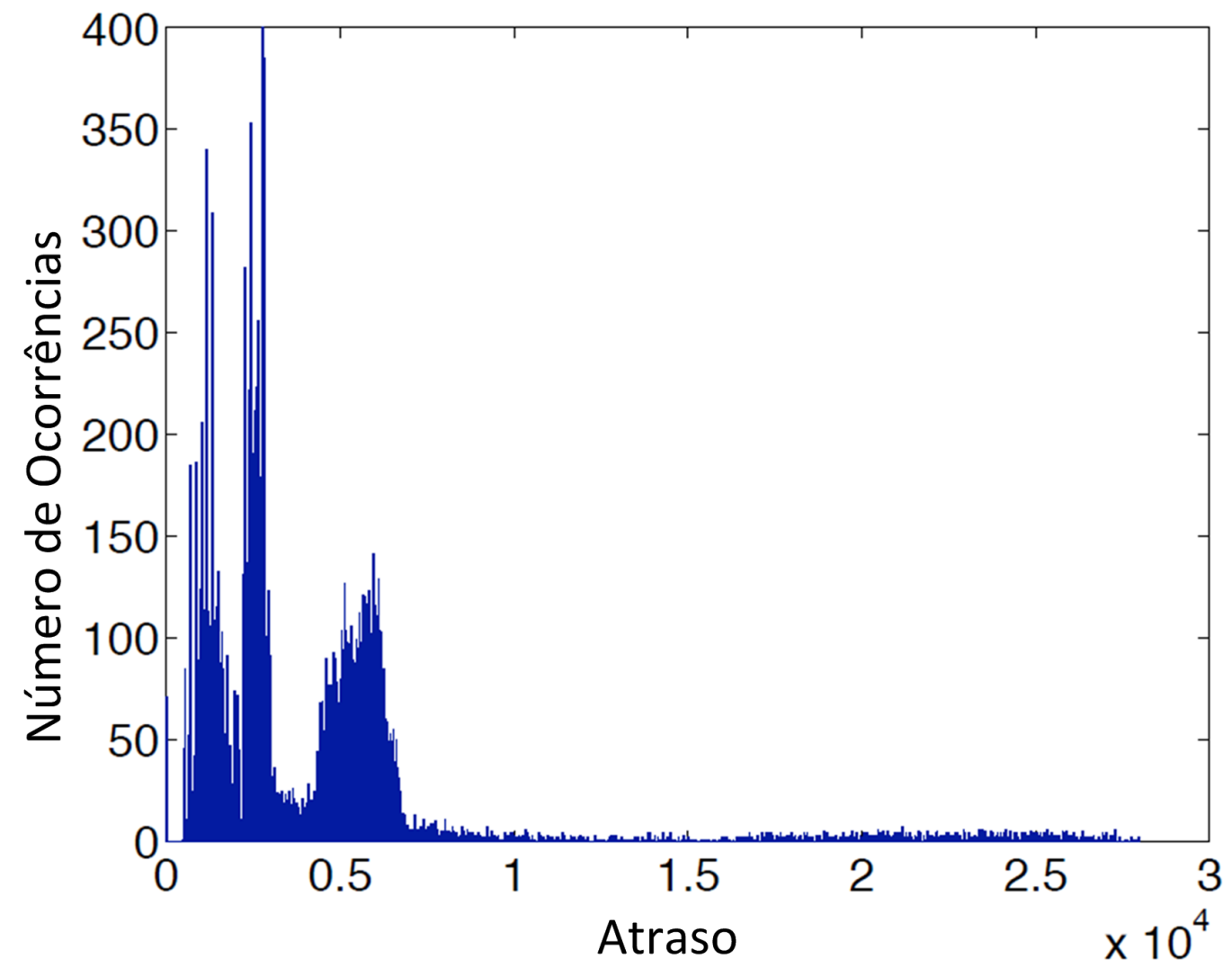

Figura 4.7: Registro de medidas do tempo de resposta para um serviço Web (traduzida de [RBHJ08])

Na prática essas restrições probabilísticas são definidas como um conjunto de quantis dos parâmetros de QoS. Esses quantis definem uma distribuição empírica de probabilidade de parâmetros de QoS. Por exemplo, a Tabela 4.2 mostra que quantis de 90\%, 95\% e 98\% correspondem a tempos de resposta de $6494 \mathrm{~ms}, 13794 \mathrm{~ms}$ e $23506 \mathrm{~ms}$ respectivamente. Assim, o quantil $95 \%$ expressa que em $95 \%$ dos casos o tempo de resposta é no máximo $13794 \mathrm{~ms}$.

Uma vez calculadas as distribuições de probabilidade dos parâmetros de QoS, estes precisam ser agregados segundo a composição. Atualmente existem poucas pesquisas acerca de restrições probabilísticas de QoS em serviços Web [HWTS07], [RBHJ08], [RBJ09] e [ZYZ10]. Não há, entretanto, abordagens específicas para coreografias de serviços Web. 
Tabela 4.2: Quantis de tempos de resposta (obtida de [RBHJ08])

\begin{tabular}{|c|c|}
\hline Quantis & Tempo de Resposta \\
\hline $90 \%$ & $6494 \mathrm{~ms}$ \\
$95 \%$ & $13794 \mathrm{~ms}$ \\
$98 \%$ & $23506 \mathrm{~ms}$ \\
\hline
\end{tabular}

\subsection{Trabalhos Relacionados: QoS em Coreografias de Serviços Web}

Existem várias abordagens para integrar modelos de QoS em composição de serviços, mas poucos focados em coreografias de serviços. WS-CDL não tem suporte a QoS integrado [ABPRT04]. Em [XCHZ07], propõe-se um modelo formal que incorpora informação de QoS, estendendo a linguagem Chor [YZQ ${ }^{+}$06], que é um WS-CDL simplificado, para adicionar informação de QoS, sobretudo tempo e custo, em um nível sintático e semântico para obter a QoS global da coreografia.

Em [PC08], propõe-se um modelo formal para estimar o mínimo, máximo e a média do custo de uma coreografia. Tal modelo proposto adiciona características semânticas para incorporar o atributo custo no seu modelo, que é uma extensão do WS-CDL. Este modelo associa o custo com instâncias de um papel. Em [XCZH09], propõe-se uma abordagem para predizer a QoS de uma coreografia de serviços especificada em WSCI. Uma Rede de Petri Estocástica Generalizada $\left(G S P N^{2}\right)$ é utilizada como modelo intermediário. A partir do modelo GSPN obtido do mapeamento do modelo WSCI, avaliações analíticas da árvore de métricas QoS são realizadas. Em [Pan10], é proposto um modelo multidimensional de QoS para coreografias. Tal QoS de coreografia é definido em termos do papel dominante, relacionamento dominante e interação dominante. Essas características são avaliadas baseadas na QoS dos papéis, operações e mensagens. Sua proposta é desenvolvida como uma extensão do metamodelo de WS-CDL para suportar QoS.

Somente em [Ros09], propõe-se um modelo multicamada para integrar QoS e SLA no nível de coreografia, orquestração e serviços. No nível de coreografias integra WSLA na linguagem WS-CDL para especificar o acordo do nível de serviço (SLA) entre os participantes. E para realizar seu cumprimento internamente em cada participante realiza o mapeamento a políticas QoS na camada de orquestração, que por sua vez utiliza os atributos QoS no nível de serviços. Até o presente momento, nenhum trabalho propõe um modelo de QoS para integrá-lo em BPMN, que é o padrão para modelar processos de negócios colaborativos, incluindo coreografias.

\subsection{Monitoramento em Coreografias de Serviços Web}

A eficiência e automatização do monitoramento de atributos de QoS em serviços Web é fundamental para linhas de pesquisa como a seleção, composição e otimização de serviços Web com consciência de QoS no escopo da SOC [MRLD09], [JTK00]. Atualmente os serviços Web não fornecem informação de QoS como parte da sua interface de contrato ou funcionalidade, por exemplo, um documento WSDL.

Alguns valores de atributos de QoS podem ser obtidos tanto em um monitoramento no lado do cliente quanto no lado do provedor, sendo que a depender do atributo, a sua medição pode ser mais precisa em um ponto específico da comunicação [MRLD09]. Por exemplo, no lado do provedor a medição do tempo de execução é mais precisa do que no lado cliente, já que no provedor é conhecida a implementação do serviço. Nesse caso a abordagem é dita intrusiva pelo fato de ser necessário realizá-la no provedor ou conhecer a implementação no lado do provedor.

Uma abordagem de monitoramento do lado do cliente é dita não intrusiva, dado que não há necessidade de se conhecer o comportamento interno do serviço fornecedor [HGDJ08]. Atualmente existem muitas abordagens para a medição de atributos de QoS. A lista a seguir apresenta uma classificação de algumas das abordagens existentes.

\footnotetext{
${ }^{2}$ GSPN: Generalized Stochastic Petri Net
} 
- Instrumentação do Lado do Provedor: Neste caso o monitoramento é realizado do lado do provedor de serviços. Existem dois tipos de instrumentação, a intrusiva e a não intrusiva. A primeira é realizada através de modificações no código-fonte do serviço. A segunda não necessita de acesso ao código-fonte do serviço. Para tanto, mecanismos como aqueles disponibilizados pelo sistema operacional do computador onde o serviço reside são utilizados. Esta abordagem não suporta a medição de atributos como o atraso de comunicação e em consequência os que dependem dele. Além disso o consumidor do serviço tem que confiar nas medidas do provedor.

- Intermediários de SOAP: Esses intermediários interceptam, processam e direcionam mensagens SOAP. Nesse ambiente, o monitor fica localizado entre o consumidor e o provedor de serviços para interceptar as mensagens e medir os atributos de QoS. Na prática o monitoramento pode ser realizado no lado cliente, no lado provedor ou por um parte externa e confiável para ambos os lados. Dado que atua como um proxy tratando todas as requisições para realizar medições de QoS, essa entidade pode se tornar um gargalo no sistema. Além disso, podem ser necessárias informações adicionais nas mensagens SOAP para calcular atributos de QoS [RR09].

- Probing: Consiste em enviar requisições de teste ao fornecedor do serviço em tempos regulares. Não há necessidade de interceptação de mensagens, e o monitor pode estar no cliente, no provedor ou entre os dois. $\mathrm{O}$ fator chave é o intervalo de tempo entre cada requisição de teste ao fornecedor, já que isso afeta a precisão da medição. Esta abordagem é utilizada principalmente para medir a disponibilidade de um serviço e o tempo que ele está ativo.

- Sniffing: Utiliza técnicas de análise dos pacotes de rede, por exemplo, na invocação de um serviço, permitindo desta maneira, a medição de atributos como o atraso e o tempo de resposta.

\subsection{Trabalhos Relacionados: Monitoramento em Coreografias de Serviços Web}

Esta dissertação propõe uma técnica para realizar monitoramento de coreografias de serviços Web utilizando SLAs probabilísticos, cujas restrições são especificadas por meio de quantis das distribuições de probabilidades dos parâmetros de QoS dos serviços Web. Além disso, o monitoramento que se pretende desenvolver é não intrusivo. Assim, são resumidos a seguir alguns trabalhos relacionados e organizados em duas subseções: Monitoramento baseado em QoS de coreografias de serviços Web e Monitoramento de serviços usando SLAs probabilísticos.

\subsubsection{Monitoramento de Coreografias de Serviços Web Baseado em QoS}

Existem várias abordagens para integrar modelos de QoS em composição de serviços, mas poucos focados em coreografias de serviços. Atualmente, as linguagens de coreografia não possuem um modelo de QoS na sua especificação. [XCHZ07], [PC08] e [Pan10] propõem modelos formais de coreografia de serviços Web para incorporar informação de QoS. Estas abordagens estão focadas no escopo da especificação de coreografias e levam em consideração apenas o tempo de resposta. Diferente das propostas em [XCHZ07], [PC08] e [Pan10], o trabalho apresentado nesta dissertação pretende realizar monitoramento de coreografias além do escopo de especificação e serão levados em consideração outros atributos de QoS como o atraso e a largura de banda, além do tempo de resposta.

Em $\left[\mathrm{WKK}^{+} 10\right]$, apresenta-se uma abordagem baseada em eventos para monitoramento de processos inter-organizacionais que compõem coreografias de serviços Web. Esse trabalho está focado em realizar acordos entre os monitores dos participantes da coreografia e realizar trocas de dados de monitoramento para realizar um monitoramento global. A abordagem proposta habilita o rastreamento e avaliação de métricas de processos, que neste contexto são chamados de KPI (Indicadores 
Chave de Desempenho). Em síntese, desenvolve-se uma infraestrutura de monitoramento de coreografias baseada em eventos e o foco não são os atributos de QoS, apesar de que trata KPIs que são de mais alto nível do que QoS. Em [ML08], é proposta uma abordagem similar. Os autores propõem uma abordagem de monitoramento de processos de negócio entre múltiplas organizações. Diferentemente dessas abordagens, esta dissertação foca na detecção de violações de restrições de QoS por meio de SLAs, e o monitoramento das coreografias não abrange restrições de mais alto nível como o uso de KPIs, os quais estão mais associados no contexto de processos de negócio.

Em [UPSB10] é proposta uma abordagem baseada em agregação de SLAs para garantir o cumprimento dos requisitos de QoS em coreografias de serviços Web. A proposta está focada na arquitetura de um arcabouço de validação baseado em regras. O trabalho em [UPSB10] não possui foco em QoS, já que o foco é fornecer uma infraestrutura baseada em regras de validação para especificar SLAs hierárquicos para interações de grande complexidade em uma coreografia. Porém, apesar de não propor uma abordagem de monitoramento de QoS como na presente pesquisa, o avanço na definição de SLAs para interações complexas em uma coreografia é útil para os objetivos da dissertação.

Em [XCZH09], propõe-se uma abordagem para predizer a QoS de uma coreografia de serviços especificada em WSCI. É utilizada uma Rede de Petri Estocástica Generalizada $\left(G S P N^{3}\right)$ como modelo intermediário. A partir do modelo GSPN obtido do mapeamento do modelo WSCI, avaliações analíticas da árvore de métricas QoS são realizadas. São definidas regras de transformação para mapear atividades, padrões de encaminhamento (sequence, all, choice, switch, while) e outras construções para fragmentos ou partes do GSPN. A partir da matriz de transições probabilísticas derivada do GSPN, métodos analíticos são utilizados para avaliar a árvore de métricas de QoS, as quais estão relacionadas com o tempo de resposta. Os autores utilizam o método de Monte-Carlo para validar os resultados teóricos. Um problema da proposta apresentada em [XCZH09] é a utilização da linguagem WSCI, que foi oficialmente descontinuada. Além disso o foco está no escopo da especificação da coreografia e apenas a métrica de tempo de resposta é utilizada. Na pesquisa proposta nesta dissertação, utiliza-se o GSPN com suporte de QoS para avaliar o desempenho de coreografias de modo a definir requisitos de QoS. Além disso, leva-se em conta outros atributos de QoS além do tempo de resposta.

Em [Ros09], propõe-se um modelo multicamada para integrar QoS e SLA no nível de coreografia, de orquestração e de serviços. No nível de coreografias integra-se WSLA na linguagem WS-CDL para especificar SLAs entre os participantes. Para realizar seu cumprimento internamente em cada participante realiza-se o mapeamento de SLA para políticas de QoS na camada de orquestração, que por sua vez utiliza os atributos de QoS no nível de serviços. Este trabalho oferece uma abordagem de monitoramento de coreografias integrada nas três camadas, no entanto, as restrições de QoS definidas no SLA são rígidas. Na pesquisa apresentada nesta dissertação, as restrições de QoS são definidas de maneira probabilística, e por conta disso o monitoramento também.

Linguagens de coreografia de serviços, tais como BPMN, Let's Dance e BPEL4Chor não aparecem em trabalhos relacionados com QoS na literatura. As buscas realizadas durante a escrita desta dissertação não retornaram nenhuma proposta de integrar um modelo de QoS no BPMN, que é um padrão para modelar processos de negócios colaborativos, incluindo coreografias. Existem várias propostas de modelos de QoS em serviços Web e orquestrações, mas poucas em coreografias, e ainda menos nas três camadas e de maneira integrada. Além disso, as poucas abordagens de monitoramento definem restrições de QoS de maneira rígida, o que não reflete a dinamicidade dos atributos de QoS dos serviços Web, e focam principalmente no monitoramento do tempo de resposta.

\footnotetext{
${ }^{3}$ GSPN: Generalized Stochastic Petri Net
} 


\subsubsection{Monitoramento de Serviços Web usando SLAs Probabilísticos}

Em [RBJ09], é proposta uma técnica estatística para especificar contratos de QoS de maneira probabilística por meio de SLAs não rígidos. Os autores em [RBJ09] também propõem uma forma de realizar um monitoramento contínuo de orquestrações de serviços Web. Sua proposta pretende diminuir os alarmes falsos, e aumentar o número de detecções corretas. Tanto na especificação de SLAs probabilísticos quanto no monitoramento, são utilizados quantis das distribuições de probabilidade, e por conta disso, é utilizado o método de Monte-Carlo para obter parâmetros e valores para a configuração do monitoramento antes da sua execução. Assim como nas outras abordagens, o trabalho em [RBJ09] está focado no tempo de resposta, e dado que trata até orquestrações, atributos de rede como a latência e largura de banda não são tão importantes [TAM00]. Esta dissertação, com relação a contratos probabilísticos, baseia-se no trabalho apresentado em [RBJ09], porque ele é dos poucos trabalhos que leva em consideração SLAs probabilísticos no monitoramento de serviços Web. Porém, na pesquisa desta dissertação, a definição de SLAs e o monitoramento probabilístico serão realizados para coreografias de serviços Web. Outra diferença é que serão levados em conta outros atributos de QoS além do tempo de resposta. Esta pesquisa e o trabalho apresentado em [RBJ09] também são similares pela utilização de métodos de testes estatísticos para detectar a violação de SLAs.

Em [ZYZ10], é proposta uma abordagem para modelar a função densidade de probabilidade $\left(\mathrm{PDF}^{4}\right)$ da $\mathrm{QoS}$ de um serviço Web, baseada em um método estatístico não paramétrico. Os autores em [ZYZ10] fundamentam que a PDF é a melhor maneira de refletir as características dinâmicas dos atributos de QoS em serviços Web, e mostram por meio de simulações que sua abordagem é mais precisa do que outras, tais como distribuições Normais e distribuições T Location-Scale. Além disso, são fornecidas fórmulas para estimar a distribuição de QoS de uma composição de serviços a partir das PDFs dos serviços componentes. Diferentemente desta dissertação, o trabalho em [ZYZ10] não cita a maneira de especificar restrições de QoS em SLAs, e nem como realizar monitoramento.

\subsection{Considerações}

Neste capítulo foi apresentado o Estado da Arte em QoS e Monitoramento para Coreografias de Serviços Web. Há poucos trabalhos sobre modelos de QoS em coreografias, e menos ainda trabalhos acerca de como as coreografias agem de maneira integrada com orquestrações e serviços Web. Também existem poucos trabalhos relacionados com monitoramento de coreografias de serviços Web baseado em atributos de QoS. Também são poucas as abordagens que propõem um monitoramento baseado em contratos SLA de atributos de QoS de maneira probabilística.

A maioria dos trabalhos relacionados focam no atributo de tempo de resposta. Entretanto, no contexto de coreografias de serviços, são também importantes os atributos de rede tais como o atraso e a largura de banda, já que uma coreografia envolve vários participantes que podem possuir arquiteturas e infraestruturas de rede heterogêneas e pertencentes a domínios diferentes, tornando a rede um item fundamental para que a comunicação entre os serviços seja possível.

Nesta dissertação foi desenvolvido um monitor de coreografias que age de maneira não intrusiva levando em consideração o modelo de multicamadas que inclui QoS e SLA. Porém, já que não existem infraestruturas maduras o suficiente para a implementação de coreografias de serviços Web, desenvolveu-se um simulador de coreografias com suporte a QoS. O próximo capítulo descreve a construção do simulador e a metodologia utilizada para cumprir com os objetivos desta pesquisa.

${ }^{4}$ PDF: Probability Density Function 


\section{Capítulo 5}

\section{Visão geral}

Os capítulos anteriores apresentaram e descreveram os conceitos básicos acerca de serviços Web, computação orientada a serviços, composição de serviços, tópicos acerca de coreografias, qualidade de serviço, SLA e monitoramento em coreografias de serviços Web. A presente dissertação tem como objetivo o monitoramento e a detecção de violações de SLAs baseadas em restrições probabilísticas de QoS em coreografias de serviços Web. Assim, as seções a seguir apresentam com mais detalhe a proposta. Primeiro uma visão geral na definição de restrições de QoS e o monitoramento de coreografias. Depois, descreve-se a construção do simulador de coreografias que é necessária para a avaliação de desempenho dos mecanismos propostos.

\subsection{Visão Geral}

A Figura 5.1 ilustra a arquitetura para a definição de SLAs e monitoramento de coreografias de serviços. Apresenta-se uma coreografia de três participantes (A, B e C) que interagem entre si. Cada um dos participantes possui uma implementação local por meio de orquestrações de serviços, que por sua vez realizam a coreografia. Um SLA é definido por cada dupla de participantes que interagem. Por exemplo, na interação dos participantes A e B foi definido um SLA (SLA 1) composto pelas restrições de QoS (rótulo 1 da Figura 5.1) do tempo de resposta no fornecimento das operações que acontecem nessas interações. Tais restrições são definidas de maneira probabilística utilizando uma distribuição de probabilidade. Desta maneira, podem-se definir SLAs probabilísticos para cada dupla de participantes que interagem (SLA 2 e SLA 3) de acordo com a especificação da coreografia. Cabe ressaltar que as restrições de QoS definidas no SLA de um serviço podem ser o resultado da agregação de QoS de outros serviços oferecidos por outros participantes de acordo com as suas dependências.

O monitoramento da coreografia (rótulo 2 da Figura 5.1) e a deteç̧ão de violações de SLAs são realizados uma vez que os SLAs probabilísticos tenham sido definidos. Em tempo de execução, o monitor deve realizar as medições dos atributos de QoS dos serviços Web, estimar suas distribuições de probabilidade, realizar a agregação de QoS mediante as distribuições de probabilidade e comparar a distribuição agregada com a distribuição de probabilidade especificada no SLA. Dessa maneira, o monitor realiza as verificações necessárias para detectar violações de SLA.

\subsection{Características}

O modelo de interação para especificar coreografias foi adotado nesta pesquisa. Escolheu-se essa abordagem já que esse modelo representa melhor as interações entre participantes e porque possui menos complexidade do que o modelo de interconexão. Assim, o padrão BPMN2 é levado em consideração por suportar o modelo de interação. A Figura 5.2 mostra os elementos BPMN 


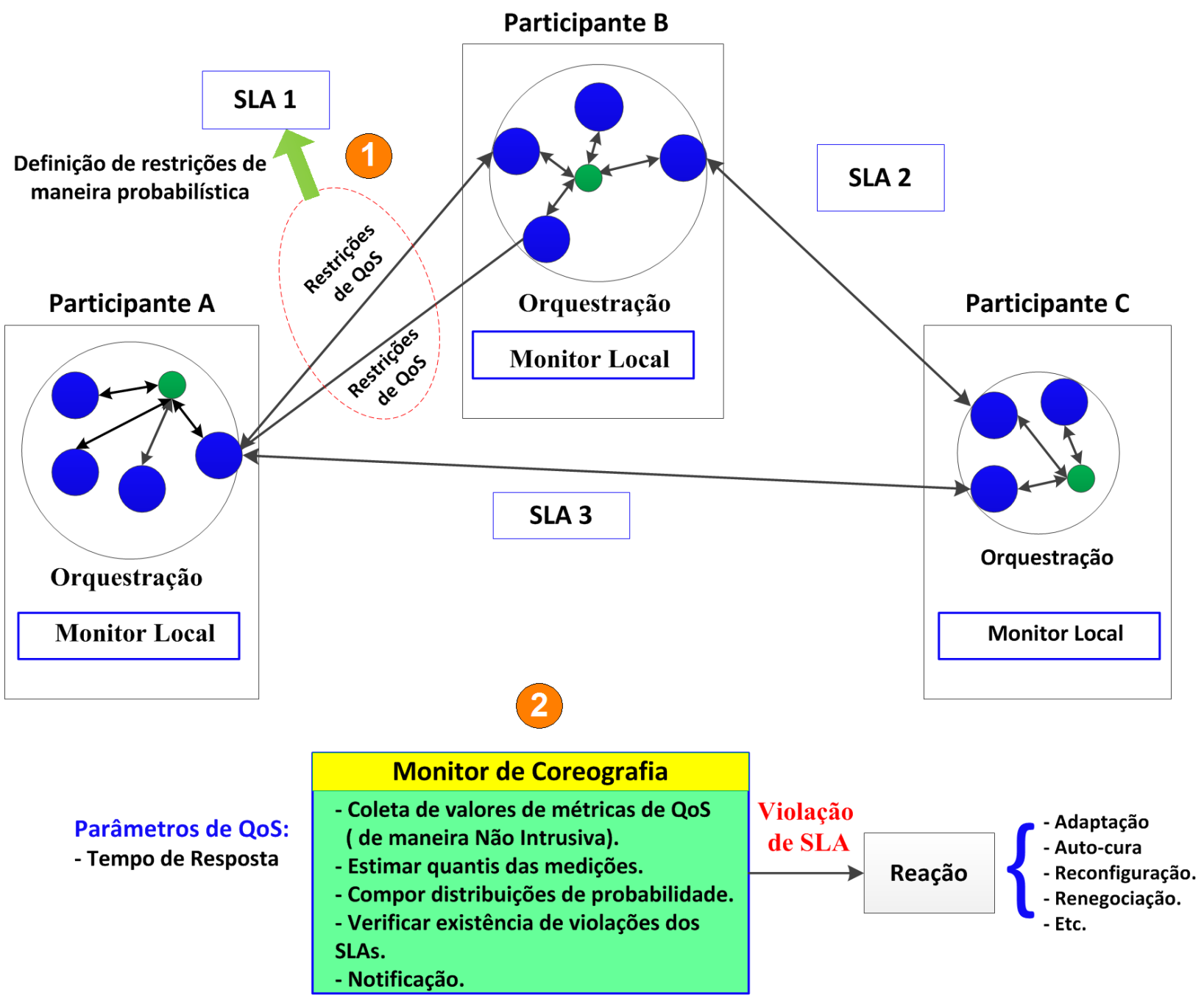

Figura 5.1: Arquitetura do monitoramento de coreografias baseado em SLAs probabilisticos

considerados no desenvolvimento desta pesquisa. Considerou-se somente um subconjunto do total de elementos, já que são suficientes para avaliar as técnicas e abordagens propostas.

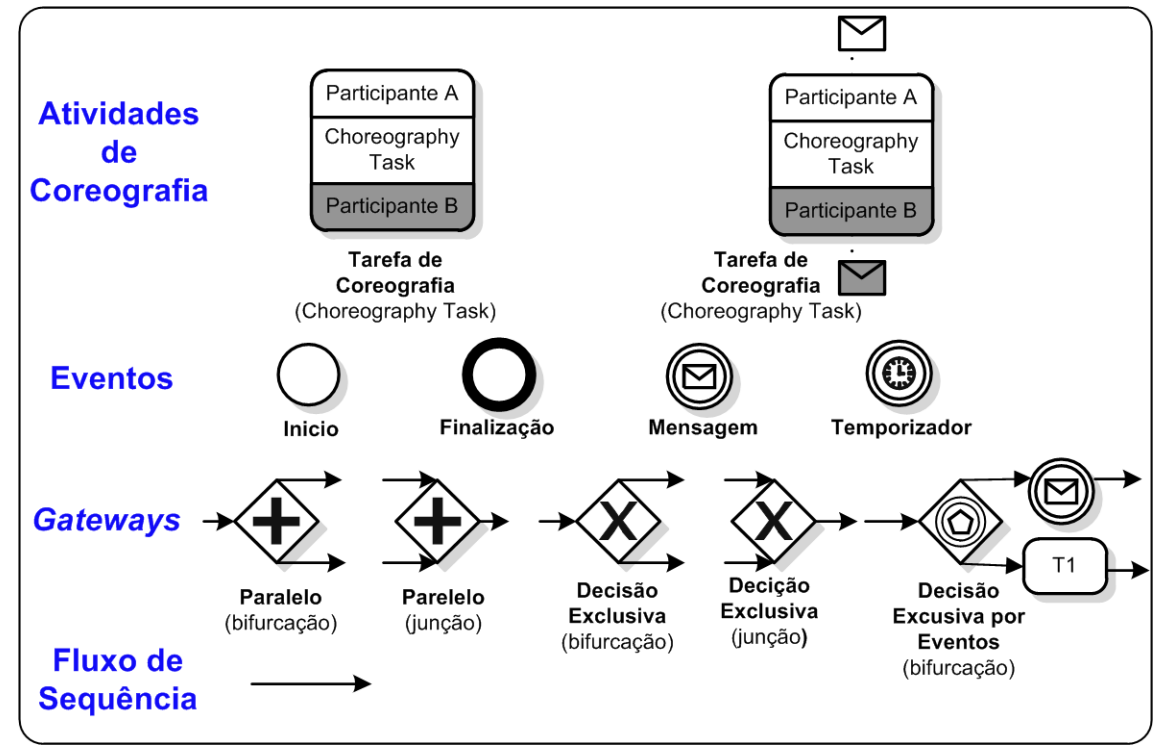

Figura 5.2: Elementos BPMN para modelagem de coreografias que são levados em consideração. 


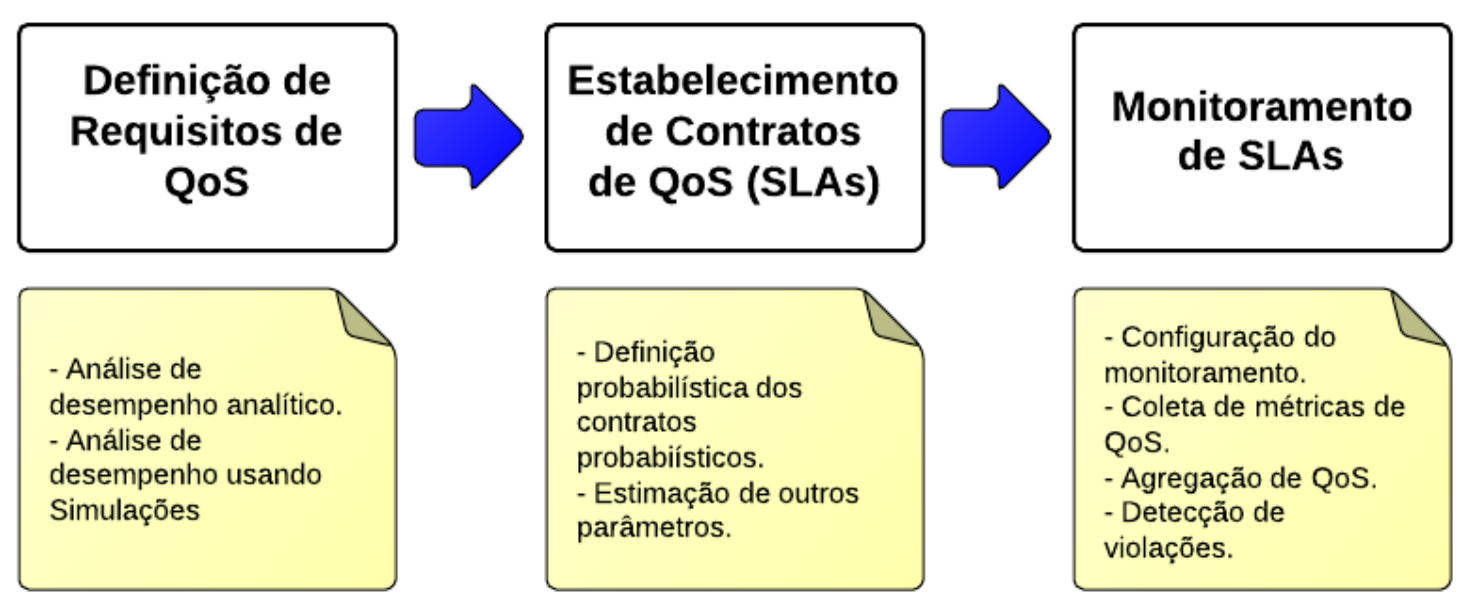

Figura 5.3: Etapas para realização do monitoramento.

A Figura 5.3 mostra as três principais etapas envolvidas para realizar o monitoramento de coreografias. Primeiro, precisa-se definir os requisitos de QoS por meio de métodos analíticos ou simulações. Depois, especifica-se o contrato de QoS (SLA) por meio de alguma distribuição de probabilidade. Por fim, configuram-se os parâmetros de monitoramento, se realiza a coleta e agregação de QoS, e se realizam as verificações para detectar as violações de SLAs. Dessa maneira, para atingir o objetivo de realizar a detecção de violações de SLAs em coreografias de serviços Web, desenvolveu-se as seguintes atividades:

- Definição de requisitos de QoS de maneira analítica, por meio da avaliação de desempenho de coreografias usando Redes de Petri Estocásticas Generalizadas (GSPN).

- Construção de um simulador para rodar coreografias de serviços. O simulador de coreografias possui suporte a QoS, e acima dele um monitor centralizado foi desenvolvido.

- Definição de requisitos de QoS de maneira probabilística usando o simulador de coreografias.

- Especificação de contratos probabilísticos baseados nos requisitos de QoS.

- Monitoramento de SLAs probabilísticos e a detecção de violações de SLA.

\subsection{Modelo de QoS}

Os atributos de QoS considerados neste trabalho estão envolvidos em interações de serviços, isto é, de acordo com um modelo de requisição e resposta para um serviço. Essas interações entre serviços estão baseadas nas interações atômicas do BPMN2. A Figura 5.4 mostra o mapeamento das atividades de coreografia para seu equivalente em interações de serviço, de maneira a definir aí o modelo de QoS (atributos, métricas, cálculos, entre outros).

A Figura 5.5 mostra os atributos de QoS básicos envolvidos em uma invocação de um serviço tais como, o tempo de comunicação na requisição, o tempo de execução, o tempo de comunicação na resposta e o tempo de resposta. O tempo de comunicação depende de atributos de QoS de rede como a largura de banda e a latência de rede; o tempo de resposta depende do tempo de execução e do tempo de comunicação. Além do mais, no caso de serviços compostos o cálculo dos atributos de QoS depende das medidas dos outros atributos de QoS e das dependências com outros serviços.

Os atributos de QoS podem ser calculados da seguinte forma:

- Tempo de comunicação: $t_{c}=L_{i j}+S / B i j$. Onde $S$ é o tamanho da mensagem, e $L_{i j}$ e $B i j$ são a latência e largura de banda de rede entre o ponto $i$ e o ponto $j$.

- Tempo de execução: $t_{\text {execução }}=t_{3}-t_{2}$. 

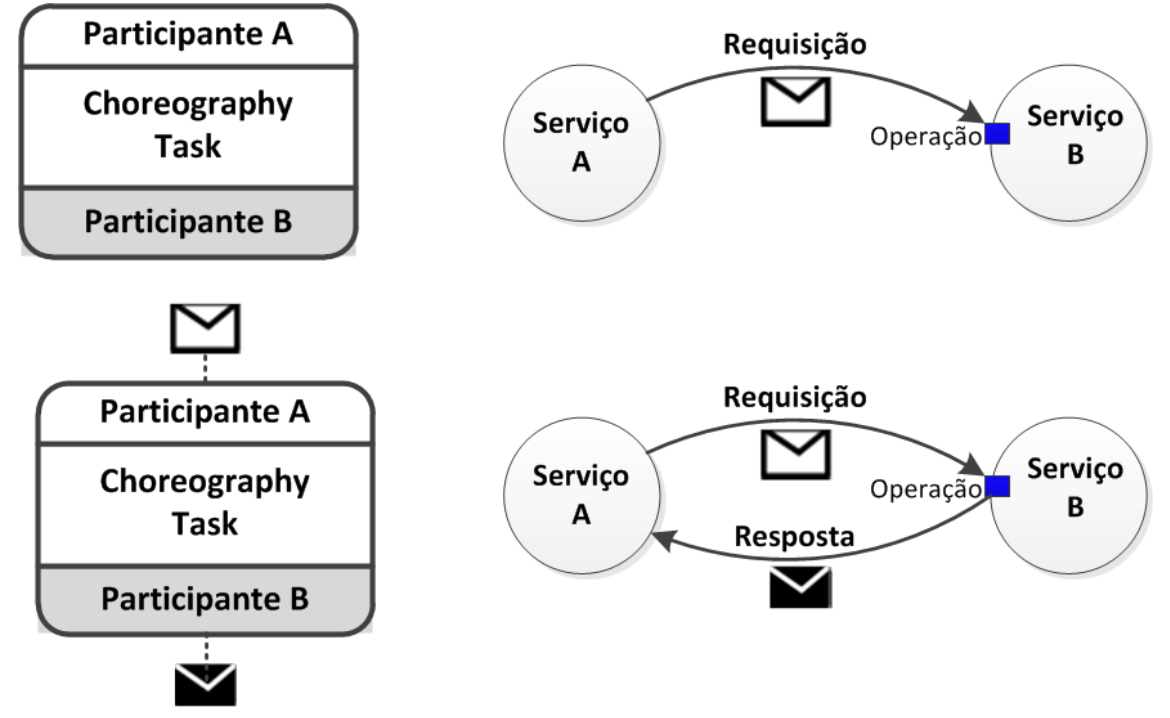

Figura 5.4: Interação de serviços a partir de interações atômicas do BPMN2.

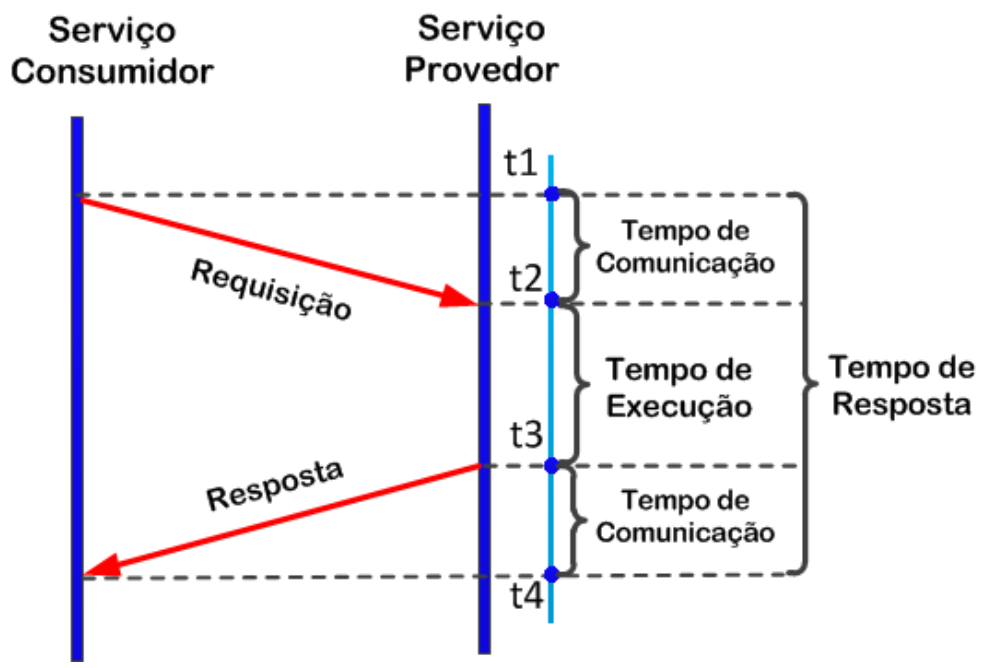

Figura 5.5: Atributos de QoS em uma interação com um serviço Web.

- Tempo de resposta: $t_{R}=t_{\text {execução }}+t_{c 1}+t_{c 2}$. Onde o $t_{c 1}$ e $t_{c 2}$ são os tempos de comunicação na requisição e na resposta respectivamente.

- Tempo de execução efetivo: $t_{\text {execução }}=t_{\text {Rcomposto }}+t_{\text {execução individual }}$. Onde $t_{\text {Rcomposto }}$ é o tempo de resposta acumulado dos serviços que são dependências do serviço atual, e

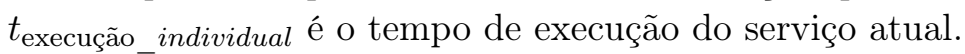

- Tempo de resposta composto:

$t_{\text {Rcomposto }}=F$ (aggregationType, dado, $\left.t_{R 1}, \ldots, t_{R k}\right)$. Onde os $t_{R 1}, \ldots, t_{R k}$ são os tempos de resposta dos serviços que são dependências do serviço atual, $F$ é a função de agregação que depende do tipo de padrão de workflow aggregationType, e dado é a informação associada. Os gateways atualmente suportados são a sequência, paralelismo e a decisão exclusiva (ver Figura 5.2):

- Sequência: $F\left(S E Q U E N C E, d a d o, t_{R 1}\right)=t_{R 1}$. Onde $t_{R 1}$ é o serviço em sequência do serviço atual.

- Paralelismo: $F\left(P A R A L L E L, d a d o, t_{R 1}, \ldots, t_{R k}\right)=\max \left\{t_{R 1}, \ldots, t_{R k}\right\}$. Onde $t_{R 1}, \ldots, t_{R k}$ são os tempos de resposta dos serviços que são dependências do serviço atual. 
- Decisão exclusiva: $F\left(E X C L U S I V E, d a d o, t_{R 1}, \ldots, t_{R k}\right)=t_{R y}$. Onde o $t_{R y}$ é o tempo de resposta do serviço escolhido de acordo com o valor de data.

\subsubsection{Modelo de Falhas}

Um modelo de falhas descreve os tipos de falhas que podem ocorrer em um sistema enquanto está sendo executado, e ajuda a determinar quais mecanismos de tolerância a falhas deveriam ser aplicados $\left[\mathrm{LLM}^{+} 10\right]$. Levando em consideração o trabalho em [LLM $\left.{ }^{+} 10\right]$, as falhas para serviços Web podem ser classificadas em quatro tipos: lógicas, de sistema, de conteúdo e de nível de serviço (SLA). A seguir, uma breve descrição desses tipos:

- Falhas Lógicas: Detectadas na lógica definida na especificação da composição.

- Falhas de Sistema: Surgem no suporte do ambiente de execução e estão relacionadas a falhas nos computadores, rede, sistema operacional, etc.

- Falhas de Conteúdo: Devido a dados ou mensagens corrompidos.

- Falhas de SLA: Devido a violações de QoS especificados em um SLA.

No contexto de coreografias, já que há serviços compostos, os atributos de QoS são individuais e agregados de acordo com os padrões de fluxo de trabalho e suas dependências. Um monitor deve ficar responsável pela coleta, medição e agregação de tais atributos, assim como por acompanhar a execução da coreografia e detectar violações de restrições de QoS.

\subsection{Simulador de Coreografias de Serviços}

Atualmente, implementar e executar uma coreografia de serviços real é uma tarefa complexa já que as tecnologias para suportar esse paradigma de composição de serviços estão ainda imaturas, especialmente pela falta de motores de execução cientes de coreografia [KELL10]. Assim, os mecanismos para medir parâmetros de QoS, e estabelecer requisitos de QoS não estão bem desenvolvidos para coreografias.

\subsubsection{Trabalhos Relacionados}

Existem poucas infraestruturas para implementação de coreografias de serviços Web [BBRW09]. O Pi4SOA $\left[\mathrm{ZTW}^{+} 06\right]$ é um arcabouço que fornece um editor para modelagem de coreografias em $\mathrm{WS}_{-} \mathrm{CDL}^{1}$, e realiza verificações, validações e simulações. Porém, não suporta enactment de coreografias e as suas simulações servem apenas para encontrar inconsistências na especificação. $\mathrm{O}$ WS-CDL+ [KWH07] é uma proposta de um motor de execução de coreografias especificadas em WS-CDL, mas foi implementado na forma de protótipo e somente a versão 1.0 foi lançada. O OpenKnowledge [BBRW09] é um arcabouço que fornece a capacidade de construir sistemas distribuídos em uma arquitetura P2P (ponto a ponto), podendo realizar enactment coreografias também, mas de maneira limitada. Além do mais, no projeto $C H O R e O S$ está sendo desenvolvido o CHOReOS Enactment Engine ${ }^{2}$, que fornece um PaaS (plataforma como serviço) que visa automatizar a implantação distribuída de coreografias de serviços na Núvem. No entanto, essa plataforma não oferece suporte a QoS e monitoramento de serviços.

Muitos simuladores para sistemas e ambientes distribuídos foram propostos. Por exemplo, o arcabouço GridSim [BMCC02], o Pi4SOA [ZTW ${ }^{+}$06] e o arcabouço SimGrid [CLQ08]. O arcabouço GridSim [BMCC02] é um motor de simulação de ambientes distribuídos baseado em eventos. Ele implementa entidades para emular usuários. As requisições dos usuários são escalonadas por meio

\footnotetext{
${ }^{1}$ WSCDL: Linguagem de especificação de coreografias proposto pela W3C

${ }^{2}$ CHOReOS Enactment Engine: http://www.choreos.eu/bin/Documentation/enactment_engine_doc
} 
de um broker que os aloca nos recursos de simulação. O SimGrid [CLQ08] é um arcabouço para simular diversos sistemas distribuídos e permite avaliar mecanismos de clusters e grades.

O simulador apresentado nesta dissertação diferencia-se daquele apresentado em [GKB12] por dar suporte à avaliação de mecanismos de garantia de QoS e de SLA.

\subsubsection{Arquitetura}

A Figura 5.6 mostra as requisições enviadas e as respostas de um serviço composto. Essas interações são registradas mediante eventos por parte de um serviço ou cliente solicitante (eventos 1 e 4) e eventos por parte das dependências (eventos 2 e 3). Os eventos indicam quando e quais atributos de QoS devem ser medidos e a correta ordem para garantir valores consistentes. Os atributos de QoS com as suas métricas e tipos de falhas associadas são apresentados na Tabela 5.1. São esses atributos que são suportados pelo simulador.

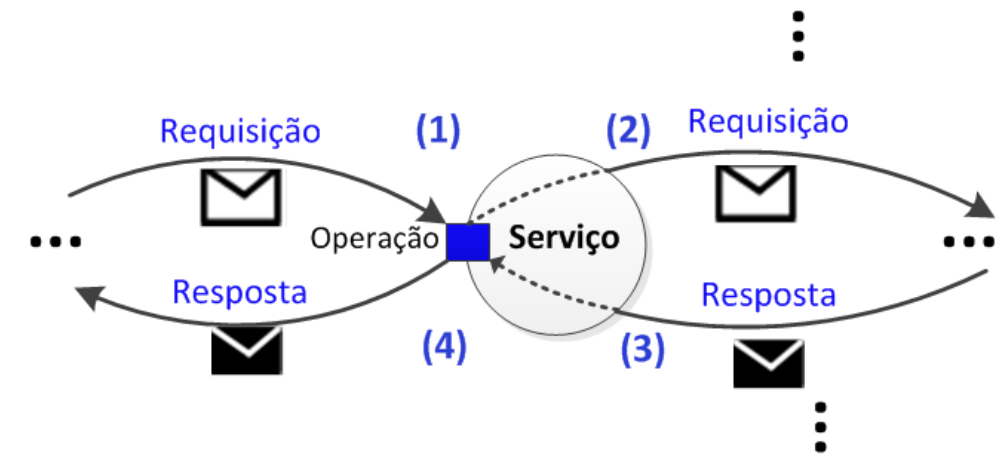

Figura 5.6: Atributos de QoS calculados. (1) Recebendo requisições de um cliente ou serviço. (2) enviando requisições para um outro serviço. (3) recebendo resposta de um outro serviço. (4) enviando resposta para um cliente ou serviço solicitante.

Tabela 5.1: Modelo de QoS e de falhas

\begin{tabular}{|c|c|c|c|}
\hline Tipo & Atributo de QoS & Métrica & Tipo de Falha \\
\hline Serviço & Tempo de Resposta & $\mathrm{ms}$ & Temporização, violação de QoS \\
Serviço & Vazão & \#requisições/s & Serviço não disponível,violação de QoS \\
Mensagem & Formato da Mensagem & - & Probabilidade de falha \\
Comunicação & Latência & $\mathrm{ms}$ & Erro de comunicação/violação de QoS \\
Comunicação & Largura de Banda(máxima) & $\mathrm{Mb} / \mathrm{s}$ & Erro de comunicação \\
\hline
\end{tabular}

Pelo fato da implementação de um simulador por completo ser uma tarefa complexa, decidiu-se estender um arcabouço de simulação já existente, o SimGrid [CLQ08]. Como o SimGrid permite a simulação de ambientes distribuídos, ele é suficiente para servir como base para o nosso simulador de coreografias, chamado de ChorSim.

A Figura 5.7 exibe a arquitetura do ChorSim ${ }^{3}$. Cada bloco representa um componente do simulador. Um componente depende de um outro componente ou vários componentes que estão embaixo dele.

A base do ChorSim está construído sobre o arcabouço SimGrid, para suportar a definição de hosts, topologia de rede, comunicação entre serviços e a especificação do consumo de recursos. O "Motor de Execução de Coreografias" do ChorSim permite criar instâncias de coreografias e iniciar as interações dos diversos serviços envolvidos que resultarão em um grafo de requisições e um grafo de informações de QoS. A topologia do ambiente físico onde a coreografia é realizada é configurada por meio de um arquivo XML de especificação de plataforma. Os serviços foram modelados como um conjunto de threads que recebem uma tarefa enviada através da rede, a executam e em seguida enviam outra tarefa através da rede para atuar como uma resposta da requisição.

\footnotetext{
${ }^{3}$ O repositório está disponível em https://github.com/choreos/ChoreographySimulator
} 


\section{ChorSim}

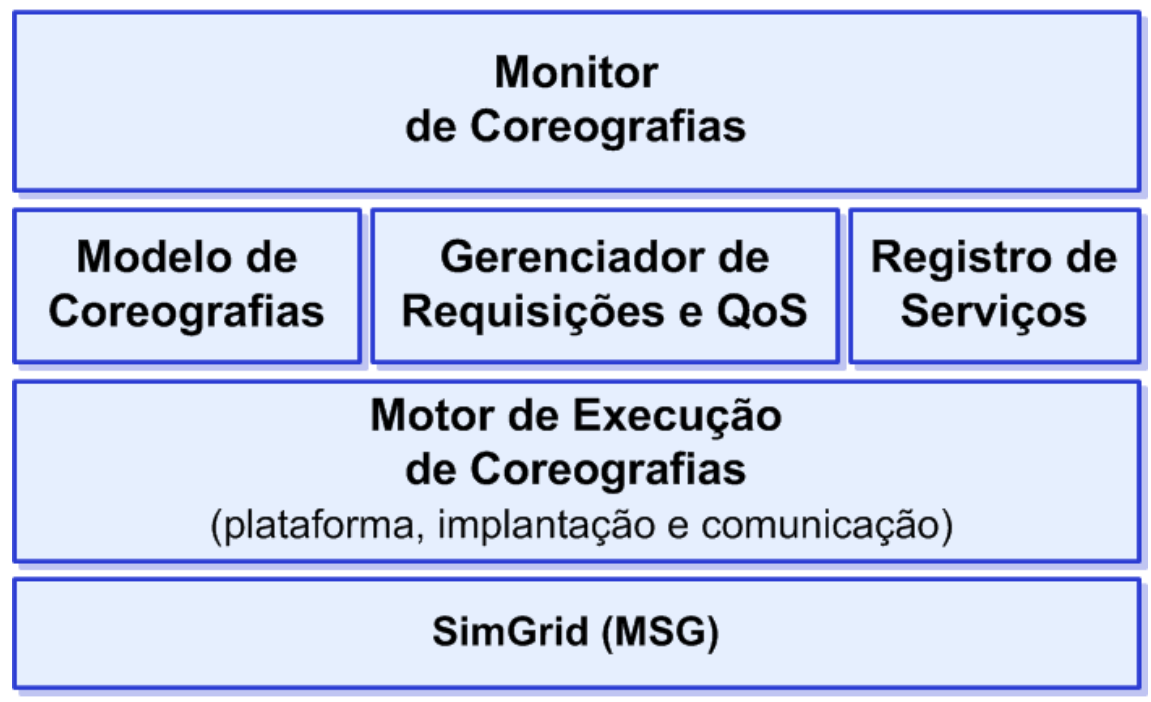

Figura 5.7: Arquitetura do simulador de coreografias.

O "Modelo de Coreografias" é construído a partir de uma especificação baseada em XML que define os serviços participantes, suas dependências e suas interações. Os recursos computacionais necessários para executar, a quantidade de threads, o tamanho médio das respostas dadas nas interações dos serviços e suas operações são configurados por meio de um arquivo XML de implantação, que está especificado de acordo como o modelo de coreografias. O arquivo de implantação serve também como base para construir o "Registro de Serviços".

O "Gerenciador de Requisições e QoS" gerencia o grafo de requisições e o grafo de informações de QoS de acordo com o avanço e execução na interação dos serviços. Acima desta infraestrutura o "Monitor de Coreografias" é desenvolvido, usando o "Modelo de Coreografias", o "Registro de Serviços" e o "Gerenciador de Requisições e QoS". Esse monitor é responsável pela medição dos atributos de QoS dos serviços individuais e por agregá-los para calcular os atributos de QoS compostos. A agregação de QoS é realizada de acordo com as dependências, interações e os padrões de fluxo de trabalho (gateways) do modelo de coreografia. Por meio do monitor criam-se e gerenciam-se as instâncias de coreografias e seus respectivos identificadores para serem usados nas mensagens durante as interações.

\subsection{Considerações}

Neste capítulo apresentaram-se as três etapas para atingir o monitoramento e detecção violações de contratos. Descreveram-se a visão geral do funcionamento do monitoramento, o modelo de QoS e a construção do simulador de coreografias ChorSim. O modelo de QoS descreve os atributos de QoS levados em consideração e os cálculos necessários para agregá-los. Finalmente, descreveu-se a motivação, importância e arquitetura do ChorSim. Assim, o monitor de coreografias e a técnica de detecção de violações de contratos de QoS propostos são implementados acima do ChorSim. 


\section{Capítulo 6}

\section{Mecanismo para Detecção de Violações de SLAs em Coreografias de Serviços Web}

Nesta seção são apresentados os mecanismos e abordagens propostos para as três etapas descrevidas no capítulo anterior e que foram ilustradas na Figura 5.3. Apresentam-se as técnicas para definir os requisitos de QoS, estabelecimento de contratos e monitoramento para realizar a detecção de violações de SLA em coreografias.

\subsubsection{Etapa 1: Definição de Requisitos de QoS - Analiticamente}

Antes do desenvolvimento do simulador de coreografias, desenvolveu-se uma maneira de definir requisitos de QoS de maneira analítica usando GSPNs (Rede de Petri Estocástica Generalizada). Assim, uma metodologia para avaliar o desempenho de coreografias para definir requisitos de QoS foi proposta [DB12]. A avaliação é realizada na fase de modelagem da coreografia. A metodologia consiste na execução dos seguintes passos:

1. Mapeamento de uma coreografia especificada em BPMN 2.0 para uma GSPN. A GSPN inclui a representação intermediária da coreografia e o modelo de QoS que leva em consideração as restrições de tempo e comunicação das interações entre os participantes. Cada participante representa um peer que está ativo durante o enactment da coreografia.

2. Definição de pesos nas transições com restrições de tempo na GSPN. Nesta etapa, as distribuições de probabilidade e pesos nas interações relacionadas com a comunicação e troca de mensagens são definidas.

3. Simulações de cenários, um cenário com uma configuração mínima de falhas e outro cenário com uma maior possibilidade de falhas. As simulações são utilizadas já que as coreografias no mundo real representam processos complexos, que geram complexas redes de Petri com muitos estados que tornam difícil realizar avaliações analíticas [OLAR09]. A partir dos resultados e analises das simulações podem-se estimar e planejar recursos, capacidade e outros requisitos em etapas antecipadas do desenvolvimento da coreografia visando melhorar a QoS.

\section{Definição formal de coreografias especificadas em BPMN}

A definição de coreografias está baseado no trabalho apresentado em [DDO07] acerca da definição de processos BPMN. Assim, as coreografias de processos especificadas em BPMN2 podem ser definidas segundo a Definição 1.

Definição 1. Uma coreografia de processos em BPMN2 é a tupla:

$P C=\left(\mathcal{O}, \mathcal{A}, \mathcal{E}, \mathcal{G}, \mathcal{T}, e^{S}, \mathcal{E}^{I}, e^{E}, \mathcal{E}^{I_{M}}, \mathcal{E}^{I_{T}}, \mathcal{G}^{F}, \mathcal{G}^{J}, \mathcal{G}^{X}, \mathcal{G}^{M}, \mathcal{G}^{V}, \mathcal{F}\right)$ onde: 
- $\mathcal{O}$ é conjunto de "objetos", que é particionado em três conjuntos disjuntos: atividades $(\mathcal{A})$, eventos $\mathcal{E}$ e gateways $\mathcal{G}$.

- $\mathcal{A}$ é conjunto de atividades de coreografia (choreography tasks) $\mathcal{T}$, sub-coreografias e call Choreographies. No entanto, sub-coreografias e call choreographies não são levados em consideração neste trabalho. Por isso, $\mathcal{A}=\mathcal{T}$.

- $\mathcal{E}$ é conjunto de eventos. Os eventos são particionados em três conjuntos disjuntos: eventos de Inicio $e^{\mathcal{S}}$, eventos Intermediários $\mathcal{E}^{\mathcal{I}}$ e eventos de Finalização $e^{\mathcal{E}}$.

- $\mathcal{E}^{\mathcal{I}}$ é particionado nos conjuntos disjuntos de eventos de mensagens $\mathcal{E}^{I_{M}}$ e eventos de temporizador (timer) $\mathcal{E}^{I_{T}}$.

- $\mathcal{G}$ é o conjunto de gateways e é particionado em cinco conjuntos disjuntos de gateways: "parallel forks" $\mathcal{G}^{F}$, "parallel join gateways" $\mathcal{G}^{J}$, "data-based XOR gateways" $\mathcal{G}^{X}$, "XOR merge gateways" $\mathcal{G}^{V}$ e "event-based XOR gateways" $\mathcal{G}^{M}$.

- $\mathcal{F} \subseteq \mathcal{O} x \mathcal{O}$ é a relação de fluxo de controle, isto é, um conjunto de fluxos de sequência que conectam objetos.

Para analisar o comportamento não funcional em coreografias é necessário definir os atributos de QoS a considerar. Para tanto, consideraram-se atributos de QoS para três entidades: serviço, rede e mensagens. No serviço, o atributo de QoS considerado é o tempo necessário para completar uma requisição. Na rede, consideram-se os atributos como o atraso de rede e os erros de comunicação, já que eles influenciam significantemente no tempo de resposta em uma coreografia. Nas mensagens, considera-se o formato da mensagem.

\section{Mapeamento de coreografias em BPMN 2.0 para GSPNs}

A Figura 6.1 apresenta o mapeamento de gateways e eventos para seus respectivos módulos de rede de Petri. A Figura 6.2 apresenta o mapeamento dos dois tipos de tarefas de coreografia. Nessa Figura, as posições $A, A_{2}$ e $B$ representam os participantes. As posições $C_{\text {init }}, C_{\text {end }}, C_{\text {init2 }}$, $C_{\text {end } 2}, C_{\text {endOk }}$ e $C_{\text {endOk2 } 2}$ representam o começo, o final e a correta validação da comunicação entre dois participantes. As transições $T_{\text {send }}$ e $T_{\text {receive }}$ representam as ações de envio e recebimento de mensagens. As demais transições $T$ representam a transmissão de mensagens por um canal de comunicação.

O passo 1 da metodologia é realizada pelo Algoritmo 1. O algoritmo mapeia uma coreografia de processos especificados em BPMN 2.0 para uma GSPN incluindo o modelo de QoS. Cada elemento BPMN é mapeado para seu respectivo módulo de rede de Petri e esses módulos são compostos por meio de uma função de acordo com os fluxos de sequência ou gateways que os conectam. Finalmente, os eventos de Início e de Finalização são adicionados na rede de Petri construída.

\subsubsection{Etapa 1: Definição de Requisitos de QoS - Simulações}

A injeção de falhas é amplamente utilizada para validar mecanismos de tolerância a falhas em sistemas computacionais. Em um ambiente de computação distribuída, os esforços de pesquisa têm desenvolvido maneiras sistemáticas de identificar falhas em tempo de design e assim projetar mecanismos de gestão de falhas. Simulações baseadas em dados reais são muitas vezes inadequadas, já que os dados podem não estar disponíveis e sua coleta pode exigir longos períodos de tempo de observação. Nesse contexto, a injeção de falhas é uma maneira prática e eficiente de validação, visto que consiste na inserção de falhas no sistema tanto no software quanto no hardware [FPR09]. Com base nisso, utilizou-se injeção de falhas no ChorSim para obter maior diversidade nas medidas dos atributos de QoS dos serviços individuais e do serviço composto.

Para definir quais requerisitos de QoS são necessários para definir um contrato, precisa-se realizar diversas simulações com diversas configurações em busca de gargalos, degradações, entre outros, 


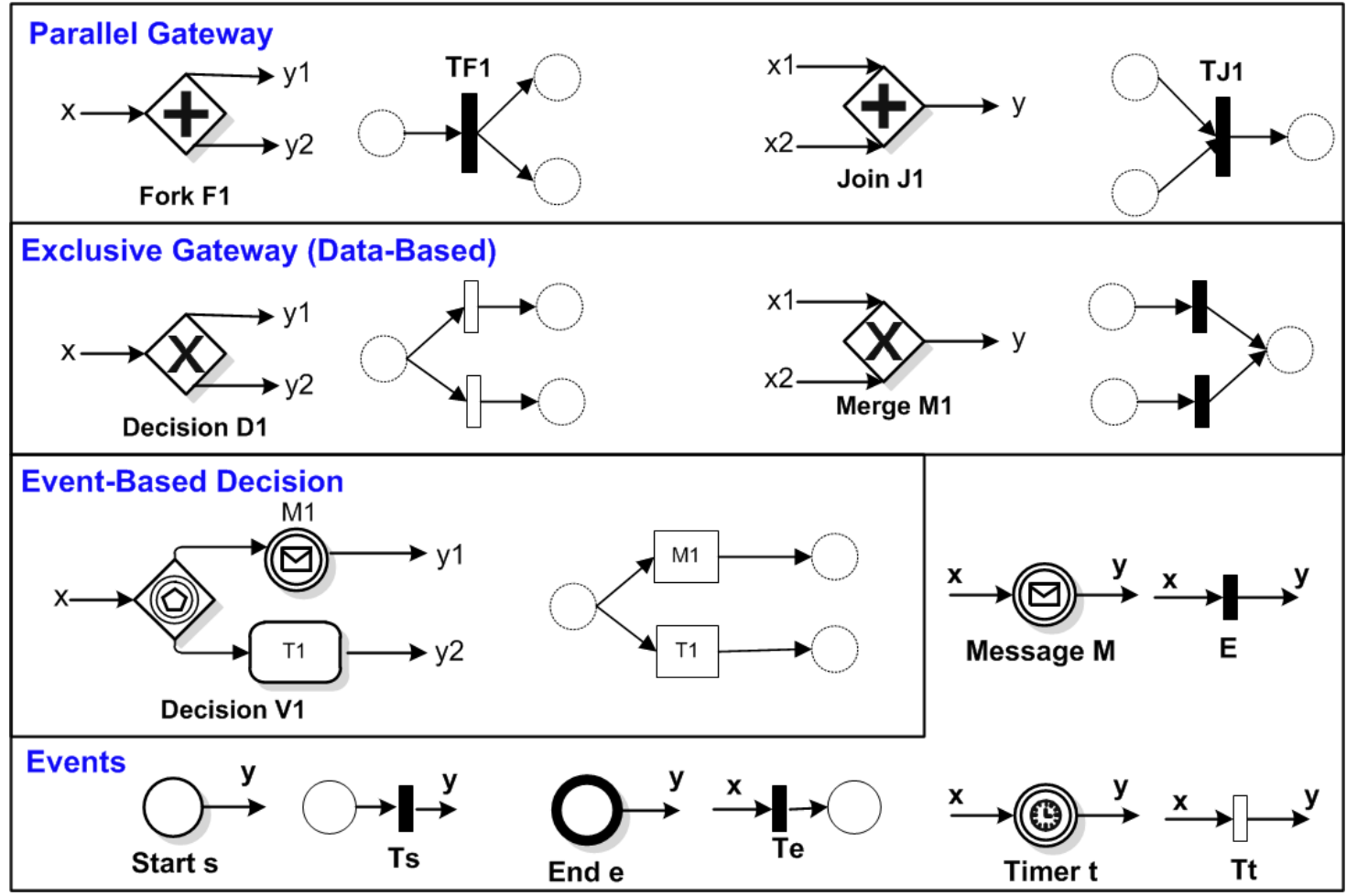

Figura 6.1: Mapeamento de eventos e gateways para módulos de redes de Petri

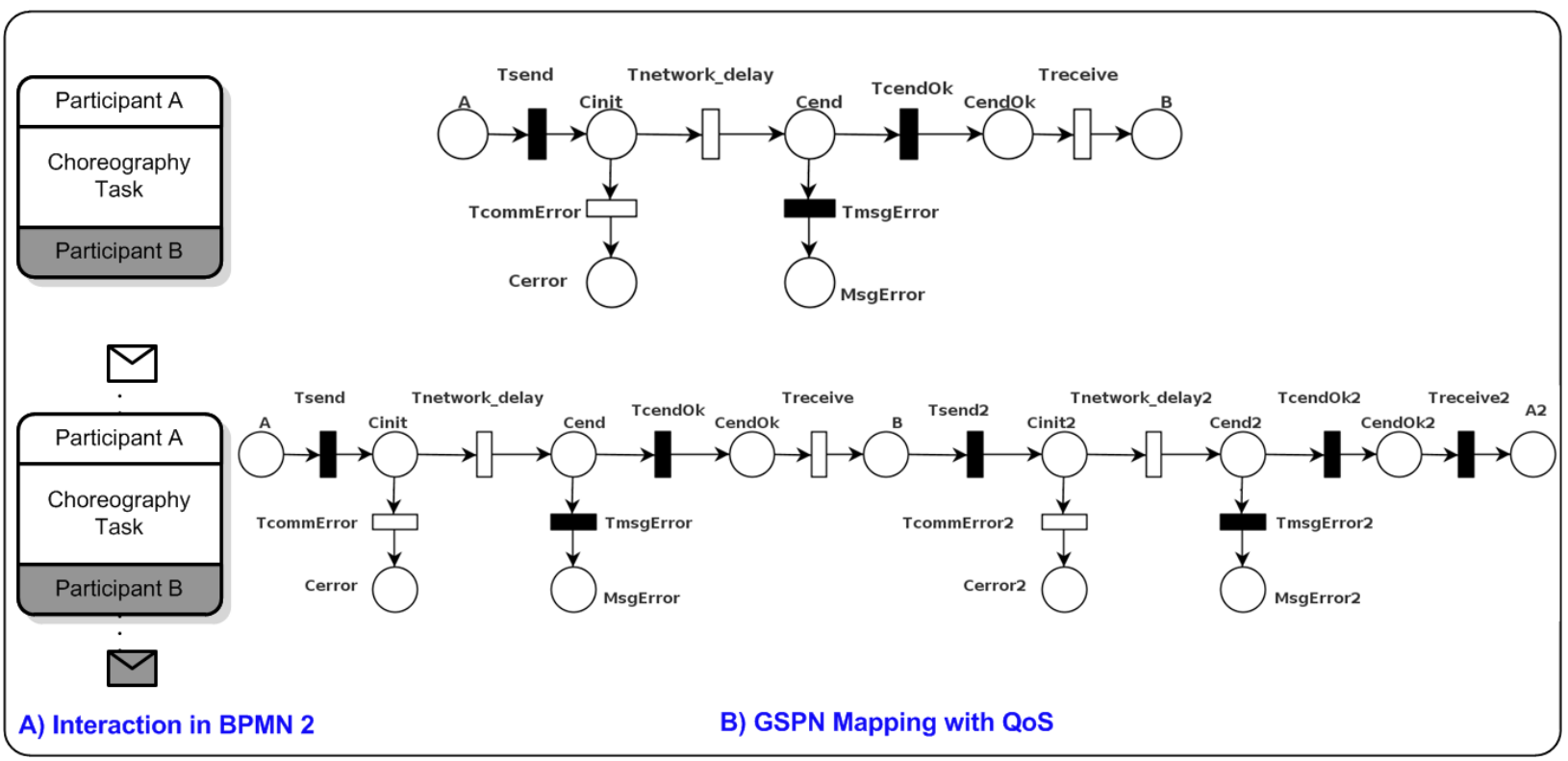

Figura 6.2: Mapeamento de dois tipos de tarefas de coreografia para módulos de redes de Petri com suporte a $Q o S$

acerca de determinados atributos de QoS. Além disso, para obter comportamentos mais realistas deve-se usar distribuições de probabilidade. Porém, o SimGrid ${ }^{1}$ não suporta a geração de eventos probabilísticos, por isso também não suporta a especificação de recursos computacionais nem de rede por meio de distribuições de probabilidade.

No ChorSim foi adicionado o suporte a distribuições de probabilidade para serem utilizadas na definição dos comportamentos dinâmicos do tempo de execução e do processamento de serviços. Atributos como a largura de banda e latência não puderam ser modificados para suportarem

${ }^{1}$ A última versão do Simgrid é a 3.8 


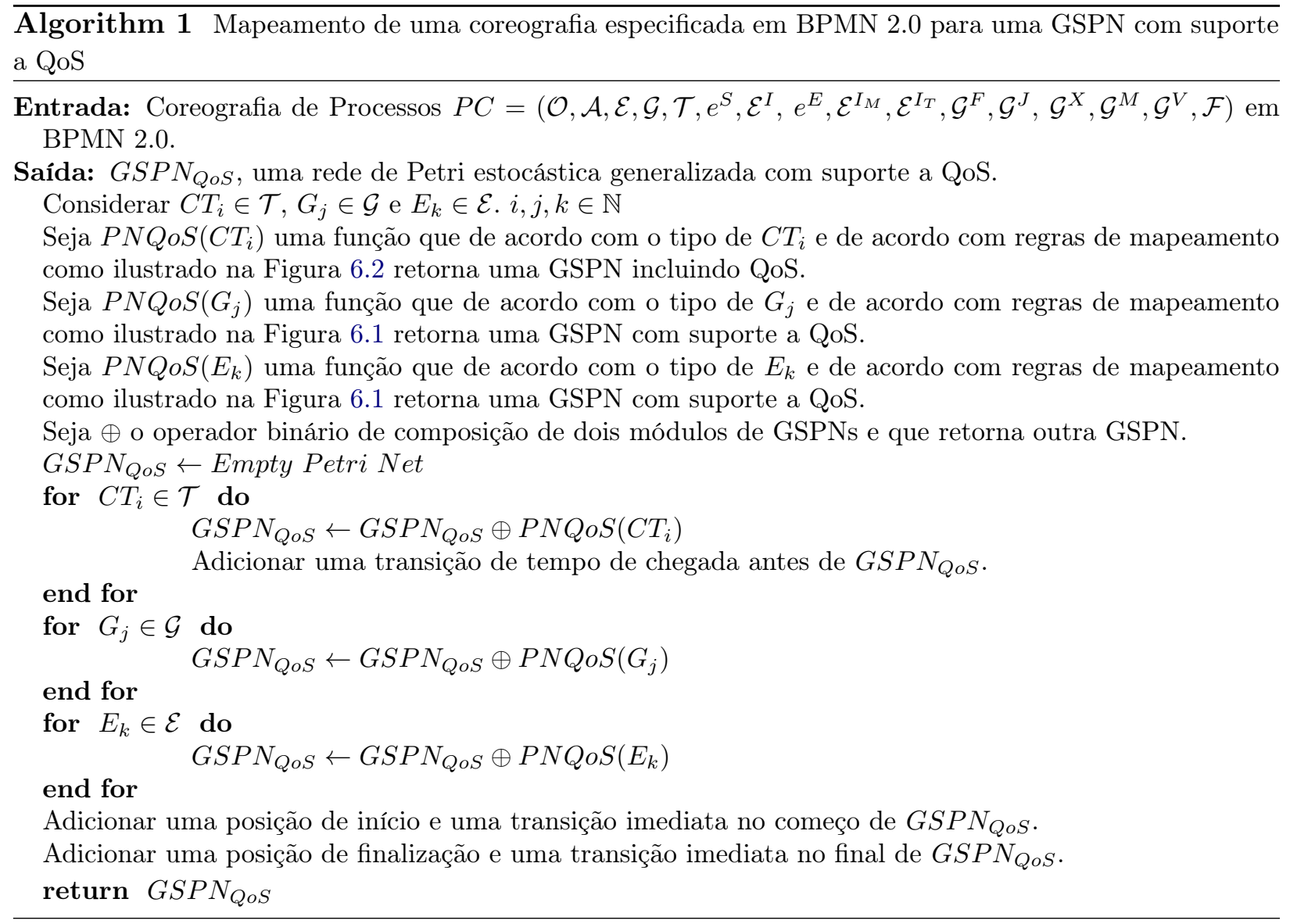

distribuições de probabilidade porque as suas implementações estão bem atreladas ao núcleo do SimGrid. Portanto, para definir um comportamento dinâmico da largura de banda usou-se valores definidos em diferentes intervalos de tempo de modo a representarem a distribuição de probabilidade requerida.

\subsubsection{Etapa 2: Estabelecimento de Contratos de QoS (SLAs)}

No mecanismo proposto, para cada relacionamento entre os participantes de uma coreografia serão especificadas restrições de QoS de maneira probabilística. Tais restrições de QoS tornarão-se um SLA probabilístico.

Assim, um contrato é especificado por meio de uma função de distribuição de probabilidade

$$
F(x)=P_{r}(\delta \leq x)
$$

Onde $P_{r}$ é a probabilidade correspondente a uma restrição sobre algum parâmetro de QoS. $\delta$ é um parâmetro de QoS (por exemplo, a largura de banda efetiva), e $x \geq 0$. O contrato ou restrição será estabelecido como um conjunto finito de quantis dos parâmetros de QoS. A forma de definir essas restrições utilizando quantis será baseada no trabalho apresentado em [RBHJ08], o qual propõe uma técnica para especificar SLAs probabilísticos entre serviços utilizados em uma orquestração.

A agregação das distribuições de probabilidade dos parâmetros de QoS é realizada de acordo com os padrões de interação de coreografia.

Para estimar os quantis

a serem utilizados nos contratos dos participantes, precisa-se compor as distribuições de probabilidade das restrições de QoS dos serviços individuais

que são dependências do serviço composto. Tais composições são realizadas com o simulador de coreografias.

A seguir o procedimento proposto para estabelecer os contratos usando o simulador ChorSim. 


\section{Condições iniciais:}

- Configurar a especificação, plataforma e a implantação da coreografia no ChorSim.

- Definir o comportamento por meio de um fda $F s_{i}$ para cada serviço $S_{i}$.

\section{Simulação usando ChorSim:}

2. 1 Para cada interação com um serviço $S_{i}$, um valor $q_{i}$ do parâmetro de QoS é obtido a partir da simulação em ChorSim.

2. 2 Agregação: Estimar o valor $Q$ do parâmetro de QoS do serviço composto $S$ a partir dos valores obtidos no passo anterior usando o ChorSim.

2. 3 Rodar as simulações dos passos 2.1 e 2.2 várias vezes, o suficiente para estimar $F_{S}$ empiricamente a partir dos valores $Q$ estimados .

3. A partir da fda $F_{S}$ se selecionam quantis para definir o contrato.

\subsubsection{Etapa 3: Monitoramento de SLAs}

O monitor proposto nesta pesquisa visa detectar violações de SLA. O monitor deve atingir o menor número de alarmes falsos e detectar o maior número de violações de SLA corretas. O monitoramento usa métodos estatísticos para verificar se o desempenho observado desvia daquele acordado no SLA.

O monitor mede os valores das métricas de QoS de um serviço $S$ de um participante. Depois os valores são comparados com a restrição de QoS $F_{s}$ definida no SLA não rígido. $F_{s}$ é a distribuição mediante quantis do parâmetro $\delta$ de $S$. Seja $\Delta$ um conjunto finito de amostras dos valores medidos de algum parâmetro de $S$. As seguintes equações de [RBJ09] são utilizadas no monitor:

$$
F_{s, \Delta}^{\prime}(x)=\frac{|\{\delta, \delta \in \Delta \leq x\}|}{|\Delta|}
$$

Onde $F_{s, \Delta}^{\prime}(x)$ é a função distribuição de probabilidade empírica, que define a proporção das amostras dos valores medidos coletados pelo monitor do parâmetro $\delta$ que são menores que $x$ dentro do conjunto $\Delta$. Daí, informalmente a restrição é cumprida se:

$$
\forall x \in R^{+}: F_{s, \Delta}^{\prime}(x) \geq F_{s}(x)
$$

Onde $R^{+}$é o conjunto de números reais positivos. De forma equivalente, a violação de uma restrição de QoS acontece se:

$$
\exists x \in R^{+}: F_{s, \Delta}^{\prime}(x)<F_{s}(x)
$$

Dado que em (2) e (3), $F_{s, \Delta}^{\prime}(x)$ pode variar aleatoriamente ao redor de $F_{s}(x)$, especialmente quando $\Delta$ é bem pequeno, precisa-se de uma zona de tolerância para tais desvios. Desta maneira a condição de violação é formulada como:

$$
\sup _{x \in R^{+}}\left(F_{s, \Delta}^{\prime}(x)-F_{s}(x)\right) \geq \lambda
$$

Onde $\lambda$ é um parâmetro positivo que define a zona de tolerância. Um valor pequeno de $\lambda$ melhora a precisão do monitoramento na detecção de violações, mas acrescenta o risco de alarmes falsos.

Nesses pontos descritos acima, precisa-se calibrar alguns parâmetros tais como o tamanho de $\Delta$ e o valor adequado de $\lambda$. Antes de utilizar essas fórmulas, precisa-se também de um método para agregar os quantis dos valores medidos dos parâmetros de QoS dos serviços individuais até achar os valores acumulados da coreografia. Para tanto, serão levados em consideração padrões de interação de coreografias [BDH05]. 


\subsubsection{Detecção de violações de SLA}

Os testes estatísticos de dominância estocástica estabelecem o quadro matemático adequado para declarar corretamente e resolver o problema de monitoramento. Aqui, o problema é estabelecido a seguir:

Seja $F_{S}$ a função de distribuição cumulativa prometida pelo contrato de um serviço $S$, e seja $F_{S}^{\prime}$ a função de distribuição cumulativa atual do serviço $S$. O problema é decidir entre duas hipóteses:

$$
\begin{aligned}
H_{0}: & \forall x, F_{S}^{\prime}(x)>=F_{S}(x) \\
\text { contra }: & \\
H_{1}: & \exists x, F_{S}^{\prime}(x)<F_{S}(x)
\end{aligned}
$$

Onde na hipótese nula $\left(H_{0}\right)$ o contrato é cumprido e na hipótese alternativa $\left(H_{1}\right)$ o contrato é violado. Dado que o comportamento dos atributos de QoS dos serviços individuais pode ter diversas distribuições de probabilidade, o comportamento de um serviço composto pode resultar também em diversas distribuições de probabilidade. Assim, o teste de Kolmogorov-Smirnov de apenas um lado de duas amostras ${ }^{2}$ é utilizado para aceitar ou rejeitar $H_{0}$ :

$$
[d, p]=k s t e s t\left(X_{\text {contract }}, X_{\text {monitoring }}, K S_{\text {side }}\right)
$$

Onde kstest é a função que desempenha o teste que compara as distribuições dos valores nos vetores $X_{\text {contract }}$ e $X_{\text {monitoring. }}$ O vetor $X_{\text {contract }}$ corresponde ao contrato e o vetor $X_{\text {monitoring }}$ é o conjunto de amostras dos valores de um atributo de QoS obtidos por meio da composição de valores dos serviços individuais usando o simulador de coreografias. A hipótese nula consiste em que $X_{\text {contract }}$ e $X_{\text {monitoring }}$ são da mesma distribuição contínua e a hipótese alternativa consiste em que $X_{\text {contract }}$ e $X_{\text {monitoring }}$ são de diferentes distribuições. O argumento $K S_{\text {side }}$ é um parâmetro cujo valor pode ser greater, less ou two-sided. Para a detecção de violações usamos os valores greater e less. $d$ é a distância entre as duas distribuições cumulativas de $X_{\text {contract }}$ e $X_{\text {monitoring }}$ e $p$ é o " $p$-value" do teste estatístico que tem valores entre $[0,1]$.

Então, para a deteç̧ão de violações usam-se:

$$
\begin{aligned}
& {\left[D^{+}, p^{+}\right]=k s t e s t\left(X_{\text {contract }}, X_{\text {monitoring }}, \text { greater }\right)} \\
& {\left[D^{-}, p^{-}\right]=k \operatorname{siest}\left(X_{\text {contract }}, X_{\text {monitoring }}, \text { less }\right)}
\end{aligned}
$$

para aceitar ou rejeitar $H_{0}$. Daí, $H_{0}$ é rejeitado quando o $p^{+}<\alpha$ é pequeno, onde geralmente $\alpha$ é 0.05. Desse modo, detecta-se uma violação do contrato.

Por outro lado, para cumprir o contrato não é suficiente ter um valor $p^{+}>=\alpha$, já que tem que se levar em consideração a flutuação aleatória de $F_{S}^{\prime}$ sobre $F_{S}$. Essa flutuação é medida por:

$$
D=\max \left\{D^{+}, D^{-}\right\}
$$

Portanto, para que um conjunto de amostras $X_{\text {monitoring }}$ cumpra o contrato uma regra baseada em $p^{+}$e $D$ tem que ser verdadeira:

$$
\text { verify }\left(X_{\text {monitoring }}\right)= \begin{cases}\text { true, } & \text { se } p^{+}>=\alpha \wedge D^{+}<\lambda \\ \text { false, } & \text { de outra maneira }\end{cases}
$$

Onde a função verif $y$ realiza a verificação do cumprimento do contrato das amostras $X_{\text {monitoring }}$, e $\lambda$ define a zona de tolerância da flutuação entre distribuições de probabilidade.

As principais características e motivos para usar o teste de Kolmogorov-Smirnov (KS) são [SL11]:

- É um teste não-paramétrico, que compara as distribuições cumulativas de dois conjuntos de dados.

\footnotetext{
${ }^{2}$ Tradução de "One-sided two-sample Kolmogorov-Smirnov test"
} 
- Dado que o teste é não-paramétrico, não assume que os dados são coletados a partir de distribuições gaussianas (ou quaisquer outras distribuições definidas).

- Os resultados não mudam se todos os valores são "transformados" por meio de logaritmos ou transformações similares.

- Porque tem baixa precisão para detectar desvios na mediana, mas tem mais precisão para detectar mudanças na forma da distribuição do que testes similares como o Mann-Whitney.

É importante observar que como o teste não compara média ou mediana, ele não reporta intervalo de confiança.

\subsection{Considerações}

Neste capítulo apresentaram-se a definição de requisitos de QoS, o estabelecimento do contrato de SLA, e o monitoramento com a deteç̧ão de violações de contrato em coreografias de serviços Web. Na definição de requisitos de QoS é utilizado um mapeamento de um subconjunto dos elementos da especificação de coreografia em BPMN2 para uma GSPN. Essa GSPN é uma representação intermediária da coreografia com suporte de QoS. O alvo é realizar avaliações de desempenho e a partir delas definir requisitos de QoS em etapas antecipadas como a modelagem.

$\mathrm{Na}$ definição de requisitos também são realizadas simulações utilizando um simulador de coreografias com suporte a QoS chamado de ChorSim. Esse simulador também corresponde a uma contribuição da dissertação. É importante observar que o modelo de falhas apresentado neste capítulo não está descrito com detalhe, já que não é o foco do trabalho. O contrato probabilístico para garantir QoS é definido por meio de uma função de distribuição acumulada a partir dos valores estimados do atributo de QoS alvo utilizando o ChorSim.

$\mathrm{Na}$ etapa de monitoramento descreveu-se a configuração do monitor e a técnica utilizada para detectar violações de SLA, a qual está baseada no uso do teste de Kolmogorov-Smirnov de apenas um lado. Esse teste permite calcular quão próxima uma distribuição está de outra e já que é de tipo não paramétrico podem ser testados diversos tipos de distribuições. 


\section{Capítulo 7}

\section{Experimentos}

Esta seção apresenta os cenários de coreografias, os experimentos e as análises dos resultados. Os experimentos e resultados abrangam as três etapas descrevidas no Capítulo 6 até realizar a detecção de violações de contratos de QoS.

\subsection{Cenários}

\section{Cenário 1}

A Figura 7.1 apresenta um exemplo de coreografia especificada de acordo com o modelo de interconexão. O exemplo é acerca de uma oferta de investimentos e está especificada utilizando a notação BPMN 2. Primeiro, um consultor financeiro (participante) oferece um produto a um cliente (outro participante). Posteriormente, o cliente tem um tempo para decidir se aceita a proposta de investimento. Cada participante é representado por meio de pools nos quais se interconectam atividades. Este cenário será utilizado nos experimentos da Etapa 1 da definição de requisitos de maneira analítica.

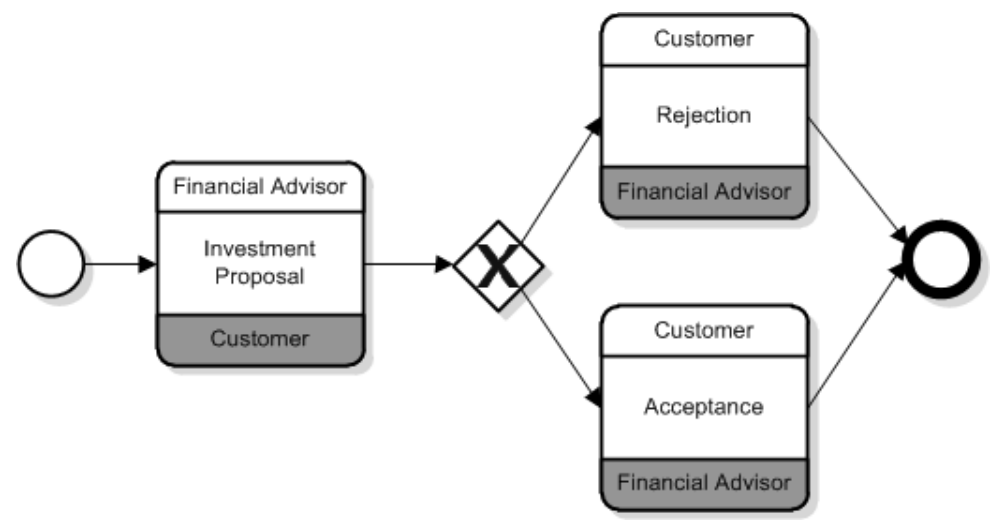

Figura 7.1: Exemplo de modelo de interação de coreografias: oferta de investimento [KLW10].

\section{Cenário 2}

A coreografia apresentada em $\left[\mathrm{BDF}^{+} 08\right]$ é utilizada nos experimentos das etapas que usem simulações sobre o ChorSim. Essa coreografia representa uma aplicação de CDN (Content Delivery Network) para fornecimento de conteúdo multimídia como áudio, vídeo e imagens. A Figura 7.2 mostra o cenário de referência: um usuário solicita, e eventualmente recebe, um serviço complexo gerido por meio de uma coreografia de diferentes serviços Web, um dos quais ( $W S_{3}$ na figura) controla o provisionamento de conteúdo de streaming. $W S_{1}$ e $W S_{2}$ mostram que vários serviços Web são internamente orquestrados. A coreografia é composta de cinco serviços Web $\left(W S_{1}, W S_{2}, W S_{3}\right.$, 
$W S_{4}$ e $W S_{5}$ ). Cada serviço pertence a um participante diferente e há sete canais de comunicação definindo a topologia $G_{c h o r}$, onde:

$G_{c h o r}=\left(V_{W S}, E\right)$ é um grafo não orientado, $W S_{i} \in V_{W S}$ é um serviço Web da coreografia e $e \in E$ é a comunicação entre dois serviços. $V_{W S}=\cup_{i=1}^{5}\left\{W S_{i}\right\}$ e $E=\left\{\left(W S_{1}, W S_{2}\right),\left(W S_{1}, W S_{3}\right)\right.$, $\left.\left(W S_{1}, W S_{4}\right),\left(W S_{2}, W S_{4}\right),\left(W S_{2}, W S_{5}\right),\left(W S_{3}, W S_{5}\right)\right\}$.

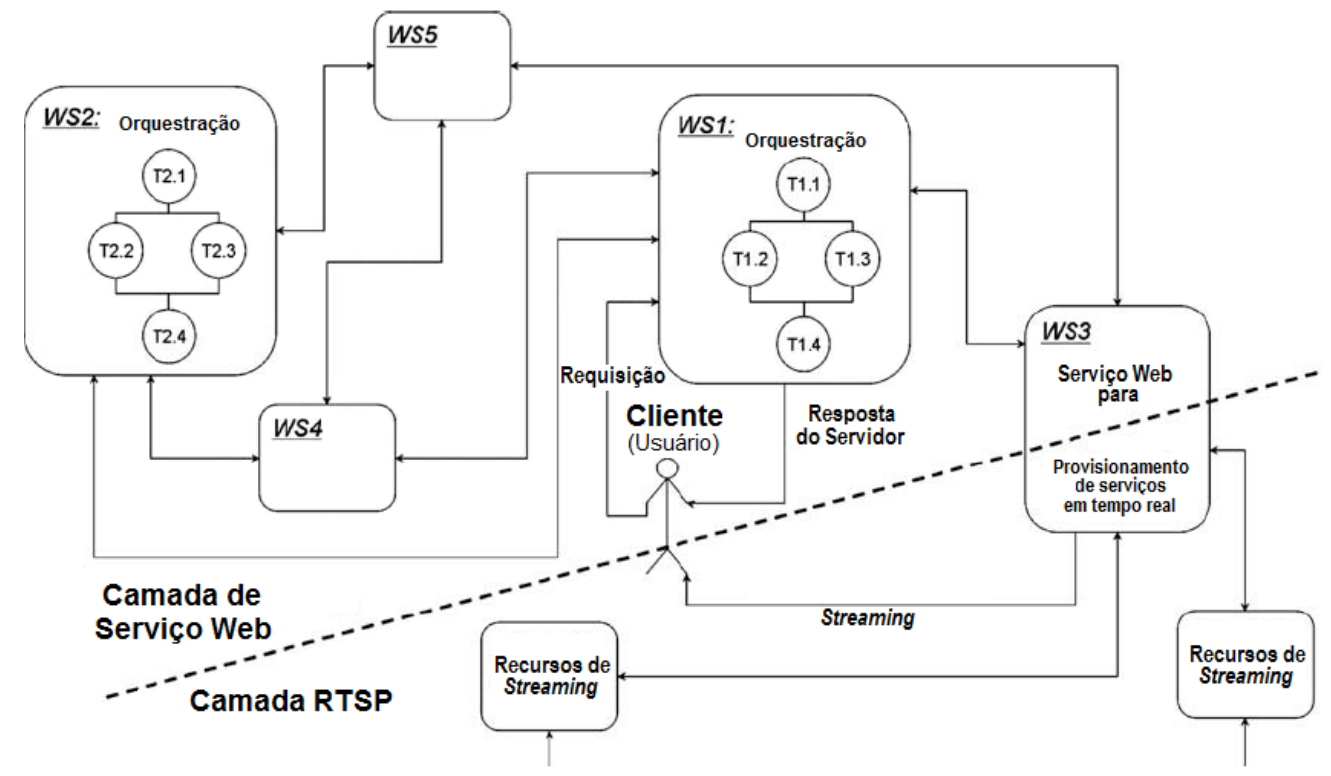

Figura 7.2: Coreografia de serviços da aplicação de $C D N \quad\left[B D F^{+} 08\right]$

Porém, nem sempre todos os serviços de uma coreografia são utilizados em uma instância de coreografia, isto é, há interações entre serviços que não acontecem porque a especificação de uma coreografia abrange várias possibilidades e todas as possíveis interações. Assim, os serviços utilizados em uma instância de coreografia dependem do ponto de entrada, ou seja, a primeira requisição para algum serviço da coreografia. Neste caso as instâncias de coreografias a simular, conforme a Figura 7.2, se iniciam com requisições do cliente para uma operação do serviço composto $W S_{1}$, que resulta em interações com os serviços $W S_{3}$ e $W S_{5}$. Assim, um usuário realiza uma requisição para o serviço $W S_{1}$ para obter um objeto multimídia, $W S_{1}$ registra o pedido e faz uma requisição para o $W S_{3}$ para obter o objeto. Porém, para completar a geração do objeto, $W S_{3}$ precisa obter uma parte do $W S_{5}$.

\subsection{Primeiro conjunto de experimentos - Definição de Requisitos de QoS Analiticamente}

Nesta seção todos os passos da metodologia proposta para definir requisitos de QoS de maneira analítica são realizados. A coreografia apresentada na Figura 7.1 é utilizada. Este cenário foi escolhido porque inclui os três tipos elementos de BPMN de coreografias considerados (atividades, gateways e eventos). As próximas subseções desenvolvem cada um dos passos da metodologia.

\subsubsection{Mapeamento}

A Figura 7.3 apresenta a GSPN obtida como resultado de realizar o mapeamento sobre a coreografia da Figura 7.1. As Tabelas 7.1 e 7.2 mostram a interpretação de todas as posições e transições da GSPN resultante. As posições representam o início e fim da coreografia, os participantes, o início e fim do canal de comunicação nas interações, pontos de decisão e os diversos erros de acordo com o modelo de QoS. 


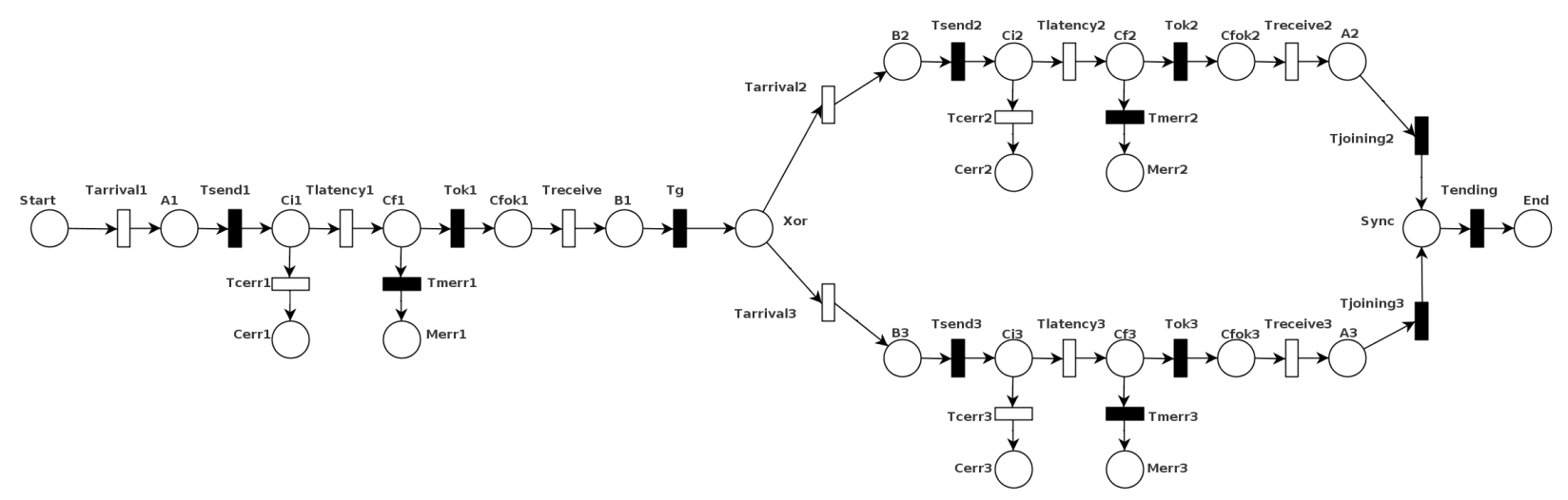

Figura 7.3: GSPN obtido da coreografia do cenário de exemplo

Tabela 7.1: Descrição das posições da GSPN resultante

\begin{tabular}{|l|l|}
\hline Posição & Descrição \\
\hline Start, End & Início e fim da coreografia. \\
$A_{1}, A_{2}, A_{3}$ & Representa ao participante "Cliente". \\
$B_{1}, B_{2}, B_{3}$ & Representa ao participante "Consultor Financeiro". \\
$C_{i 1}, C_{i 2}, C_{i 3}$ & Inicio da comunicação. \\
$C_{f 1}, C_{f 2}, C_{f 3}$ & Fim da comunicação. \\
$C_{f o k 1}, C_{f o k 2}, C_{f o k 3}$ & Formato de mensagem válido. \\
$C_{e r r 1}$ & Erro de comunicação entre A e B. \\
$C_{e r r 2}$ & Erro de comunicação entre B e A. \\
$C_{e r r 3}$ & Erro de comunicação entre B e A. \\
$M_{e r r 1}, 2,3$ & Formato de mensagem inválido. \\
Xor e Sync & Fork e Join do exclusive gateway XOR. \\
\hline
\end{tabular}

Tabela 7.2: Descrição de transições da GSPN resultante

\begin{tabular}{|c|c|}
\hline Transição & Descrição \\
\hline$T_{\text {arrival1 }}$ & Chegada de instâncias de coreografia. \\
\hline$T_{\text {arrival } 2,3}$ & Chegada de instâncias de coreografia e decisões de fluxo. \\
\hline$T_{\text {send } 1}, T_{\text {send } 2}$ e $T_{\text {send } 3}$ & Atividade e envio de mensagens. \\
\hline$T_{\text {latency } 1,2,3}$ & Latência de rede. \\
\hline$T_{\text {receive }, 2,3}$ & Recebimento de mensagem e execução do serviço. \\
\hline$T_{\text {cerr } 1,2,3}$ & Erro de comunicação. \\
\hline$T_{m e r r 1}, 2,3$ & Falha no formato da mensagem. \\
\hline & Continuação do fluxo de sequência. \\
\hline$T_{o k 1}, T_{o k 2}, T_{o k 3}$ & Mensagem válida recebida. \\
\hline$T_{\text {joining } 2,3}$ & Junção do fluxo. \\
\hline$T_{\text {ending }}$ & Final da instância de coreografia. \\
\hline
\end{tabular}

\subsubsection{Definição de pesos}

O próximo passo é definir pesos das transições de tempo e as prioridades nas transições imediatas. Esses valores dependem do conhecimento acerca do ambiente onde as coreografias serão executadas e da confiabilidade dos serviços. A Tabela 7.3 apresenta a definição dos pesos e prioridades em dois cenários, os quais serão simulados no próximo passo. O cenário 1 está configurado para ter menor chance de falhas do que o cenário 2. 
Tabela 7.3: Configuração de pesos nos Cenários 1 e 2

\begin{tabular}{|l|l|l|}
\hline & \multicolumn{2}{|c|}{ Weights } \\
\hline \multicolumn{1}{|c|}{ Transição } & Cenário 1 & Cenário 2 \\
\hline$T_{\text {latency } 1}, T_{\text {latency2 } 2}, T_{\text {latency } 3}$ & 0.99 & 0.94 \\
$T_{\text {cerr } 1}, T_{\text {cerr } 2}, T_{\text {cerr } 3}$ & 0.01 & 0.06 \\
$T_{\text {receive }}, T_{\text {receive2 } 2}, T_{\text {receive } 3}$ & 99 & 97 \\
$T_{\text {merr } 1}, T_{\text {merr } 2}, T_{\text {merr } 3}$ & 1 & 3 \\
$T_{\text {arrival } 2}, T_{\text {arrival } 3}$ & 0.5 & 0.5 \\
\hline
\end{tabular}

\subsubsection{Simulações}

Na simulação, 100 tokens foram considerados para cada cenário na Posição de Início. Cada token representa uma instância de coreografia na simulação. Assim, para cada simulação, 100 instâncias concorrentes dos cenários foram executados. As simulações dos dois cenários foram executadas várias vezes de acordo com as configurações estabelecidas na Tabela 7.3. Foram realizados 1500 disparos com 10 replicações. A ferramenta Pipe2 $\left[\mathrm{BPM}^{+} 07\right]$ foi utilizada para modelar as GSPNs e simular os cenários.

A Tabela 7.4 mostra os resultados das simulações com um intervalo de confiabilidade de $95 \%$. Os números apresentados na tabela mostram a média do número de tokens que chegaram em cada uma das Posições da GSPN.

Tabela 7.4: Resultados (em \%)

\begin{tabular}{|l|l|l|l|l|}
\hline & \multicolumn{2}{|l|}{ Média do \# de tokens } & \multicolumn{2}{l|}{ Intervalo de confiabilidade 95\% $(+/-)$} \\
\hline Place & Cenário 1 & Cenário 2 & Cenário 1 & Cenário 2 \\
\hline Start & 35.28 & 40.15 & 5.83 & 6.23 \\
End & 41.95 & 38.78 & 2.53 & 3.82 \\
$A_{1}$ & 0.08 & 0.08 & 0.00 & 0.00 \\
$B_{2}$ & 0.04 & 0.01 & 0.01 & 0.01 \\
$B_{3}$ & 0.04 & 0.01 & 0.01 & 0.01 \\
\hline$B_{1}$ & 0.08 & 3.23 & 0.00 & 0.00 \\
$A_{2}$ & 0.04 & 0.01 & 0.01 & 0.01 \\
$A_{3}$ & 0.04 & 0.01 & 0.01 & 0.01 \\
\hline$M_{\text {err } 1}$ & 0.39 & 0.91 & 0.95 & 1.92 \\
$M_{\text {err } 2}$ & 0.00 & 0.93 & 0.63 & 0.64 \\
$M_{\text {err } 3}$ & 0.00 & 0.66 & 0.87 & 0.74 \\
\hline$C_{e r r 1}$ & 0.74 & 2.94 & 0.82 & 2.02 \\
$C_{\text {err } 2}$ & 0.00 & 0.00 & 0.67 & 1.75 \\
$C_{\text {err } 3}$ & 0.78 & 0.16 & 0.92 & 1.52 \\
\hline$C_{i 1}$ & 8.32 & 8.90 & 5.33 & 7.48 \\
$C_{i 2}$ & 0.63 & 0.69 & 0.23 & 0.52 \\
$C_{i 3}$ & 0.75 & 8.90 & 0.39 & 0.21 \\
\hline
\end{tabular}

\subsubsection{Análise de Resultados}

Pelos resultados apresentados na Tabela 7.4 é possível notar que no Cenário 1, uma média de $1.52 \%\left(C_{e r r 1}+C_{e r r 2}+C_{e r r 3}\right)$ das instâncias não finalizaram o processo devido a erros de rede no momento da troca de mensagens. Além disso, uma média de $0.39 \%\left(M_{e r r 1}+M_{e r r 2}+M_{e r r 3}\right)$ das instâncias não finalizaram o processo devido a formatos de mensagens inválidos, que foram detectados quando as mensagens foram recebidas.

No cenário 2, uma média de $3.10 \%$ e $2.50 \%$ das instâncias não finalizaram o processo devido a erros na rede e a formatos de mensagens inválidos, respectivamente. Como esperado, os resultados 
estão de acordo com os parâmetros definidos para cada cenário (Tabela 7.3).

Um importante resultado com as simulações desses cenários, e que pode ser útil para desenvolvedores e administradores de rede está relacionado com a existência de gargalos na primeira interação $\left(C_{i 1}\right)$, a qual evitou que $8.32 \%$ e $8.90 \%$ das instâncias fossem enviadas pela rede. Essa informação pode afetar a modelagem e a implementação da coreografia definitiva, bem como definir novas políticas de QoS para serem configuradas na rede com o objetivo de reduzir o atraso na execução.

\subsection{Segundo conjunto de experimentos - Definição de Requisitos de QoS em Coreografias}

O objetivo dos experimentos apresentados nesta seção é analisar o comportamento do tempo de resposta total do serviço composto $W S_{1}$ em função do tamanho da resposta de $W S_{1}$ e diferentes valores de largura de banda. Para tanto, utilizam-se dois cenários definidos pelo comportamento da largura de banda da rede. O primeiro cenário possui valores de largura de banda que são fixos ao longo do tempo. O segundo cenário consiste em usar valores de largura de banda que são variáveis no decorrer do tempo representando assim a dinâmica do ambiente e a degradação por conta de falhas. A Figura 7.4 mostra como a largura de banda varia em um período de 100 segundos. Esta é a variação na simulação do segundo cenário. Essas variações foram geradas aleatoriamente.

A variável independente nos experimentos é o tamanho da resposta do serviço composto $W S_{1}$ que varia de $1 K B$ até $100 M B$. A variável dependente é o tempo médio da resposta total do serviço composto $W S_{1}$ de várias requisições simultâneas (que variam de 1 para 10 requisições) e de acordo à largura de banda da rede.

As Tabelas 7.6 e 7.7 apresentam os valores dos atributos de QoS das requisições e das respostas que são usados para as simulações. Diferente do primeiro conjunto de experimentos, estes experimento foram simulador no ChorSim, e não utilizando o Pipe2. Cada simulação consistiu na execução de instâncias de coreografia iniciadas por requisições de um cliente. Desse modo, foram realizadas 960 simulações ( 1 a 5 requisições, 120 valores de tamanhos resposta e 16 valores de largura de banda ) para cada cenário (modelo normal e variável da largura de banda). As simulações foram executadas em um computador equipado com processador Intel Core $i 7-2700 \mathrm{~K} 3.5 \mathrm{Ghz}, 16 \mathrm{~GB}$ de memória RAM rodando o sistema operacional Debian GNU/Linux versão 6.0.

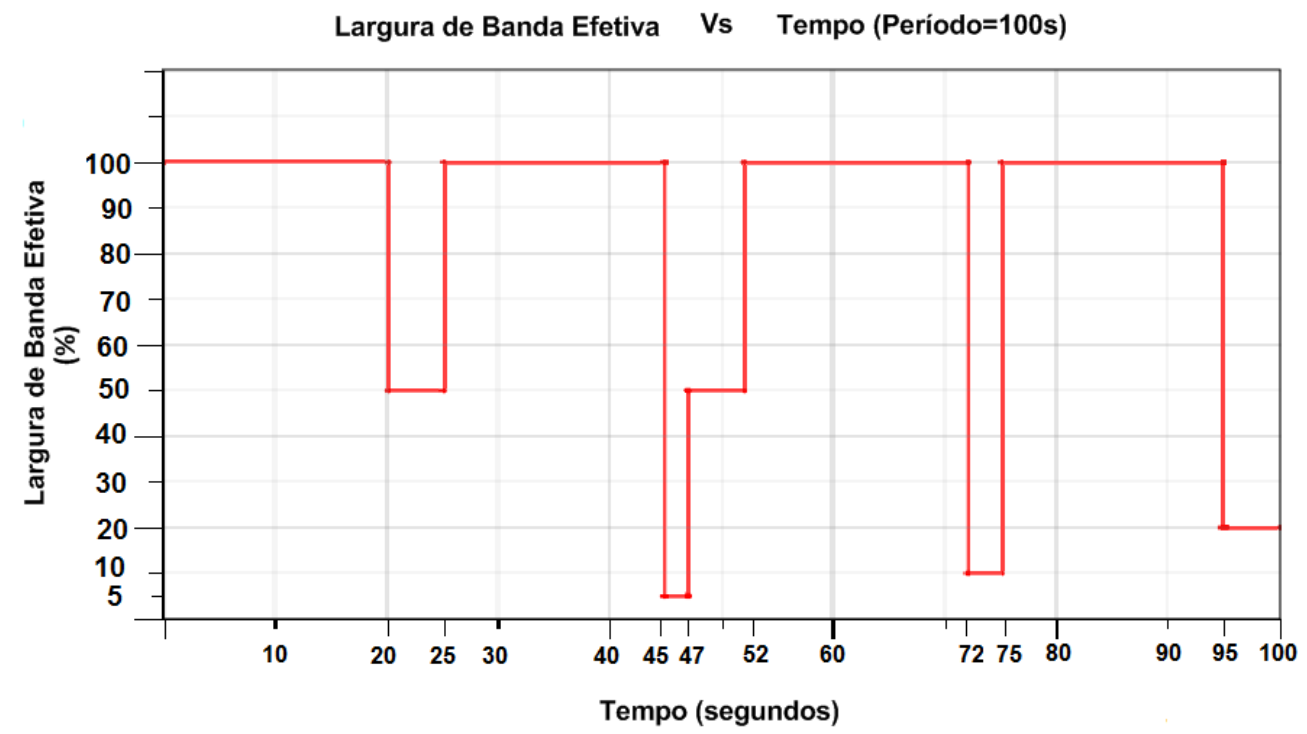

Figura 7.4: Modelo de falhas que mostra a largura de banda efetiva devido à degradação da largura de banda em um período de 100 segundos. 
Tabela 7.5: Configuração dos cenários de simulação

\begin{tabular}{|c|c|c|c|}
\hline Atributo de QoS & Condição & Valor & Tipo de Falha \\
\hline Tempo de Execução & fixo & Simulador & timeout=100000ms (tolerância) \\
Vazão & variável & $w s_{i}=1$ a 10 Requisições $/ \mathrm{ms}$ & serviço não disponível $=0.5 \%$ \\
Formato da Mensagem & $\begin{array}{c}\text { fixo } \\
\text { Latência }\end{array}$ & - & - \\
fixo & $w s=20 \mathrm{~ms}, 7 \mathrm{~ms}, 5 \mathrm{~ms}, 7 \mathrm{~ms}, 5 \mathrm{~ms}$ & Erro de comunicação=3\% \\
\hline
\end{tabular}

Tabela 7.6: Configuração de valores dos atributos de QoS nas requisições

\begin{tabular}{|l|c|c|c|c|}
\hline Requisições & Largura de banda & Tamanho da requisição & latência & \# requisições \\
\hline Cliente a $W S_{1}$ & $1 \mathrm{Mbps}$ & $1.95 \mathrm{MB}$ & $0.002 s$ & De 1 a 10 \\
$W S_{1}$ a $W S_{3}$ & $1 \mathrm{Mbps}$ & $5.47 \mathrm{MB}$ & $0.002 s$ & De 1 a 10 \\
$W S_{3}$ a $W S_{5}$ & $1 \mathrm{Mbps}$ & $5.47 \mathrm{MB}$ & $0.002 s$ & De 1 a 10 \\
\hline
\end{tabular}

Tabela 7.7: Configuração de valores dos atributos de QoS nas respostas

\begin{tabular}{|l|c|c|c|c|}
\hline Respostas & Largura de banda & Tamanho de resposta & latência & timeout \\
\hline$W S_{1}$ a $C l i e n t e$ & $1 \mathrm{Mbps}$ a $16 \mathrm{Mbps}$ & $1 \mathrm{~KB}$ a $100 \mathrm{MB}$ & $0.002 \mathrm{~s}$ & $1000 \mathrm{~s}$ \\
$W S_{3}$ a $W S_{1}$ & $20 \mathrm{Mbps}$ & $8 \mathrm{MB}$ & $0.002 \mathrm{~s}$ & $1000 \mathrm{~s}$ \\
$W S_{5}$ a $W S_{3}$ & $40 \mathrm{Mbps}$ & $200 \mathrm{MB}$ & $0.002 \mathrm{~s}$ & $1000 \mathrm{~s}$ \\
\hline
\end{tabular}

\subsubsection{Análise de Resultados}

Os gráficos das Figuras 7.5 e 7.6 mostram os resultados dos dois cenários de simulação, isto é, para o modelo normal e para o modelo variável com falhas. No modelo normal (Figura 7.5) percebe-se que o comportamento do tempo de resposta é menor quanto maior é a largura de banda, e estabiliza-se a partir de $5 \mathrm{Mbps}$ com um tempo de resposta de cerca de $150 \mathrm{~ms}$. Além disso, com valores pequenos nos tamanhos de resposta de até $30 M B$ os tempos de resposta são similares com larguras de banda a partir de $2 M b p s$. Com base nisso já pode-se definir restrições de QoS tais como, poder oferecer tempos de resposta menores que $200 \mathrm{~ms}$ desde que se tenha uma infraestrutura para suportar uma largura de banda de mais de 5Mbps.

Já no modelo variável com falhas, os tempos de resposta continuam diminuindo quanto maior é a largura de banda, mas diferente do modelo normal, neste cenário o tempo começa a se estabilizar a partir de $14 M b p s$ de largura de banda, apesar de a partir dos $8 M b p s$ os tempos de resposta serem bem próximos. Além disso, o tempo de resposta tem quase o mesmo comportamento para todos os tamanhos de resposta, diferente do modelo normal, onde para tamanhos de resposta menores que $30 M B$ podia se obter algumas vantagens. Neste cenário, houveram estouros de temporização (timeouts) com as larguras de banda de $1 M$ bps e $2 M b p s$ com mais de 2 requisições simultâneas e por conta disso essas curvas não aparecem no gráfico. Dessa maneira, as restrições de QoS estariam focadas em garantir larguras de banda mínimas maiores que $2 M b p s$ e para garantir tempos de resposta mínimos são necessários valores de largura de banda maiores que 14Mbps. 


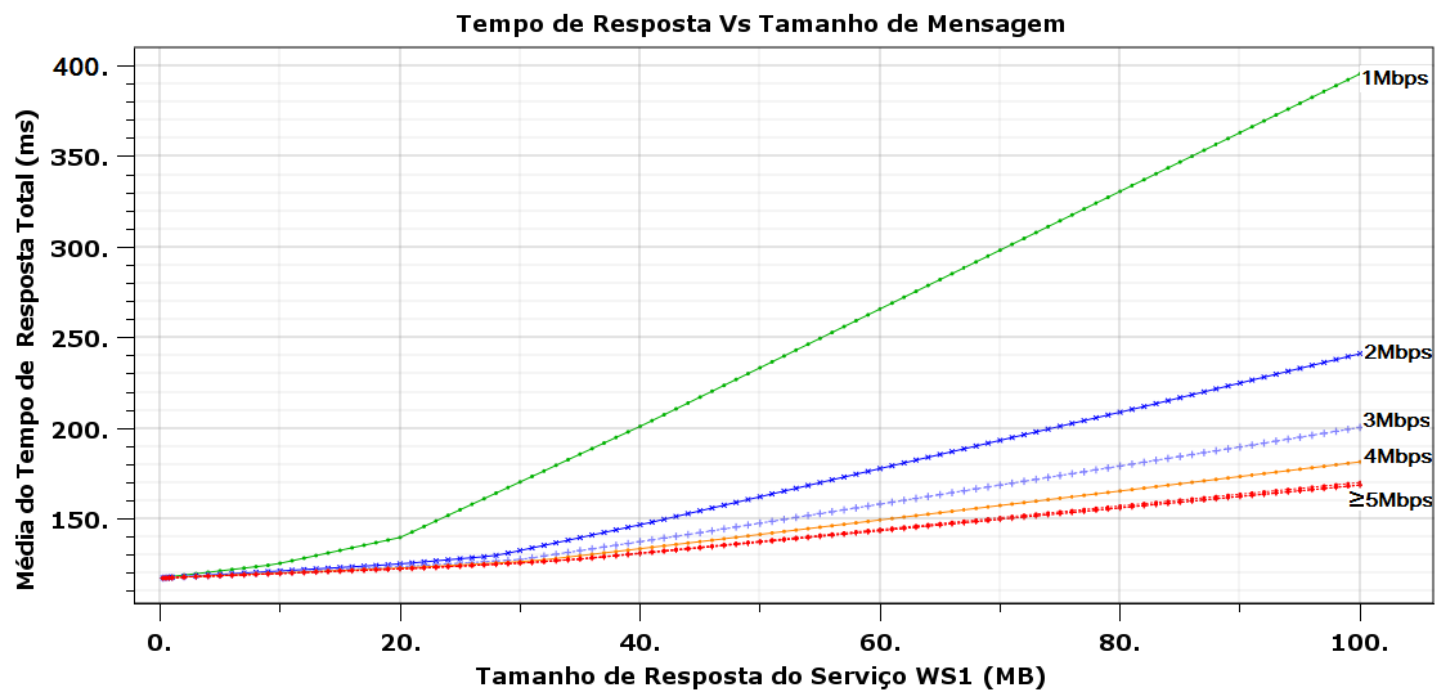

Figura 7.5: Tempo médio de resposta total da coreografia em função do tamanho de resposta do serviço WS1 com larguras de banda de 1Mbps até 16Mbps (intervalos de confiança não são visíveis por terem ficado muito pequenos).

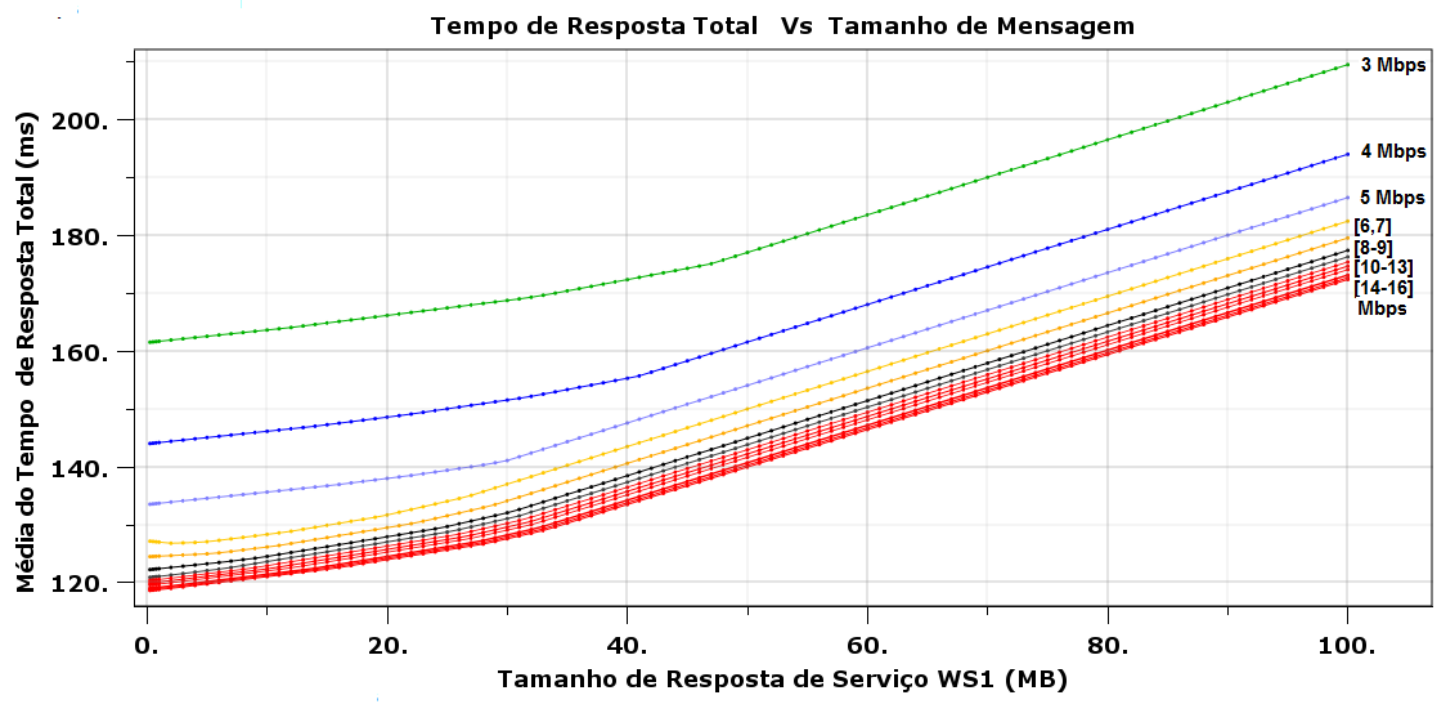

Figura 7.6: Tempo médio de resposta total da coreografia em função do tamanho de resposta do serviço WS1 segundo o modelo de falha. A largura de banda varia de 1Mbps até 16Mbps

\subsection{Terceiro conjunto de experimentos - Estabelecimento de con- tratos de QoS}

Nesta etapa, um cenário similar ao do segundo conjunto de experimentos é utilizado. A diferença está na largura de banda nas respostas de $W S_{1}$ para o cliente, que foi definida como $10 \mathrm{Mbps}$. Vamos considerar que a degradação do tempo de processamento ou execução dos serviços individuais $W S_{1}$ e $W S_{3}$ e $W S_{5}$ se comporta de acordo com distribuições exponenciais. A escolha foi feita porque não queremos considerar que há memória em relação à falhas que aconteceram no passado, o que é possível de ser simulado com uma distribuição exponencial. Para todos os serviços a taxa de degradação, que será a média da distribuição exponencial, foi considerada como 1/10000. 
Após obter por meio do ChorSim um conjunto de 5000 amostras dos tempos de resposta do serviço composto $W S_{1}$, já é possível obter a distribuição de probabilidade empírica (ECDF) $F_{w s 1}$ que represente o contrato. A Figura 7.7 mostra a ECDF obtida que representa o contrato probabilístico. Os quantis de $F_{w s 1}$ são mostrados também na Tabela 7.8.

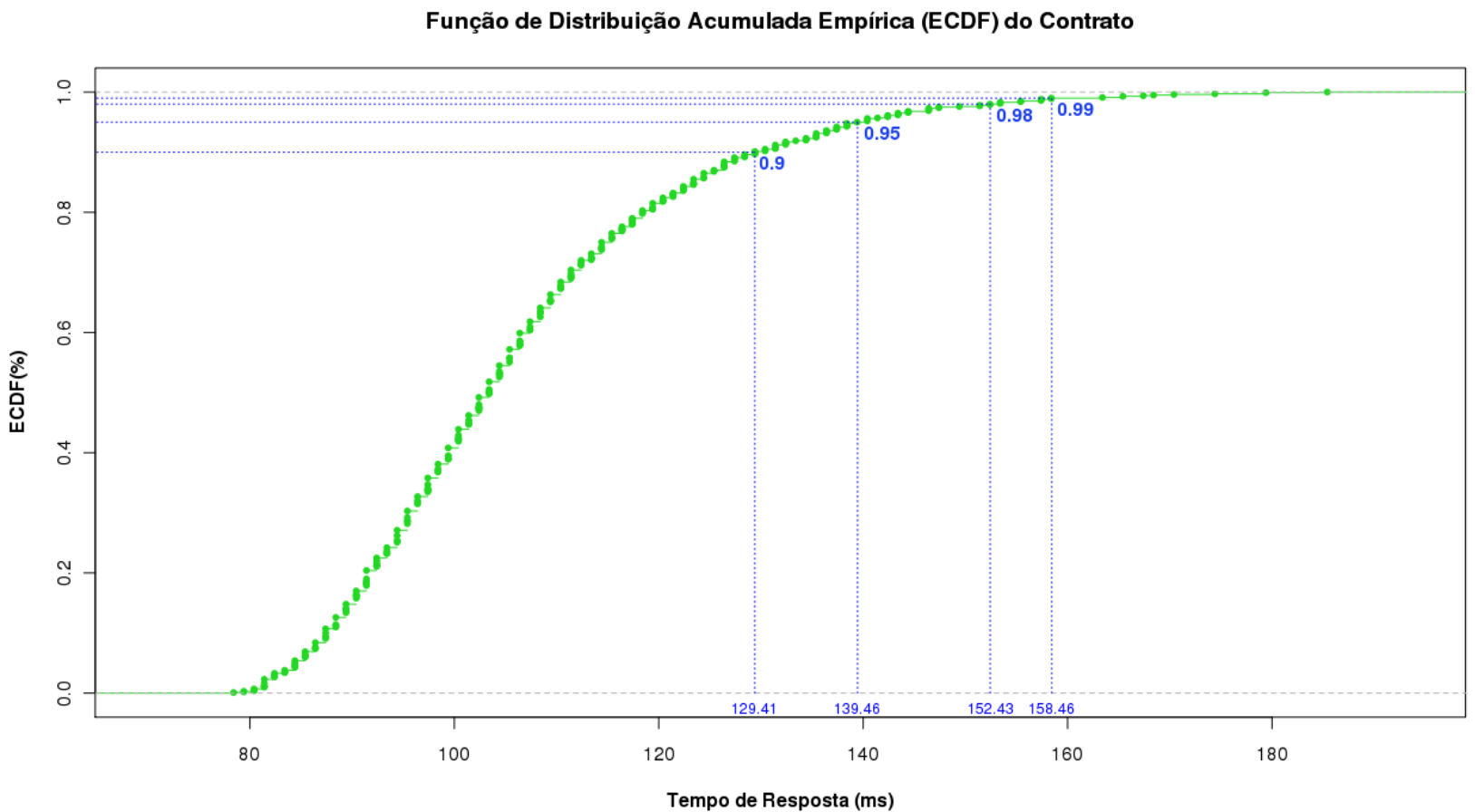

Figura 7.7: Distribuição de probabilidade empírica (ECDF) do contrato do serviço W $S_{1}$ com base nos tempos de resposta

Tabela 7.8: Quantis do contrato probabilístico dos tempos de resposta de $W S_{1}$.

\begin{tabular}{|c|c|}
\hline Quantis & Tempo de Resposta \\
\hline $90 \%$ & $129.4052 \mathrm{~ms}$ \\
$95 \%$ & $139.4552 \mathrm{~ms}$ \\
$98 \%$ & $152.4252 \mathrm{~ms}$ \\
$98 \%$ & $158.4552 \mathrm{~ms}$ \\
\hline
\end{tabular}

\subsection{Quarto conjunto de experimentos - Monitoramento de QoS em Coreografias}

\section{Configuração}

Além de ter estabelecido o contrato probabilístico e antes de começar o processo de monitoramento precisa-se configurar alguns outros parâmetros, tais como o tamanho da janela de amostras $N$, o desvio da janela de amostras $p$, e os parâmetros relacionados à regra de cumprimento de garantia de QoS.

A Tabela 7.9 mostra os valores utilizados para os parâmetros a usar no monitoramento. A regra específica para o cumprimento de garantia de QoS precisa definir os parâmetros de zona de tolerância $\lambda$ e o nível de significância $\alpha$. Desse modo, a regra de garantia fica da seguinte forma:

$$
\text { verify }\left(X_{\text {monitoring }}\right)= \begin{cases}\text { true }, & \text { se } p^{+}>=0.05 \wedge D^{+}<0.15 \\ \text { false, }, & \text { de outra maneira }\end{cases}
$$


Onde $X_{\text {monitoring }}$ é o conjunto de amostras dos tempos de resposta do serviço composto $W S_{1}$. Para habilitar um monitoramento sequencial e on-line precisa-se computar um conjunto de amostras sequenciais de tamanho $N$ que se sobrepõem. Assim, o conjunto de janelas de amostras a monitorar seria: $\{1, \ldots, N\},\{p, \ldots, p+N\}, \ldots,\{m p, \ldots, m p+N\}$, e assim por diante, onde $p<=N$ e $m=1,2, \ldots$. O tamanho de amostras $(N)$ para realizar a deteç̧ão é de 100, e o desvio $p$ é 1 .

Tabela 7.9: Definição de valores na configuração para o monitoramento.

\begin{tabular}{|c|c|}
\hline Parâmetro & Valor \\
\hline$\lambda$ & 0.15 \\
$\alpha$ & 0.05 \\
$N$ & 100 \\
$p$ & 1 \\
\hline
\end{tabular}

\section{Detecção de violações de SLA}

Para mostrar a eficácia da abordagem de deteç̧ão de violações de SLA na etapa de monitoramento, desenvolveu-se diversos cenários de modo a apresentar diversos comportamentos nos tempos de resposta e na detecção de violações do contrato estabelecido. Tais cenários são caracterizados pela configuração de valores das taxas de degradação do tempo de execução dos serviços $W S_{1}$, $W S_{3}$ e $W S_{5}$. A Tabela 7.10 mostras os valores das taxas de degradação dos serviços Web para quatro cenários, onde do primeiro até o terceiro cenário há taxas de degradação maiores do que as degradações que foram usadas para o estabelecimento do contrato, mas que vão se aproximando como no terceiro cenário. O quarto cenário possui taxas de degradação de desempenho que são um pouco menores do que as usadas no estabelecimento do contrato.

Tabela 7.10: Estabelecimento das taxas de degradação de tempo de processamento dos serviços para os cenários.

\begin{tabular}{|c|c|c|c|}
\hline & \multicolumn{3}{|c|}{ Taxa de degradação $(\lambda)$} \\
\hline Cenário & $W S_{1}$ & $W S_{3}$ & $W S_{5}$ \\
\hline Cenário 1 & $1 / 13000$ & $1 / 12500$ & $1 / 11500$ \\
Cenário 2 & $1 / 12000$ & $1 / 11000$ & $1 / 12000$ \\
Cenário 3 & $1 / 10500$ & $1 / 10000$ & $1 / 10500$ \\
Cenário 4 & $1 / 9000$ & $1 / 10000$ & $1 / 9000$ \\
\hline
\end{tabular}

Para cada um dos quatro cenários, foram executadas simulações de 1000 requisições para o serviço composto $W S_{1}$. Além disso, a topologia e configuração da implantação (largura de banda, latência, capacidade de processamento, etc) é a mesma como definida no estabelecimento de contrato probabilístico. Os gráficos 7.8, 7.9, 7.10 e 7.11 mostram as distâncias $(D)$ e os $p^{+}$-values do teste de Kolmogorov-Smirnov utilizado na detecção de violações do contrato e ressalta-se os valores de $\lambda$ e $\alpha$ com uma linha horizontal vermelha para cada um. Esses gráficos mostram a distância do teste de Kolmogorov, o qual mostra o quanto flutua a distribuição dos tempos de resposta em relação ao contrato e de acordo com a regra (7.1) deve ser menor que 0.15 para ser cumprida. Os gráficos também mostram os $p^{+}$-values para cada uma das requisições realizadas, e de acordo com a regra em (7.1) devem ser maiores ou iguais que 0.05 para cumprir o contrato. 

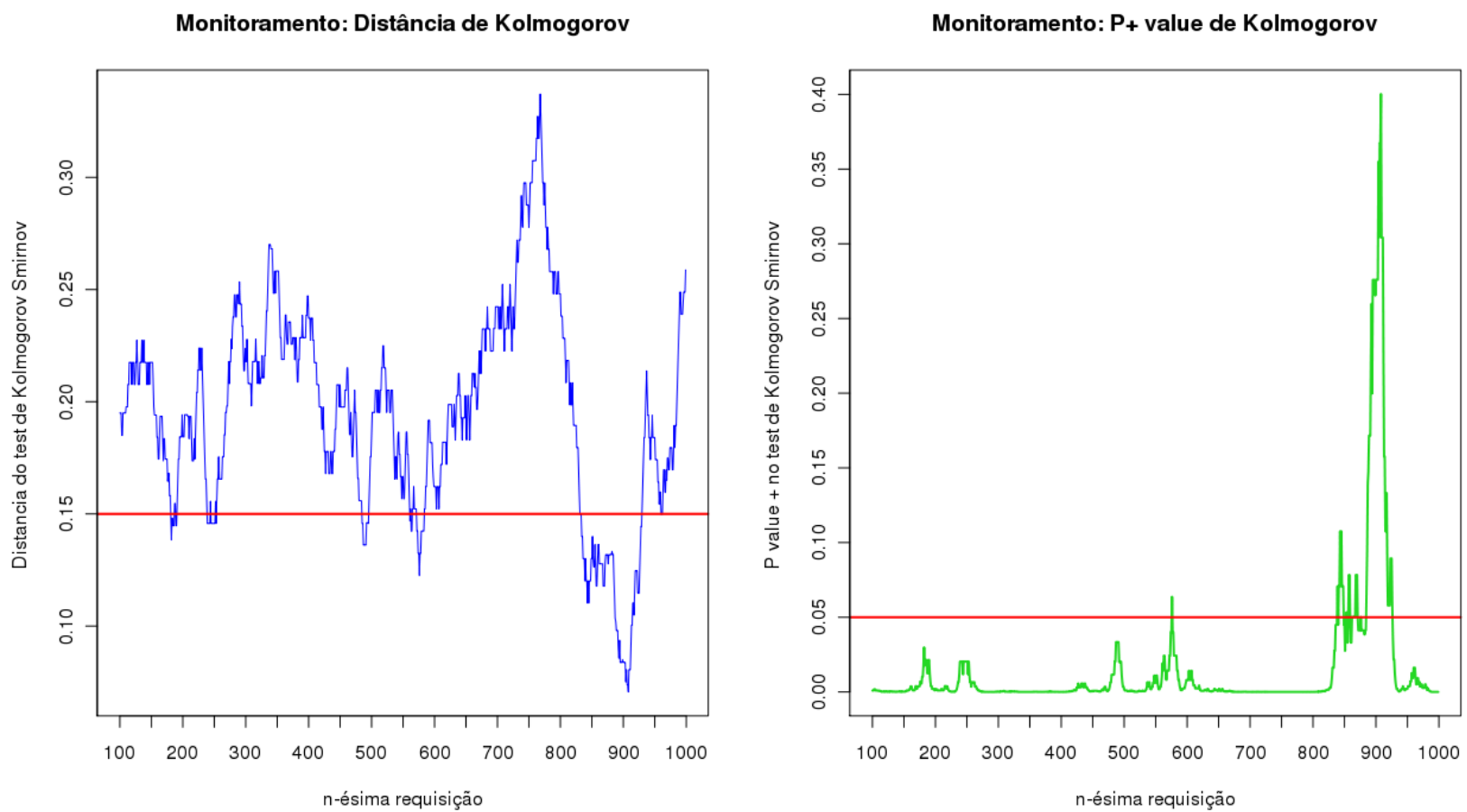

Figura 7.8: Monitoramento e detecção de violações de SLA para o cenário 1.
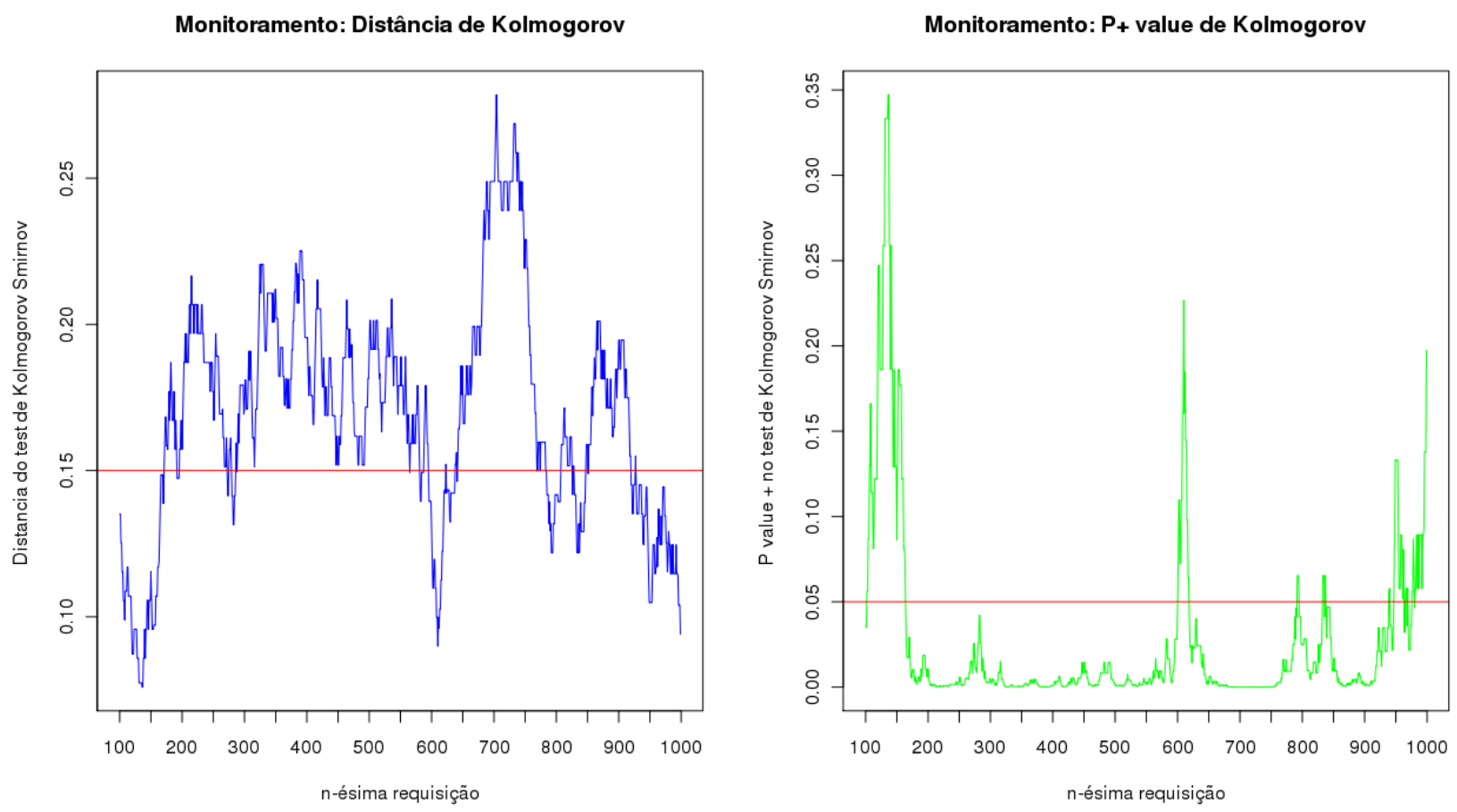

Figura 7.9: Monitoramento e detecção de violações de SLA para o cenário 2 

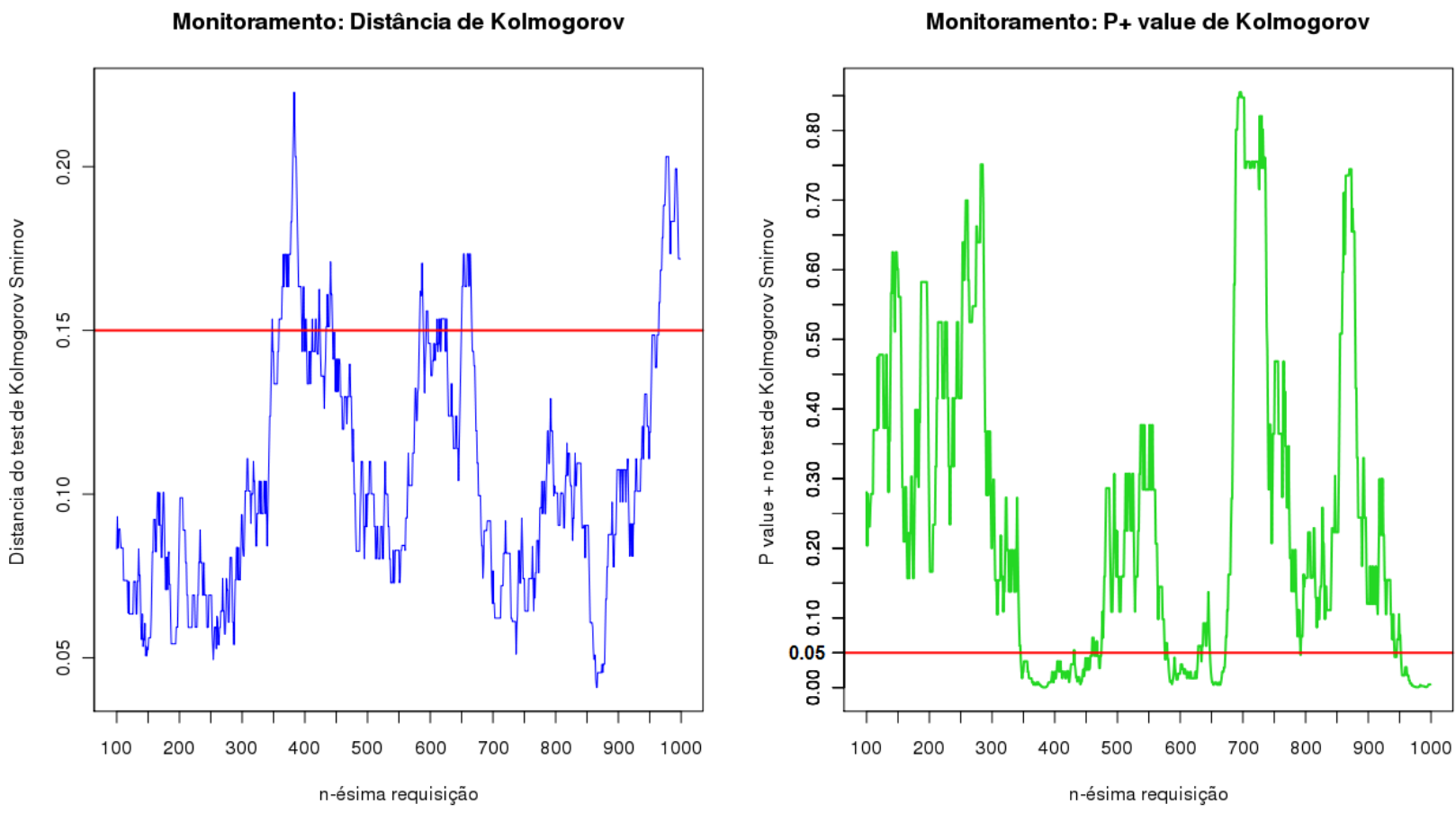

Figura 7.10: Monitoramento e detecção de violações de SLA para o cenário 3
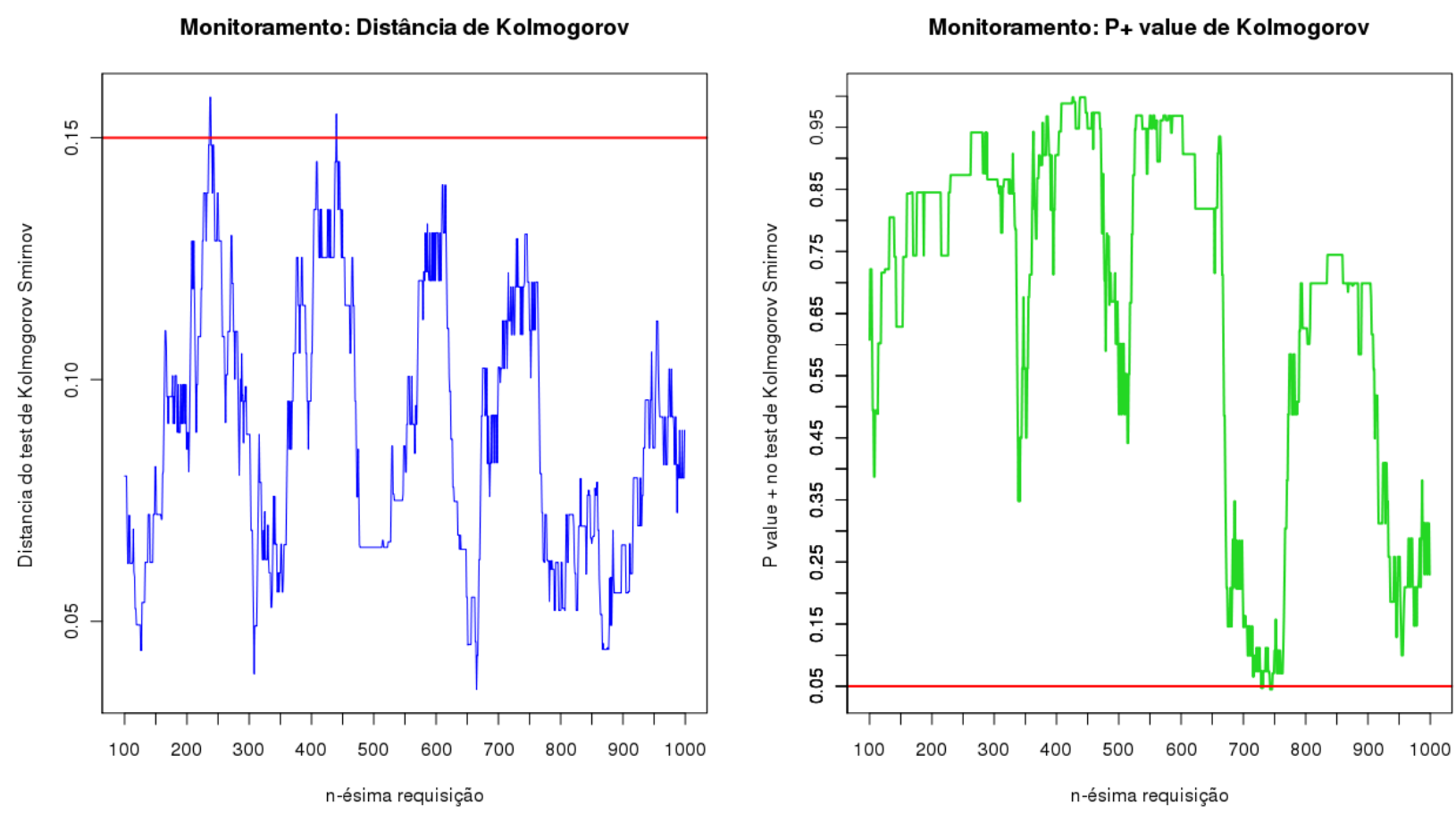

Figura 7.11: Monitoramento e detecção de violações de SLA para o cenário 4

No cenário 1 houve violações do contrato em $92.33 \%$ dos casos, o que se evidencia pelos vários $p$ values menores do que 0.05 e flutuações maiores do que a zona de tolerância $\lambda$ definida. O contrato foi garantido apenas no intervalo entre as requisições 839 e 926, onde as flutuações tem maior queda e os p-values atingem valores altos. No cenário 2 houve violações em $85.33 \%$ dos casos, onde o contrato foi garantido poucas vezes e principalmente nos intervalos das requisições de 103 a 163 , de 601 a 618 e de 947 a 1000. Como no primeiro cenário, as requisições que cumpriram com o contrato coincidem em lugares onde há flutuações com picos baixos e p-values com picos altos.

Diferente dos cenários anteriores, o cenário 3 apresenta violações 
de contrato em menos casos $(28.22 \%$ dos casos).

No cenário 4 não aconteceram violações de contrato nas 1000 requisições que foram realizadas. Dessa vez não houve p-values menores que 0.05 ,

e nem flutuações maiores que 0.15 representadas pelas distâncias $\left(D^{+}\right)$. Conforme era esperado, o contrato foi garantido já que os serviços individualmente

tinham menor tempo de processamento do que no contrato.

Além do mais, os resultados na detecção de violações de contrato

nos quatro cenários teriam

sido os mesmos se a regra de detecção tivesse levado em consideração só um dos parâmetros $D^{+}$ ou $p$-value.

Porém, precisa-se de cenários que envolvam diversos comportamentos nos tempos de processamento dos serviços para saber quais parâmetros e quais valores

usar na definição de uma regra de detecção de violações de SLA.

\subsection{Considerações Finais}

scripts dos experimentos foram escritos em bash para repetirs $\mathrm{R}$ para a visualizacao

validacoes estudo experimental limitacoes

Neste capítulo apresentaram-se os experimentos e suas análises correspondentes das três etapas propostas. Os experimentos realizados envolveram simulações usando Redes de Petri Estocásticas Generalizadas apenas na Etapa 1 e o ChorSim em todas as etapas.

As avaliações de desempenho baseadas nas simulações usando GSPNs na etapa 1 (definição de requisitos) no cenário 1 serviram para mostrar a quantidade relativa de instâncias de coreografias que conseguiram finalizar e quantas não. Os resultados permitem conhecer a porcentagem de erros na comunicação, consistência das mensagens e gargalhos nas trocas de mensagens. Com essas informações, a modelagem, implementação da coreografia, o planejamento de capacidade de recursos (como a rede) podem ser ajustadas de acordo com as politicas de QoS a serem atingidas.

$\mathrm{Na}$ etapa 1 também se realizaram experimentos, mas dessa vez usando o simulador ChorSim. O objetivo desses experimentos foi obter mais informações acerca do impacto da largura de banda no tempo de resposta total. Para tanto, dois tipos de comportamentos de larguras de banda foram levadas em consideração (uma constante e a outra variável) para dar suporte à transferência de diversos tamanhos de mensagens. Com larguras de banda constantes, o comportamento do tempo de resposta total do serviço composto alvo se estabiliza com larguras de banda a partir de $5 \mathrm{Mbps}$. Já no cenário com larguras de bandas variáveis, o comportamento do tempo de reposta total se estabiliza com larguras de banda a partir de 14Mbps. Em ambos os casos os resultados forneceram valores de largura de banda que podem ser considerados como requisitos minimos para atingir e prover um tempo de resposta estável para o seus clientes, o que implicaria também planejar os recursos de rede para garantir a qualidade.

Na etapa 2, os experimentos têm o intuito de estabelecer os contratos de QoS (SLAs) usando o procedimento descrevido no Capítulo 6. Para tanto, precisou-se de estabelecer o tempo de processamento dos serviços por meio de distribuições de probabilidade exponenciais de modo a obter comportamentos dinâmicos que decaem no tempo. Assim, a distribuição estimada do serviço composto alvo representa o contrato que será referenciado nos experimentos de monitoramento.

Na etapa 3, monitoramento e detecção de violações de contrato, usou-se quatro cenários cujos serviços possuem tempos de processamento com diversas taxas de degradação. Desse modo, obteve-se comportamentos dos tempos de resposta total melhores e piores do que o comportamento referencial do contrato da etapa anterior, isto é, garantias ou violações de contrato. A técnica de detecção de violações do contrato está baseada em uma regra que envolve os parâmetros $D^{+}$(distância de Kolmogorov) e $p^{+}$( $p$-value). Porém, baseado nos resultados dos experimentos, percebe-se que a detecção poderia se basear em apenas um parâmetro $\left(D^{+}\right.$ou $\left.p^{+}\right)$, já que usados independentemente oferecem resultados bem próximos. Trabalhos futuros poderiam considerar propor a melhor forma de estebelecer a regra de detecção de violações, e em geral, obter a configuração mais adequada 
para o monitoramento. Desse modo, diversos experimentos foram realizados para mostrar a eficácia das técnicas e mecanismos propostos nas três etapas até chegar no monitoramento de coreografias de serviços Web. 


\section{Capítulo 8}

\section{Conclusões}

Neste Capítulo final da dissertação, são apresentadas as principais considerações finais, contribuições do trabalho e sugestões para futuros trabalhos acerca desta pesquisa.

\subsection{Considerações Finais}

A presente pesquisa apresentou diversas abordagens e técnicas das etapas que abrangem da definição de requisitos de QoS, estabelecimento do contrato de SLA, até o monitoramento com a detecção de violações de contrato em coreografias de serviços Web, que é o objetivo principal. No desenvolvimento de todas as etapas se levou em consideração o modelo de interação de coreografias e padrão BMPN 2 que o suporta.

$\mathrm{Na}$ definição de requisitos de QoS em coreografias apresentou-se uma nova metodologia para avaliar o impacto da QoS por meio de simulações em uma GSPN. A metodologia inclui um algoritmo para mapear uma especificação de coreografia para uma GSPN que possui características para QoS. Desse modo, conseguiu-se achar falhas na comunicação, na integridade das mensagens e gargalos em diversos pontos das interações entre serviços em etapas antecipadas como a modelagem.

Os objetivos foram atingidos por meio de simulações de coreografias. Construiu-se um simulador de coreografias com suporte de QoS chamado de ChorSim. A construção do simulador leva em consideração elementos do modelo de interação de coreografias (atividades de coreografia, gateways, entre outros) que é oferecido no padrão BPMN2. O simulador permite rodar coreografias, realizar medições de atributos de QoS atômicos e compostos, e possui um monitoramento para acompanhar a execução das instâncias de coreografias. Dessa maneira, foi possível simular comportamentos que atualmente não podem ser realizados pela falta de implementações maduras e que permitam realizar pesquisas em coreografias de serviços Web, especialmente as relacionadas com QoS e monitoramento. Atualmente o simulador de coreografias já suporta o estabelecimento do tempo de processamento nos serviços por meio de distribuições de probabilidade. Porém, os atributos de QoS relacionados com comunicação (largura de banda, latência, entre outros) ainda não possuem essa característica porque o Simgrid não a suporta.

Assim, a definição de requisitos de QoS se atingiu com base nos resultados das simulações usando ChorSim usando cenários com diferentes comportamento na largura de banda e observando seu impacto no tempo de resposta total. A partir dos resultados das simulações se estabelecer requisitos e restrições de QoS de maneira a definir SLAs iniciais.

O estabelecimento do contrato probabilístico foi possível porque se conseguiu definir o tempo de processamento por meio de distribuições de probabilidade. No estabelecimento do contrato probabilístico e no monitoramento para detecção de violações de SLA se utilizaram taxas de degradação do desempenho por meio de distribuições exponenciais. Na etapa de monitoramento a configuração de diversas taxas de degradação permitiram definir cenários para mostrar a eficácia da abordagem de detecção de violações de contrato de QoS. Assim, a deteç̧ão de violações de SLA está baseada no uso do teste de Kolmogorov-Smirnov de apenas um lado, o qual permite calcular quão próxima uma distribuição qualquer está de outra. Os resultados nessa última etapa foram consistentes com 
as taxas de degradação definidas para os diversos cenários.

Finalmente, os resultados não foram comparados com outras propostas já que coreografia de serviços Web é ainda uma linha de pesquisa emergente e há poucos trabalhos com relação a QoS.

\subsection{Contribuições}

As principais contribuições deste trabalho foram:

- Mecanismos para definir requisitos de QoS em coreografias de serviços Web. Para tanto, utilizaram-se duas abordagens:

- Analítica: Usando Redes de Petri Estocásticas Generalizadas (GSPN).

- Simulações: Por meio de avaliações de desempenho usando o simulador de coreografias.

- Estabelecimento de contratos probabilísticos de QoS entre os serviços em coreografias de serviços Web.

- Técnicas de monitoramento de coreografias para detectar violações de SLA com restrições de QoS probabilísticas.

- Desenvolvimento de um simulador de coreografias (ChorSim) com suporte de QoS. O ChorSim está disponível públicamente sob licença LGPL ${ }^{1}$.

- Atributos de QoS: tempo de resposta, tempo de processamento, largura de banda e latência de rede.

Em relação às publicações, até o mommento, foi produzido um artigo que envolve a primeira etapa usando a abordagem analítica:

A. P. Diaz and D. M. Batista, A methodology to define QoS and SLA requirements in service choreographies. In 2012 IEEE 17th International Workshop on Computer Aided Modeling and Design of Communication Links and Networks (CAMAD 2012), pp. 201-205, Barcelona, 2012.

\subsection{Trabalhos Futuros}

Esta pesquisa está focada em atributos QoS não determinísticos de desempenho e confiabilidade. Futuros trabalhos podem adicionar outros tipos, tais como o custo, pagamento, segurança, reputação, entre outros. Além disso, o monitoramento poderia incluir predição de QoS baseado no histórico dos valores medidos anteriormente, isto serve de base para realizar, por exemplo, auto-cura (self-healing) em vários níveis (serviços, orquestração e coreografia), melhorar a adaptação, etc.

Nesta pesquisa somente foram levados em consideração um subconjunto do total de elementos disponíveis para especificar coreografias com o padrão BPMN 2. Trabalhos futuros deveriam envolver suporte de mais elementos de coreografias de modo a poder simular completamente uma coreografia de processos.

Dado que o monitoramento baseado em QoS e SLA é a um fator chave para alavancar a adaptação, então trabalhos futuros podem considerar usar o monitoramento como base para uma ferramenta que forneça de adaptação dinâmica, reconfiguração e autocura baseada em QoS para coreografias de serviços Web.

Atualmente dá para especificar degradações do tempo de processamento dos serviços individuais por meio de distribuições de probabilidade. O suporte para realizar o mesmo com atributos de comunicação (largura de banda, latência, etc) precisará de adicionar funcionalidade no core do Simgrid mesmo.

Atualmente, no projeto $\mathrm{CHOReOS}$ está se implementando um motor de execução de coreografias, o que habilitaria a posibilidade de realizar validações dos resultados obtidos com o simulador.

\footnotetext{
${ }^{1}$ Repositório: http://github.com/choreos/ChoreographySimulator
} 
No futuro, estamos considerando utilizar diversos exemplos mais complexos de modo a a melhorar e sxtender as abordagens propostas nesta pesquisa. 


\section{Apêndice A}

\section{Especificação da coreografia para o monitoramento no ChorSim}

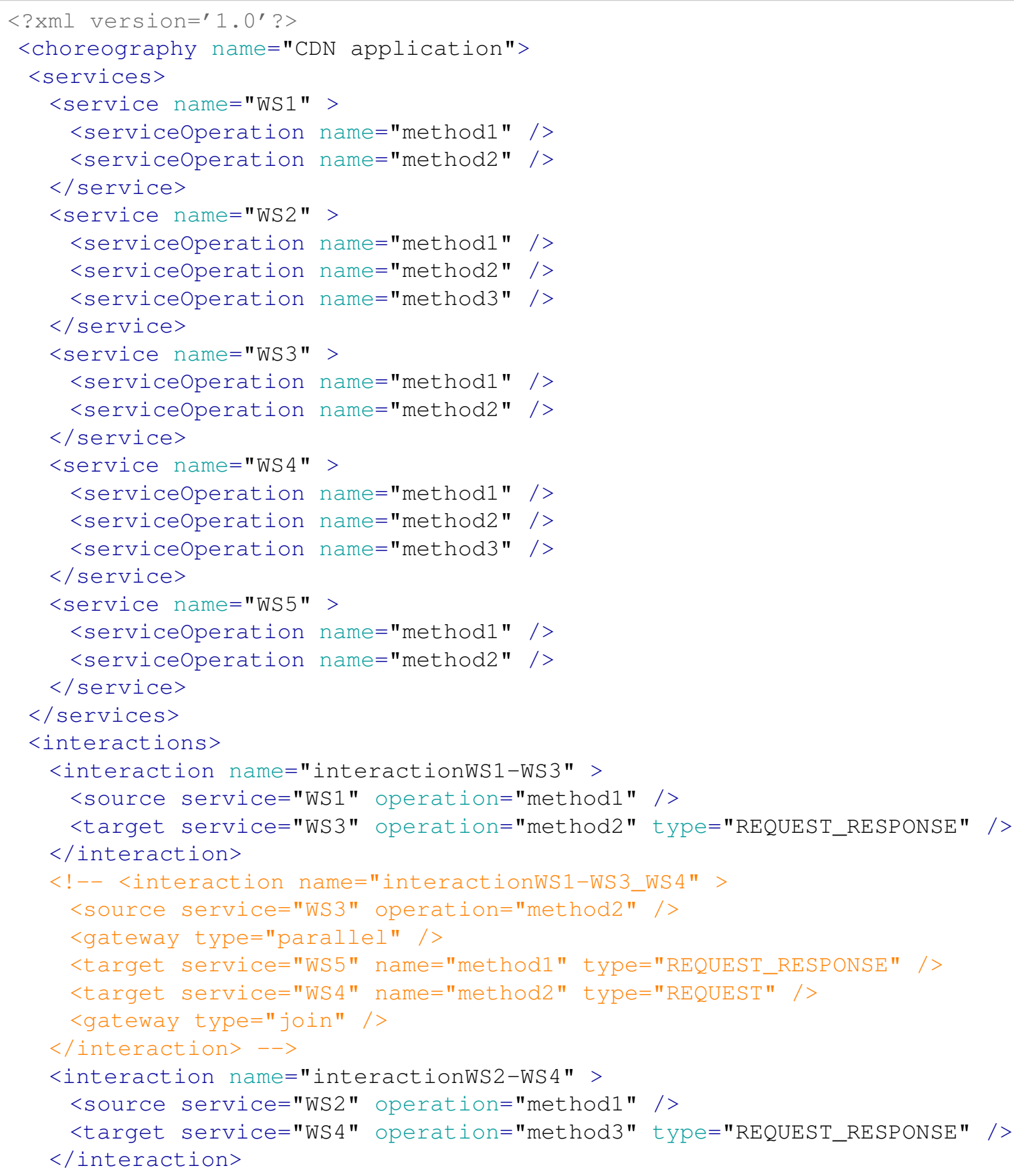




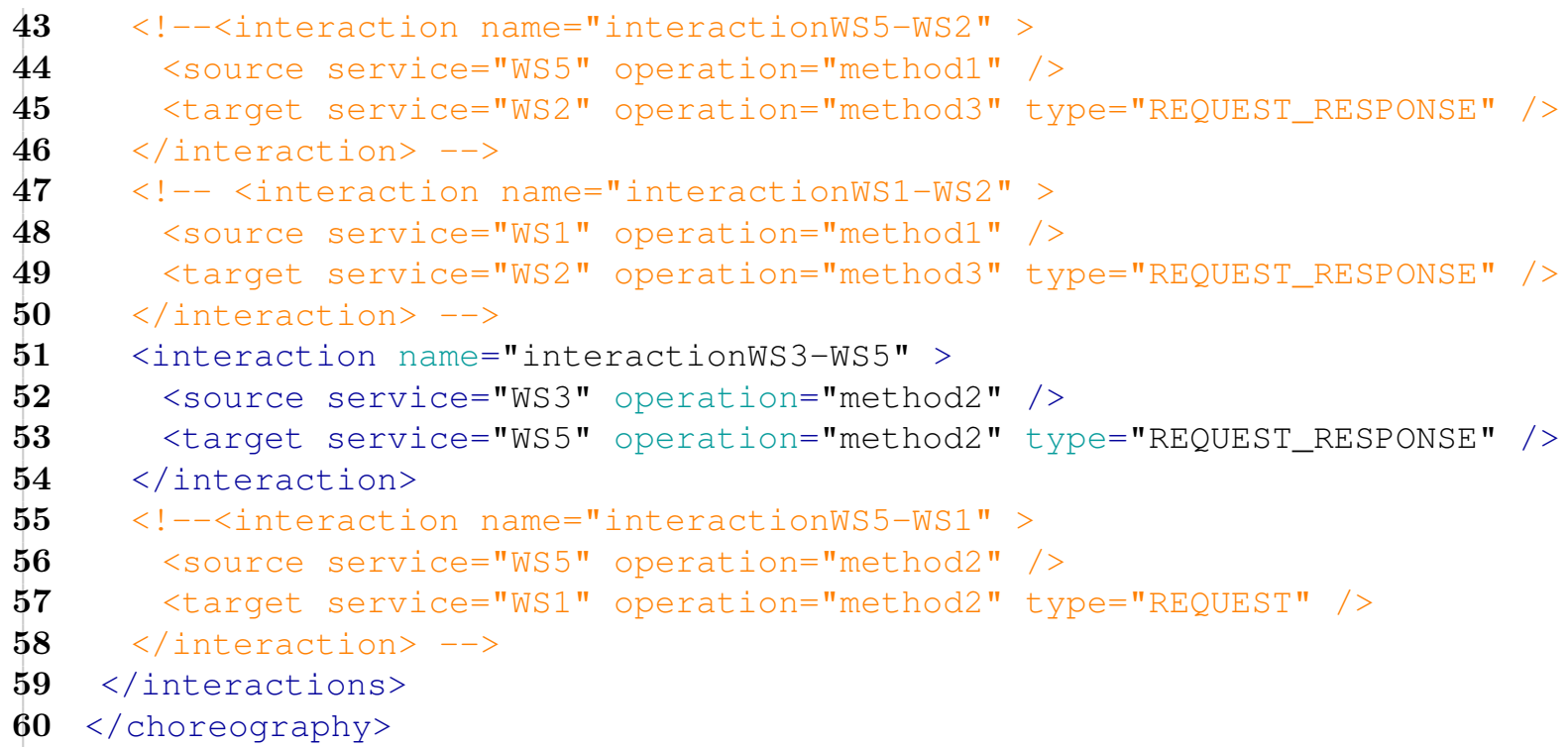




\section{Apêndice B}

\section{Configuração da plataforma para o monitoramento no ChorSim}

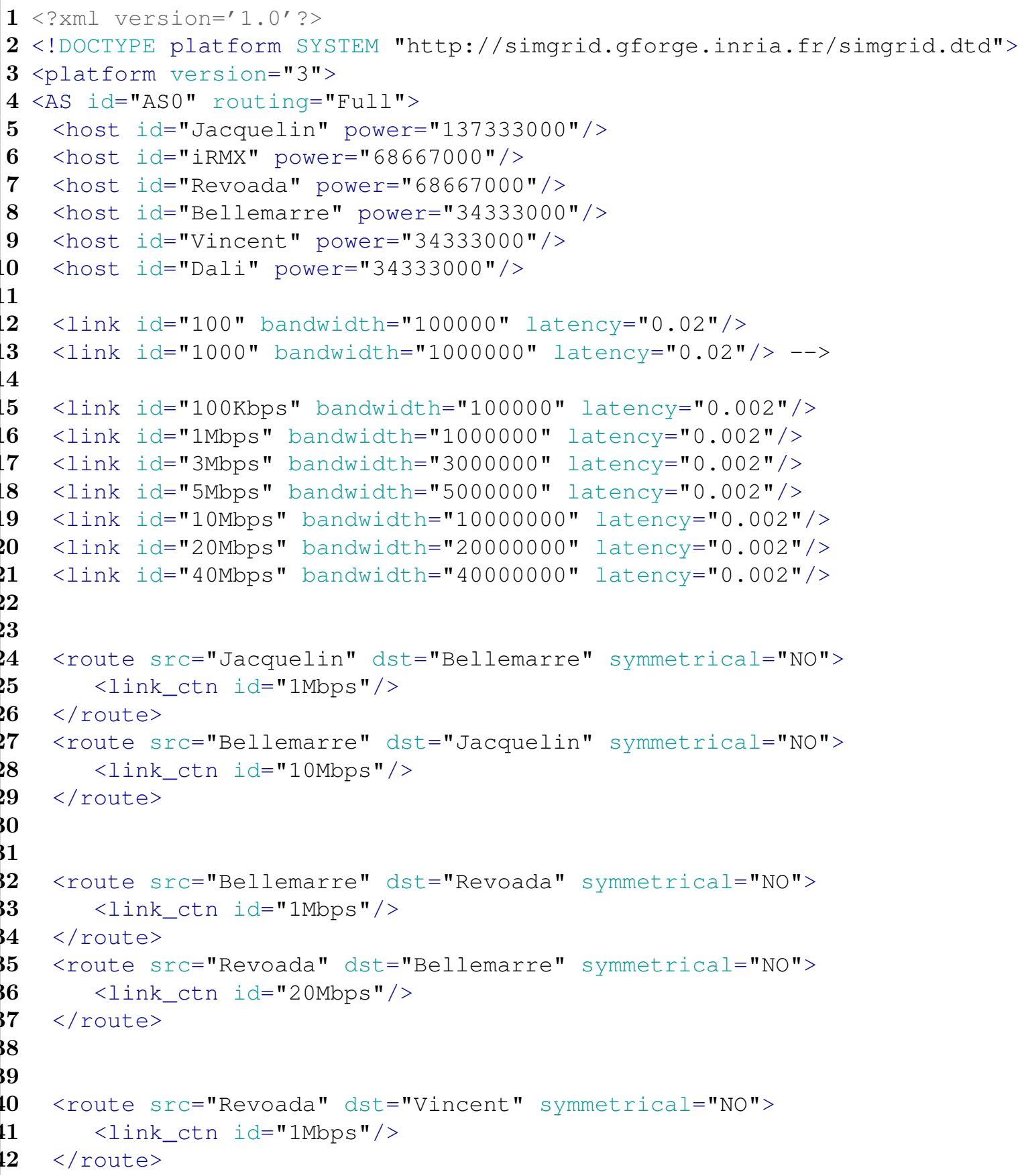




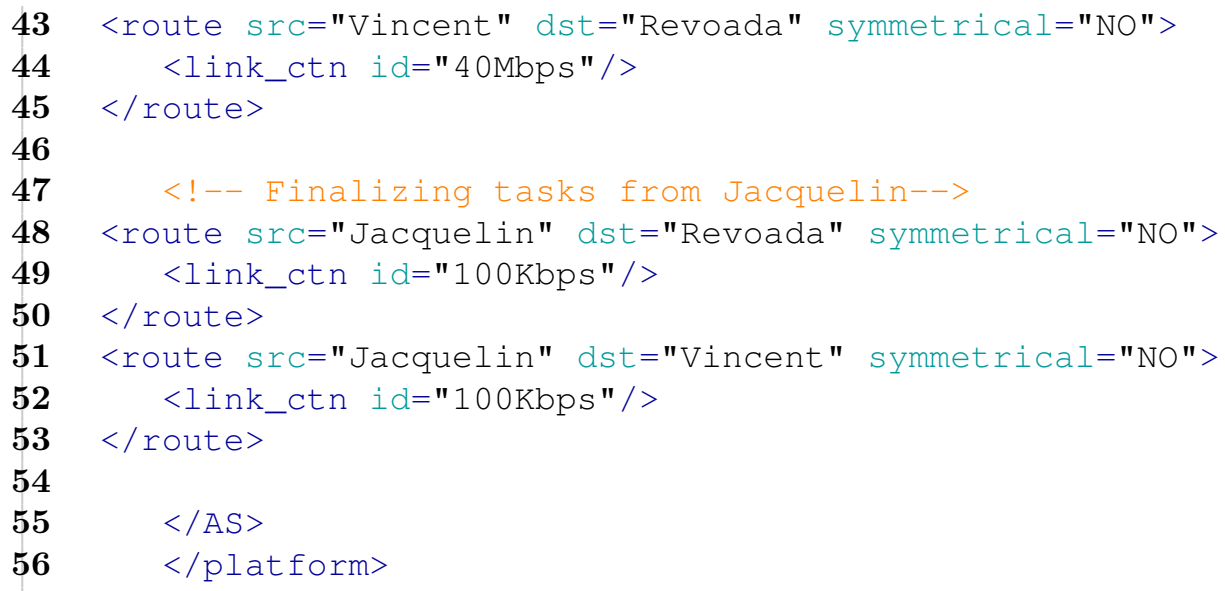




\section{Apêndice C}

\section{Configuração da implantação para o monitoramento no ChorSim}

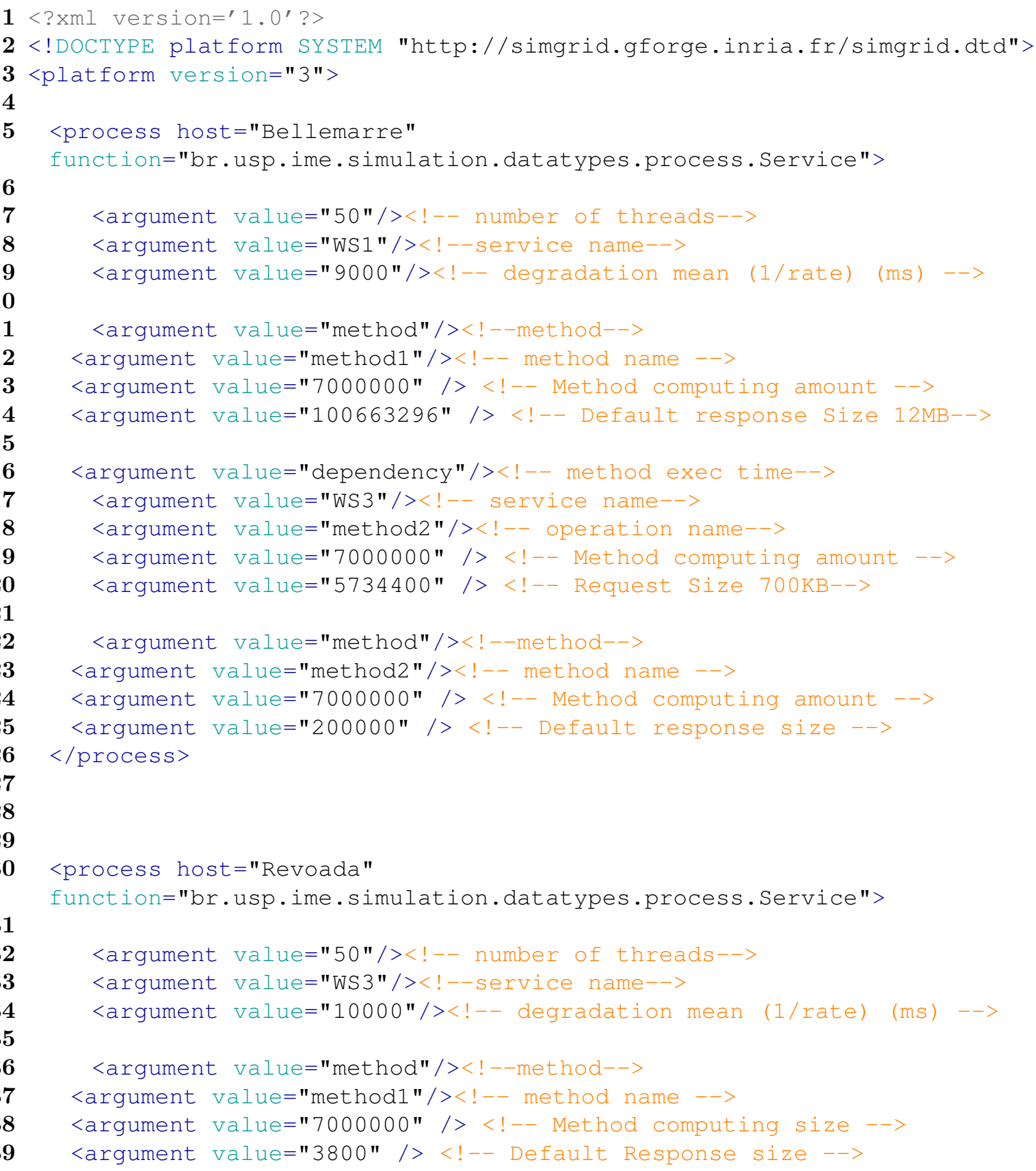




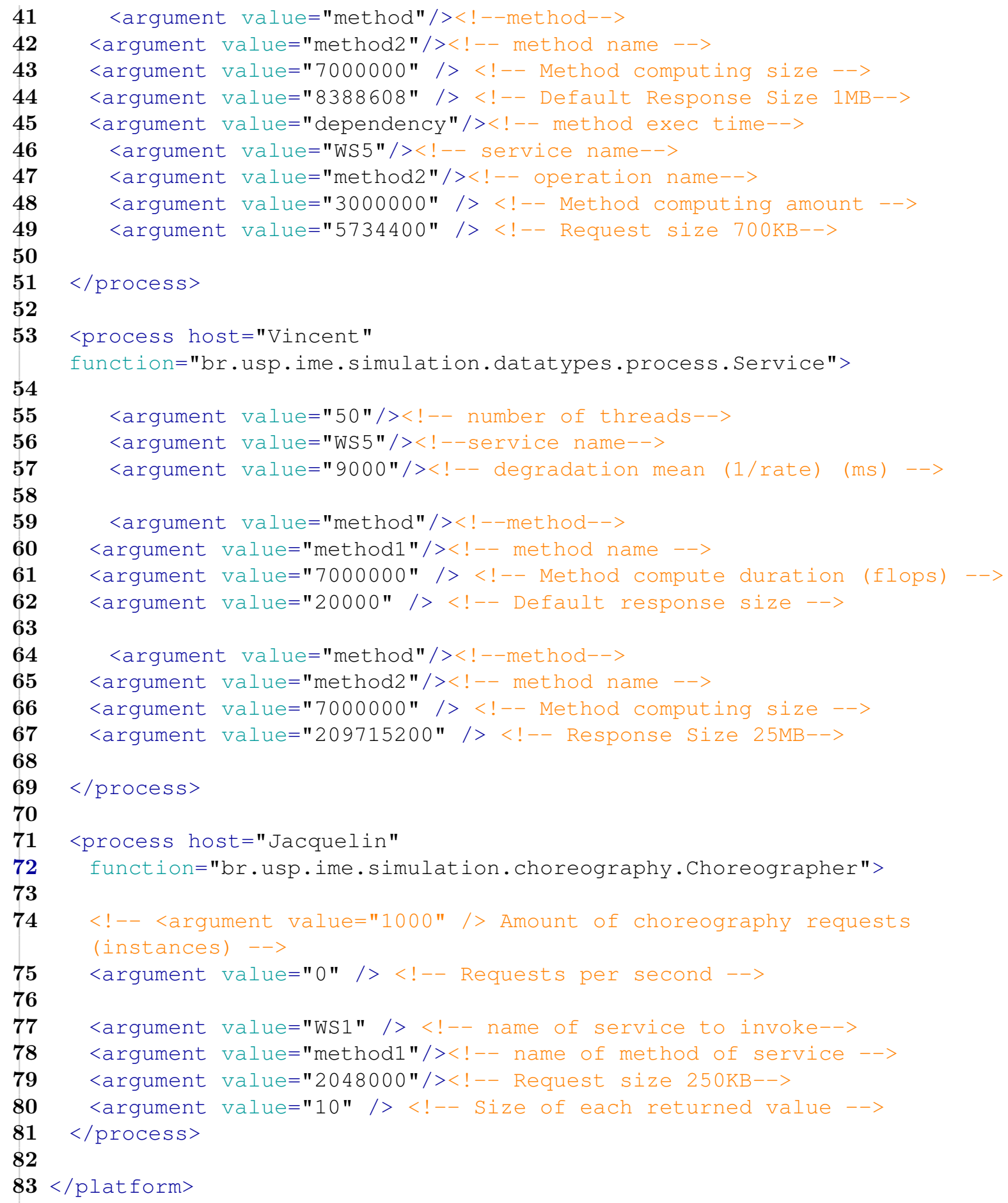

71 


\section{Referências Bibliográficas}

[ABPRT04] Daniel Austin, Abbie Barbir, Ed Peters, e Steve Ross-Talbot. Web Service Choreography Requirements, 2004. 35

[ACKM04] Gustavo Alonso, Fabio Casatu, Harumi Kuno, e Vijay Machiraju. Web Services: Concepts, Architecture and Applications. Springer-Verlag, 2004. 7

[ADHR05] W M P Van Der Aalst, M Dumas, A H M Hofstede, e N Russell. Life After BPEL ? Em Proceedings of the Formal Techniques for Computer Systems and Business Processes, volume 3670, páginas 35-50. Springer-Verlag, 2005. viii, 13, 14, 27

[BA11] Khoutir Bouchbout e Zaia Alimazighi. Inter-Organizational Business Processes Modelling Framework. Em Advanced in Databases and Information Systems ADBIS 2011, 2011. 15

[BBRW09] Adam Barker, Paolo Besana, David Robertson, e Jon B Weissman. The Benefits of Service Choreography for Data-Intensive Computing. Em In Proceedings of the 7th international workshop on Challenges of large applications in distributed environments, CLADE '09, páginas 1-10, 2009. 43

[BCdFZ10] Daniel M Batista, Luciano Chaves, Nelson L. S. da Fonseca, e Artur Ziviani. Performance Analysis of Available Bandwidth Estimation Tools for Grid Networks. The Journal of Supercomputing, 53(1):103--121, 2010. 1

$\left[\mathrm{BCG}^{+} 05\right]$ Daniela Berardi, Diego Calvanese, Giuseppe De Giacomo, Richard Hull, e Massimo Mecella. Automatic Composition of Transition-based Semantic Web Services with Messaging. 31st Intl. Conference on Very Large Databases, páginas 613-624, 2005. 17

$\left[\mathrm{BDF}^{+} 08\right]$ F Buccafurri, P Demeo, M Fugini, R Furnari, a Goy, G Lax, P Lops, S Modafferi, B Pernici, e D Redavid. Analysis of QoS in cooperative services for real time applications. Data \&3 Knowledge Engineering, 67(3):463-484, Dezembro 2008. ix, 53, 54

[BDH05] Alistair Barros, Marlon Dumas, e Arthur H M Hofstede. Service Interaction Patterns. Em Proceeedings of 3rd International Conference on Business Process Management, páginas 302-318, Nancy, France, 2005. Springer Verlag. 19, 50

[BDO05] A Barros, Marlon Dumas, e P Oaks. A critical overview of the web services choreography description language, 2005. 13, 19

[BF08] Tevfik Bultan e Xiang Fu. Specification of realizable service conversations using collaboration diagrams. IEEE International Conference on Service-Oriented Computing and Applications (SOCA), 2(1):27-39, Abril 2008. 17

[BFHS03] Tevfik Bultan, Xiang Fu, Richard Hull, e Jianwen Su. Conversation Specification: A New Approach to Design and Analysis of E-Service Composition. 12th international conference on World Wide Web (2003), páginas 403-410, 2003. 17 
[BMCC02] Rajkumar Buyya, Manzur Murshed, Caulfield Campus, e Gippsland Campus. GridSim: A Toolkit for the Modeling and Simulation of Distributed Resource Management and Scheduling for Grid Computing. CONCURRENCY AND COMPUTATION: PRACTICE AND EXPERIENCE (CCPE), 14:1175-1220, 2002. 43

[BPB ${ }^{+}$09] Paolo Besana, Vivek Patkar, Adam Barker, David Robertson, e David Glasspool. Sharing Choreographies in OpenKnowledge: A Novel Approach to Interoperability. Journal of Software (JSW), 4(8):833-842, Outubro 2009. 20

$\left[\mathrm{BPM}^{+}\right.$07] Pere Bonet, Ramon Puigjaner, Palma De Mallorca, William J Knottenbelt, South Kensington Campus, e United Kingdom. PIPE v2.5: a Petri Net Tool for Performance Modeling. Relatório técnico, 2007. 56

[BR09] Tevfik Bultan e Nima Roohi. Realizability of Choreographies using Process Algebra Encodings. Em Proceedings of the 7th International Conference on Integrated Formal Methods, number 99 in IFM 2009. LNCS 5423, páginas 1-14. Springer-Verlag Berlin, Heidelberg, 2009. 17

[Bul08] Tevfik Bultan. Service Choreography and Orchestration with Conversations. Em Proceedings of the 19th international conference on Concurrency Theory, CONCUR '08, páginas 10-11. Springer-Verlag Berlin, Heidelberg, 2008. 16

[BWR09] Adam Barker, Christopher D. Walton, e David Robertson. Choreographing Web Services. IEEE Transactions on Services Computing, 2(2):152-166, 2009. 1, 18

[CCMW01] Erik Christensen, Francisco Curbera, Greg Meredith, e Sanjiva Weerawarana. W3C Web Services Description Language (WSDL) 1.1, 2001. 7

[CDMV09] María Emilia Cambronero, Gregorio De, Enrique Martnez, e Valentn Valero. A Comparative Study between WSCI, WS-CDL, and OWL-S. Proceeedings of the IEEE International Conference on e-Business Engineering, páginas 377-382, 2009. 13

[CHY07] Marco Carbone, Kohei Honda, e Nobuko Yoshida. Structured Communication-Centred Programming for Web Services. Em Proceedings of the 16th European conference on Programming, Lecture Notes in Computer Science, páginas 1-16, Berlin, Heidelberg, 2007. Springer-Verlag. 13

[CLQ08] Henri Casanova, Arnaud Legrand, e Martin Quinson. SimGrid: a Generic Framework for Large-Scale Distributed Experiments. Em Proceedings of the Tenth International Conference on Computer Modeling and Simulation, UKSIM '08, páginas 126-131. IEEE Computer Society, 2008. 43, 44

[CRBS98] E. Crawley, R.Nair, B. Rajagopolan, e H. Sandick. RFC 2386 - A Framework for QoS-based Routing in the Internet, 1998. 26

[DB08] Gero Decker e Alistair Barros. Interaction Modeling using BPMN. Em In Proceedings of the 2007 international conference on Business process management (BPM'07), páginas 208-219. Springer-Verlag, Berlin, Heidelberg, 2008. 22

[DB12] Alfonso Phocco Diaz e Daniel M. Batista. A methodology to define QoS and SLA requirements in service choreographies. Em 2012 IEEE 17th International Workshop on Computer Aided Modeling and Design of Communication Links and Networks (CA$M A D)$, páginas 201-205. Ieee, Setembro 2012. 46

[DDO07] Remco M Dijkman, Marlon Dumas, e Chun Ouyang. Formal Semantics and Analysis of BPMN Process Models using Petri Nets. Relatório técnico, Australian Research Council under Discovery Grant DP0451092, 2007. viii, 21, 46 
[DKB08] Gero Decker, Oliver Kopp, e Alistair Barros. An Introduction to Service Choreographies. Information Technology, 50(2):122-127, Fevereiro 2008. 18, 19

[DKLW07] Gero Decker, Oliver Kopp, Frank Leymann, e Mathias Weske. BPEL4Chor: Extending BPEL for Modeling Choreographies. Em Proceedings of the IEEE International Conference on Web Services (ICWS 2007), páginas 296-303, Utah-USA, 2007. IEEE Computer Society. 14, 19

[Dou05] Andrew Douglas. WS-CDL Eclipse, 2005. 19

[EA06] Mauricio Espinoza e Pedro Alvarez. A life cycle of a composite Web service: strengths and weaknesses of current solutions. Relatório técnico, Department of Engineering and Informatic Systems, University of Zaragoza, 2006. viii, 10

[Eng09] Lasse Engler. BPEL gold: Choreography on the Service Bus. Thesis, University of Stuttgart, 2009. viii, 18

[FPR09] Maria Grazia Fugini, Barbara Pernici, e Filippo Ramoni. Quality analysis of composed services through fault injection. Vital And Health Statistics. Series 20 Data From The National Vitalstatistics System Vital Health Stat 20 Data Natl Vital Sta, (May 2008):227-239, 2009. 47

[GG11] Nawal Guermouche e France Claude Godart. Characterizing Compatibility of Timed Choreography. International Journal of Web Services Research, 8(June):2008-2010, 2011. 17

[GKB12] Felipe Pontes Guimaraes, Eduardo Hideo Kuroda, e Daniel Macedo Batista. Performance Evaluation of Choreographies and Orchestrations with a New Simulator for Service Compositions. Em Workshop on Computer-Aided Modeling Analysis and Design of Communication Links and Networks (CAMAD), páginas 140-144, 2012. 44

[HGDJ08] Riadh Ben Halima, Karim Guennoun, Khalil Drira, e Mohamed Jmaiel. Non-intrusive QoS monitoring and analysis for self-healing web services. Proceedings of the 1st International Conference on the Applications of Digital Information and Web Technologies (ICADIWT), (1):549-554, 2008. 26, 35

[Hil09] Marc Oriol Hilari. Quality of Service (QoS) in SOA Systems: A Systematic Review. Tese de Doutorado, Catalunya University, 2009. 28

$\left[\mathrm{HMG}^{+}\right.$03] Hugo Haas, Nilo Mitra, Martin Gudgin, Marc Hadley, Noah Mendelsohn, Jean-Jacques Moreau, e Henrik Frystyk Nielsen. W3C SOAP 1.2 Recommendation, 2003. 7

[HWTS07] San-Yih Hwang, Haojun Wang, Jian Tang, e Jaideep Srivastava. A probabilistic approach to modeling and estimating the QoS of web-services-based workflows. Information Sciences, 177(23):5484-5503, 2007. 34

[ISO86] ISO. SGML. Standard Generalized Markup Language, ISO 8879. 1986., 1986. 7

[JDM10] Yassine Jamoussi, Maha Driss, e La Manouba. QoS Assurance for Service-Based Applications Using Discrete-Event Simulation. IJCSI International Journal of Computer Science Issues, 7(4):11, 2010. 1

[JMS02] Li-jie Jin, Vijay Machiraju, e Akhil Sahai. Analysis on Service Level Agreement of Web Services. Relatório técnico, Hewlett-Packard Laboratorie, 2002. 32

[JTK00] By Yuming Jiang, Chen-khong Tham, e Chi-chung Ko. Challenges and approaches in providing QoS monitoring. International Journal of Network Management, 10(6):323 $-334,2000.35$ 
[KELL10] Oliver Kopp, Lasse Engler, Tammo Van Lessen, e Frank Leymann. Interaction Choreography Models in BPEL: Choreographies on the Enterprise Service Bus. Em SBPM ONE 2010 the Subjectoriented BPM Conference (2010), 2010. 1, 24, 43

[KL03] Alexander Keller e Heiko Ludwig. The WSLA Framework: Specifying and Monitoring Service Level Agreements for Web Services. Journal of Network and Systems Management, 11(1):57-81, 2003. viii, 32, 33

[KLN08] Oliver Kopp, Tammo Van Lessen, e Jörg Nitzsche. The Need for a Choreography-aware Service Bus. YR-SOC 2008, (Yrsoc), 2008. 24

[KLW10] Oliver Kopp, Frank Leymann, e Fei Wu. Mapping Interconnection Choreography Models to Interaction Choreography Models. Em 2nd Central-European Workshop on Services and their Composition, Services und ihre Komposition, ZEUS 2010., volume 563 of CEUR Workshop Proceedings, páginas 81-88, 2010. viii, ix, 22, 23, 25, 53

[KLW11] Oliver Kopp, Frank Leymann, e Sebastian Wagner. Modeling Choreographies: BPMN 2.0 versus BPEL-based Approaches. Business, 2011. 21, 22

[Kum09] Bhavish Kumar. Getting Serious about Enterprise Architecture. Relatório técnico, JBoss Savara Project, 2009. 19

[KWH07] Zuling Kang, Hongbing Wang, e Patrick C.K. Hung. WS-CDL+: An Extended WSCDL Execution Engine for Web Service Collaboration. Em Proceedings of the IEEE International Conference on Web Services (ICWS 2007), páginas 928-935. IEEE Computer Society, 2007. 19, 24, 43

[Lie11] Benedikt Liegener. Service Choreography - Definitions, 2011. 13

[LK08] Niels Lohmann e Oliver Kopp. Tool Support for BPEL4Chor Choreographies. Em Monika Solanki, Barry Norton, e Stephan Reiff-Marganiec, editors, Proceedings of the 3rd Young Researchers Workshop on Service Oriented Computing YR-SOC, páginas 74-75, London, 2008. 20

[LLM+10] An Liu, Qing Li, Senior Member, Liusheng Huang, e Mingjun Xiao. FACTS: A Framework for Fault-Tolerant Composition of Transactional Web Services. Framework, 3(1):46-59, 2010. 43

[MGI09] Nebil Ben Mabrouk, Nikolaos Georgantas, e Valerie Issarny. A Semantic End-to-End QoS Model for Dynamic Service Oriented Environments. Business, (i):34-41, 2009. 29

[MH05] Jan Mendling e Michael Hafner. From Inter-Organizational Workflows to Process Execution: Generating BPEL from WS-CDL. OTM Workshops 05, páginas 506-515, 2005. 15

[ML08] T Matheis e P Loos. Monitoring cross-organizational business processes. Em International Conference on E-Learning, E-Business, Enterprise Information Systems, and E-Government CSREA EEE, páginas 270-275, Nevada, USA, 2008. CSREA Press. 37

[MPRW10] Michele Mancioppi, Mikhail Perepletchikov, C Ryan, e WJ. Towards a Quality Model for Choreography. Em Proceedings of the 2009 International Conference on ServiceOriented Computing, ICSOC/ServiceWave'09, páginas 435-444, Stockholm, Sweden, 2010. Springer-Verlag. 16, 17

[MRLD09] Anton Michlmayr, Florian Rosenberg, Philipp Leitner, e Schahram Dustdar. Comprehensive QoS monitoring of Web services and event-based SLA violation detection. Proceedings of the 4 th International Workshop on Middleware for Service Oriented Computing - MWSOC '09, páginas 1-6, 2009. viii, 26, 27, 32, 35 
[MSDC12] Daniele Miorandi, Sabrina Sicari, Francesco De Pellegrini, e Imrich Chlamtac. Internet of things: Vision, applications and research challenges. Ad Hoc Networks, 10(7):14971516, Setembro 2012. 12

[New02] Eric Newcomer. Understanding Web Services: XML, WSDL, SOAP, and UDDI. Addison-Wesley Longman Publishing Co., Inc. Boston, MA, USA, 2002. 5

[NF10] O M G Document Number e P D F Associated File. BPMN 2.0 by Example. 2010. viii, 23,24

[OLAR09] Cesar Oliveira, Ricardo Lima, Thiago Andre, e Hajo A Reijers. Modeling and Analyzing Resource-Constrained Business Processes. Em Systems, Man and Cybernetics, 2009. SMC 2009. IEEE International Conference on, páginas 2824-2830. IEEE Computer Society, 2009. 46

[Pan10] Ravi Shankar Pandey. A Meta-Model Based Proposal for QOS of WSCDL Choreography. Em Proceeedings of the International MultiConference of Engineering and Computer Scientists IMECS 2010, volume I, páginas 2-8, Hong Kong, 2010. Newswood Limited. viii, 31, 35, 36

[PC08] Ravi Shankar Pandey e B D Chaudhary. A Cost Model for Participating Roles Based on Choreography Semantics. Proceedings of the IEEE Asia-Pacific Services Computing Conference, páginas 277-283, 2008. 35, 36

[PDKL08] Kerstin Pfitzner, Gero Decker, Oliver Kopp, e Frank Leymann. Web Service Choreography Configurations for BPMN. Architecture, 2008. 21

[Pel03] C. Peltz. Web services orchestration and choreography. Computer, 36(10):46-52, 2003. viii, 15

[Pel05] Vicente Pelechano. Web Services Standards, Extensions and Future Prospects. Relatório técnico, Department of Information Systems, University of Valencia, Valencia, 2005. viii, 7,8

[PH07] Mike P. Papazoglou e Willem-Jan Heuvel. Service oriented architectures: approaches, technologies and research issues. The VLDB Journal, 16(3):389-415, Março 2007. 8

[PML09] Yu-Yen Peng, Shang-Pin Ma, e Jonathan Lee. REST2SOAP: A framework to integrate SOAP services and RESTful services. Em Proceedings of the IEEE International Conference on Service-Oriented Computing and Applications (SOCA), páginas 1-4. IEEE Computer Society, 2009. 7

$\left[\mathrm{PSW}^{+}\right.$07] Geguang Pu, Jianqi Shi, Zheng Wang, Lu Jin, Jing Liu, e Jifeng He. The Validation and Verification of WSCDL. 14th Asia-Pacific Software Engineering Conference (APSEC'07), (60603033):81-88, Dezembro 2007. 18

[PTDL07] Michael P Papazoglou, Paolo Traverso, Schahram Dustdar, e Frank Leymann. ServiceOriented Computing: State of the Art and Research Challenges. Computer, 40(11):3845, 2007. viii, 8,9

[PTDL08] Michael P. Papazoglou, Paolo Traverso, Schahram Dustdar, e Frank Leymann. ServiceOriented Computing: a Research Roadmap. International Journal of Cooperative Information Systems, 17(02):223, 2008. 1, 8

[RBHJ08] Sidney Rosario, Albert Benveniste, Stefan Haar, e Claude Jard. Probabilistic QoS and Soft Contracts for Transaction-Based Web Services Orchestrations. IEEE Transactions on Services Computing, 1(4):187-200, 2008. viii, x, 34, 35, 49 
[RBJ09] Sidney Rosario, Albert Benveniste, e Claude Jard. Monitoring probabilistic SLAs in Web service orchestrations. Em Proceedings of the 11th IFIP/IEEE international conference on Symposium on Integrated Network Management, IM'09, páginas 474-481, iscataway, NJ, USA, 2009. IEEE Press. 34, 38, 50

[REM ${ }^{+}$07] Florian Rosenberg, Christian Enzi, Anton Michlmayr, Christian Platzer, e Schahram Dustdar. Integrating Quality of Service Aspects in Top-Down Business Process Development Using WS-CDL and WS-BPEL. Enterprise Distributed Object Computing Conference, IEEE International, 0:15, 2007. 30, 32

[Rob05] David Robertson. A Lightweight Coordination Calculus for Agent Systems. Em Declarative Agent Languages and Technologies II Second International Workshop, DALT 2004, Revised Selected Papers, páginas 183-197. Springer Berlin / Heidelberg, New York - USA, 2005. 20

[Ros09] Florian Rosenberg. QoS-Aware Composition of Adaptive Service-Oriented Systems. Tese de Doutorado, University Vienna - Austria, 2009. viii, 1, 14, 26, 29, 30, 32, 35, 37

[RR09] Michael Von Riegen e Norbert Ritter. Reliable Monitoring for Runtime Validation of Choreographies. Em Proceedings of the 2009 Fourth International Conference on Internet and Web Applications and Services, páginas 310-315. IEEE Computer Society, 2009. 36

[Rt05] Stephen Ross-talbot. Orchestration and Choreography: Standards, Tools and Technologies for Distributed Workflows. Workshop on Network Tools and Applications in Biology (NETTLAB 2005), página 8, 2005. 13, 14

[SAV09] SAVARA Project. Savara - Project Charter. Relatório Técnico August, Red Hat Ltd, 2009. 19

[SBFZ07] Jianwen Su, Tevfik Bultan, Xiang Fu, e Xiangpeng Zhao. Towards a theory of web service choreographies. Em Proceedings of the 4th international conference on Web services and formal methods, WS-FM'07, páginas 1-16, Brisbane, Australia, 2007. Springer-Verlag. 13, 16, 17, 18

[SL11] Richard Simard e Pierre L'Ecuyer. Journal of Statistical Software. Journal Of Statistical Software, 39(11), 2011. 51

$\left[\mathrm{SLD}^{+} 10\right]$ Jun Sun, Yang Liu, Jin Song Dong, Geguang Pu, e Tian Huat Tan. Model-based Methods for Linking Web Service Choreography and Orchestration. Em Proceedings of the Asia Pacific Software Engineering Conference APSEC '10, páginas 166--175. IEEE Computer Society, 2010. 17

[SR09] G Salaün e N Roohi. On Realizability and Dynamic Reconfiguration of Choreographies. Em Proceeedings of the Workshops on Autonomic and Self-Adaptative Systems WASELF '09, volume 3, páginas 21-31. JISBD 2009, 2009. 17

[SSDS10] M Sathya, M Swarnamugi, P Dhavachelvan, e G Sureshkumar. Evaluation of QoS Based Web- Service Selection Techniques for Service Composition. International Journal of Software Engineering (IJSE), (1):73-90, 2010. 26

[Stu12] U Stuttgart. Research Challenges on Adaptive Software and Services in the Future Internet: Towards an S-Cube Research Roadmap. Em Software Services and Systems Research - Results and Challenges (S-Cube), 2012 Workshop on European, páginas 1-7, 2012. 1 
[TAM00] E.S.H. Tse-Au e P.a. Morreale. End-to-end QoS measurement: analytic methodology of application response time vs. tunable latency in IP networks. Em Proceedings of the IEEE/IFIP Network Operations and Management Symposium 'The Networked Planet: Management Beyond 2000' (Cat. No.00CB37074), páginas 129-142, Honolulu, HI, USA, 2000. IEEE Computer Society. 38

[TPM06] Otón Salvador Tortosa, Lourdes Jiménez Rodríguez Roberto Barchino Plata, e José Ramón Hilera González José María Gutiérrez Martínez. Web Services Oriented Architecture for the Implementation of Learning Objects Distributed Repositories. Em Nuno Guimarães, Pedro Isaías, e Ambrosio Goikoetxea, editors, Proceedings of the IADIS International Conference on Applied Computing, página 313. Alcala, IADIS, 2006. 5,6

[TW10] Lu Tan e Neng Wang. Future Internet: The Internet of Things. Em Advanced Computer Theory and Engineering (ICACTE), 2010 3rd International Conference on, volume 5, páginas V5-376 -V5-380, 2010. 12

[UDD05] UDDI OASIS Standard. UDDI, 2005. 7

[UPSB10] Irfan Ul Haq, Adrian Paschke, Erich Schikuta, e Harold Boley. Rule-based validation of SLA choreographies. The Journal of Supercomputing, 9999:1—-22, 2010. 37

[Van03] A. P. Van Der Aalst, W. M. P. and Ter Hofstede, A. H. M. and Kiepuszewski, B. and Barros. Workflow Patterns. Distributed and Parallel Databases, 14(1):5-51, 2003. 32

[VGF10] Hugues Vincent, Nikolaos Georgantas, e Emilio Francesquini. CHOReOS : Scaling Choreographies for the Internet of the Future. Em Middleware'10 Posters and Demos Trac, number i in Middleware Posters '10, páginas 8:1--8:3, Bangalore, India, 2010. ACM. 1

[W3C98] W3C Consortium. W3C Working Group. eXtensible Markup Language (XML), 1998. 7

[W3C05] W3C Candidate Recommendation. Web Services Choreography Description Language, version1.0, 2005. 14

[Wan04] H Wang. Web services: problems and future directions. Web Semantics: Science, Services and Agents on the World Wide Web, 1(3):309-320, Abril 2004. 6

[Web05] Web Services Choreography Working Group. Web Services Choreography Description Language Version 1.0, 2005. 19

$\left[\mathrm{WKK}^{+} 10\right]$ Branimir Wetzstein, Dimka Karastoyanova, Oliver Kopp, Frank Leymann, e Daniel Zwink. Cross-organizational process monitoring based on service choreographies. Em Proceedings of the 2010 ACM Symposium on Applied Computing - SAC '10, página 2485, New York, New York, USA, 2010. ACM Press. 36

[WSI05] WSI. Web Services Interoperability Organization, 2005. 5

[XCHZ07] Zhao Xiangpeng, Cai Chao, Yang Hongli, e Qiu Zongyan. A QoS View of Web Service Choreography. IEEE International Conference on e-Business Engineering (ICEBE'07), páginas 607-611, Outubro 2007. 35, 36

[XCZH09] Yunni Xia, Jun Chen, Mingqiang Zhou, e Yu Huang. A Petri-Net-Based Approach to QoS Estimation of Web Service Choreographies. Em Advances in Web and Network Technologies, and Information Management, number 2006, páginas 113-124. SpringerVerlag, Berlin, Heidelberg, 2009. 35, 37 
[YZQ ${ }^{+}$06] Hongli Yang, Xiangpeng Zhao, Zongyan Qiu, Geguang Pu, e Shuling Wang. A Formal Model for Web Service Choreography Description Language (WS-CDL). Em Proceedings of the IEEE International Conference on Web Services (ICWS'06), number 605730081, páginas 893-894. IEEE Computer Society, 2006. 35

[ZBDH06] Johannes Maria Zaha, Alistair Barros, Marlon Dumas, e Arthur Hofstede. Letâs Dance: A Language for Service Behavior Modeling. Em OTM Proceedings of the 14th International Conference on Cooperative Information Systems (CoopIS'06), Lecture Notes in Computer Science, páginas 145-162. Springer, 2006. 14, 17, 19

$\left[Z^{+} W^{+} 06\right]$ X. Zhou, W. Tsai, X. Wei, Y. Chen, e B. Xiao. Pi4SOA: A Policy Infrastructure for Verification and Control of Service Collaboration. Proceedings of the IEEE International Conference on e-Business Engineering (ICEBE'06), páginas 307-314, 2006. 19, 43

[ZWPZ10] Yongxin Zhao, Zheng Wang, Geguang Pu, e Huibiao Zhu. A Formal Model for Service Choreography with Exception Handling and Finalization. Em Theoretical Aspects of Software Engineering (TASE), 2010 4th IEEE International Symposium on, páginas 15-24, 2010. 17

[ZXCH07] Qiu Zongyan, Zhao Xiangpeng, Cai Chao, e Yang Hongli. Towards the Theoretical Foundation of Choreography. Em Proceedings of the 16th international conference on World Wide Web, number 60573081 in WWW '07, Banff, Alberta, Canada, 2007. ACM. 18, 19

[ZYZ10] Huiyuan Zheng, Jian Yang, e Weiliang Zhao. QoS Probability Distribution Estimation for Web Services and Service Compositions. Em Proceedings of the EEE International Conference on Service-Oriented Computing and Applications, SOCA '10, páginas 1-8, Perth, Australia, 2010. IEEE Computer Society. 34, 38 